\title{
EXPANDING IMAGINARIES // \\ A New Mythology for a Changing World
}

\author{
by \\ Charles-Étienne Déry \\ A thesis submitted to the Faculty of Graduate and Postdoctoral Affairs in partial fulfillment of the \\ requirements for the degree of
}

Master of Architecture

Carleton University

Ottawa, Ontario, Canada

(C) 2021

Charles-Étienne Déry 
Abstract 
This thesis uses a science fiction videogame to reframe geographic imagination. Set in a fictitious Canada, the game imagines a future in which drastically altered environments have transformed human's perception of territory and technology. As a colonial project, Canada has relied heavily on imagery and myth to justify territorial expansion and curate a sense of nationhood. Such a mythology is rapidly eroding in view of the current climate crisis. Considering that works of fiction can influence decision-making, the project uses worldbuilding to reflect critically on the agency of representation.

Critical analysis of visual material and works of literature serve as inspiration for the game world. Architecture is interpreted as the act of curating space to communicate meaning. Hence, game space is designed to challenge dichotomies regarding nonhuman nature. Considering this, the project investigates how the use of storytelling technologies can make tangible the abstract reality of a changing world. 


\section{Acknowledgements}


To my advisors Ozayr Saloojee and Piper Bernbaum for their inspiring advice, their humour, and for their incredible empathy. Thank you for all the memes and the openheart sessions.

To my parents for their unwavering support, and for always asking the right questions.

To all the friends for checking in regularly, through Zoom or in person, and for making this experience seem a little less daunting.

And to Shaylyn for her patience and reassurance, and for helping me making it through this year. 


\section{Table of Contents}


Abstract

Acknowledgments

Table of Contents

List of Figures

Part I

Seeing

Mythological Eye

Military Eye

Technological Eye

Romantic Eye

Disrupting Vision

Part II

Imagining

Thinking in Aggregate

Shrinking the Trouble

Transitioning Terra

Part III

\section{Worlding}

Embracing Hybridity: The Cyborg as a Trope

\section{Epilogue}

Postcript

Glossary 


\section{List of Figures}


Figure 01 > Blade Runner 2049

Figure 02 >> California Wildfires 2020, San Francisco xii

Figure 03 >> Discovery of the Mississippi by De Soto, William H. Powell XV

Figure 04 >> Sable Video Game Still _ Xx

Figure 05 >> Sable Video Game Still I Xx

Figure 06 >> The Creation of the World and the Expulsion from Paradise, Giovanni di 6 Paolo

Figure 07 >> First Day of Creation, Francisco de Holanda 8

Figure 08 >> Androgyny, Norval Morisseau $\quad 10$

Figure 09 >> Ordnanace Survey Triangulation Diagram, Alexander Ross Clarke, 186813

Figure $10>$ General View of the Instrument 14

Figure $11 \gg$ Geological Survey of Canada, Montreal 14

Figure $12>$ Alfred Selwyn 15

Figure 13 > George Dawson 15

Figure $14>>$ Theodolite 16

Figure $15>$ Telescope 16

Figure $16>>$ Measuring Tape 16

Figure 17 > Reconnaissance Map of the Rocky Mountains, Alfred Barlow 17

Figure 18 >> Geological and Topographical Map of the Northern Part of the Lake of 18 the Woods and Adjacent County, Alfred Barlow

Figure 19 >> Steam Engine Locomotive 21

Figure 20 >> The New Highway to the Orient: Across the Mountains, Prairies and 22 Rivers of Canada

Figure 21 >> Map of Western Canada 23

Figure 22 > CPR Poster 23

Figure 23 >> Irrigation Farming in Sunny Alberta 25

Figure 24 > Priarie Grain Elevator 26

Figure $25>>$ Pinhole Camera, Louis-Jacques Goussier 28

Figure $26>>$ Fall of Montmorenci, George Fisher 29

Figure $27>$ Victorian Panorama 30 
Figure 28 >> Museum Diorama 30

Figure 29 >> Sunrise on the Saguenay, Lucas O’Brien 31

Figure $30>$ Untitled Alberta Landscape, A.Y. Jackson 33

Figure 31 > The Drowned World 43

Figure $32>>$ The Burning World, or The Drought 43

Figure $33>>$ The Road 44

Figure 34>> Man versus Nature 44

Figure 35 >> Geostories: Another Architecture for the Environment 48

Figure $36>>$ Pacific Aquarium 49

Figure $37 \gg$ Ecoregion Map 51

Figure $38>>$ Vitrines Front View 51

Figure 39 >> Vitrine Artifact-Jack Pine 53

Figure $40>$ Vitrine Artifact - Grain Elevator 53

Figure 41 > Vitrine Artifact - Mountain Peak 53

Figure 42 >> Vitrine Artifact - Crab Net 53

Figure 43 >> Overview of Nested Vitrines 53

Figure 44 >> Particulate Cloud Experiment - Boreal Forest I 54

Figure $45>>$ Particulate Cloud Experiment - Boreal Forest II 54

Figure 46 >> Particulate Cloud Experiment-Maritimes 54

Figure 47 >> Particulate Cloud Experiment-Grasslands 54

Figure $48>$ Carbon Capture 57

Figure 49 >> Liam Young's Specimens of Unnatural History 58

Figure $50>$ Techno-Bovidae and Stainless Towers 61

Figure $51 \gg$ Anishinaabe Carrying Bag 65

Figure 52 > The Witness Game Still 66

Figure 53 >> Techno-Bovidae Kitbash 70

Figure 54 >> Conceptual collage showing the diorama concept. 72

Figure 55 >> Diagram depicting the museum gallery hub world 73

Figure 56 >> Topographical surface 74 
Figure $57>>$ Topographical surface $\quad 74$

Figure 58 >> Topographical surface 74

Figure 59 >> Conceptual Sketches/Clay renders for Techno-Bovidae and Carbon Elevators 75

Figure $60>$ Conceptual Sketches/Clay renders for Techno-Bovidae and Carbon Elevators 75

Figure 61 > Conceptual Sketches/Clay renders for Techno-Bovidae and Carbon Elevators 75

Figure 62 >> Conceptual Sketches/Clay renders for Techno-Bovidae and Carbon Elevators 75

Figure 63 >> Techno-Bovidae Development 76

Figure 64 >> Techno-Bovidae Development 76

Figure 65 >> Blueprint drawing for the Techno-Bovidae 77

Figure $66>>$ Blueprint drawing for the Carbon Elevators 78

Figure $67>$ Storyboard Frame 01

Figure 68 >> Storyboard Frame 02

Figure 69 >> Storyboard Frame 03

Figure $70>>$ Storyboard Frame 04

Figure $71 \gg$ Storyboard Frame 05

Figure $72>>$ Storyboard Frame 06

Figure 73 >> Storyboard Frame 07

Figure 74 >> Storyboard Frame 08

Figure $75>>$ Storyboard Frame 09

Figure $76>>$ Storyboard Frame 10

Figure 77 >> Storyboard Frame 11

Figure 78 >> Storyboard Frame $12 \quad 91$

Figure 79 >> Storyboard Frame 13

Figure $80>>$ Field Work 01

Figure $81 \gg$ Field Work 02

Figure 82 >> Field Work03 95

Figure 83 >> Field Work 04 


\section{Introduction}

It can seem, at times, deflating to talk about climate change. Between the raging forest fires that cloud the skies with a Blade Runner haze ${ }^{1}$, seemingly unstoppable sea level rise, and the increase in devastating tornadoes inspiring awe on social media, it appears as though once hypothetical apocalyptic futures are now on our doorstep. Therefore, it is no surprise that recent studies place us right on time for civilizational collapse. ${ }^{2}$ We know the apocalypse is coming, but how do we feel it? Certainly, it is in the subtle changes of our own environment, but perhaps more clearly it is through media. Inundated by news, sound bytes and images, we are now confronted on an increasing basis with the realities of a climate catastrophe.
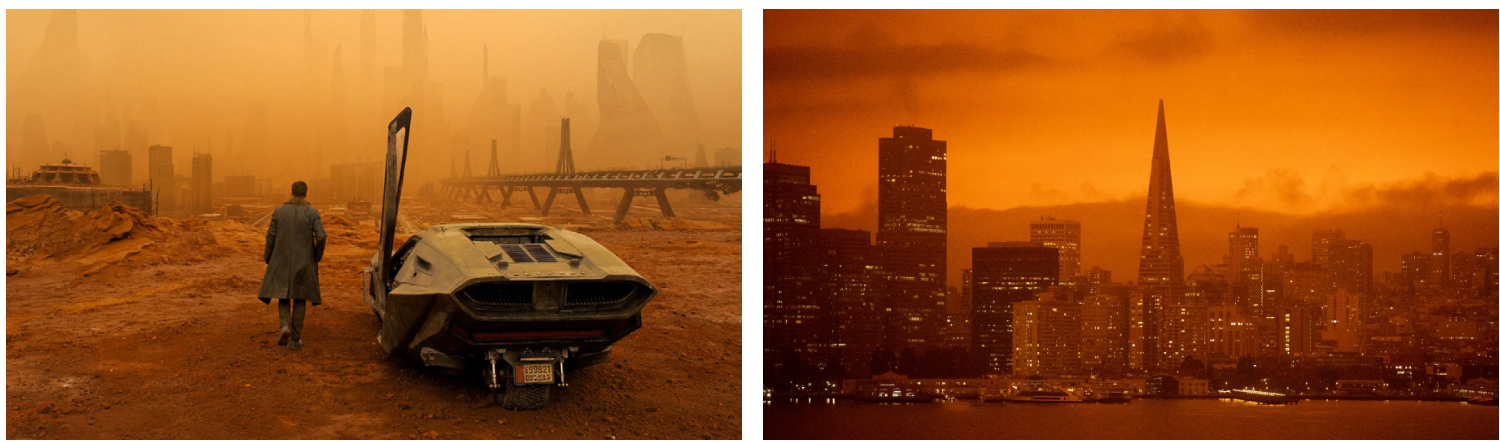

Apocalypse $>>$ A disaster resulting in drastic, irreversible damage to human society and/or the environment on a global scale. The term is biblical in origin, referring to the Second Coming of Christ and the destruction of the world. 


\subsection{1 >> Thinking in Images}

The study of spatial images is what grounds this research and images are not neutral. Rather, they are the product of a culture's collective experiences, or in the words of Marshall McLuhan, of "... the cultural matrix within which the particular medium operates." 3 Defining images, and in particular spatial images as operational media is key to the central argument of this thesis. McLuhan observes that "... "the medium is the message" because it is the medium that shapes and controls the scale and form of human association and action." ${ }^{*}$ The collection of these spatial images constructs what can be described as the geographical imagination. In the words of geographer David Harvey, geographical imagination allows the individual to "... relate to the space that he sees around him" and to "recognize the relationship that exists between him and his territory."s Following Harvey, Ste-

phen Daniels expands the notion, describing it as "... encompassing the condition of both the known world and the hori-

\section{Spatial Images >> Rep- resentations of what is governed by or subject to the conditions of space, that speculate how we perceive relations involv- ing space.}

3 Marshall McLuhan, Understanding Media (Berkley California: Ginnko Press Inc, 2013), 13.

$4 \quad$ McLuhan, 9.

5 David Harvey, Social Justice and the City (Basil Blackwell, 1973), 24. 
zons of possible worlds."' Under this framework, images act as more than mere recordings of cultural behavior; they can operate as instructions for how a given culture exists in and occupies space. Visual production, such as photographs, paintings, and other media, help to communicate how cultures perceive themselves in the world. These worldviews, in turn, determine how those cultures begin to structure the material world that they inhabit. These worldviews can be at once productive, generative and meaningful. They can also be profoundly disruptive.

Imagery plays a crucial role in the legitimization of colonial European presence in North America. From the early Age of Discovery, images were produced by Europeans to make sense of the New World they had discovered and to promote its inclusion and belonging to the European sphere. The depiction of settlers triumphing over untamed wilderness soon became a blueprint for European occupation of the territory. This type of imagery was widely circulated in the Old World, effectively serving to support the colonial effort both spiritually and financially. Parallel developments in surveying technology allowed for the production of maps and atlases that cemented colonial expansion by parcelling the

$6 \quad$ Stephen Daniels, "Geographical Imagination," Transactions of the Institute of British Geographers 36, no. 2 (2011): 183, https://doi. org/10.1111/j.1475-5661.2011.00440.x.

\begin{abstract}
New World $>>$ Refers to the North American continent post "discovery" and colonization, establishing its view as the next frontier.
\end{abstract}

Old World $>>$ The world known to Europeans prior to the discovery of the Americas, this included the continents of Europe, Asia, and Africa. 
landscape and locating resources for exploitation. Meanwhile the execution of landscape paintings reinforced the justification of European expansion with divine undertones. This visual production partitioned European worldviews between the civilized and uncivilized, and the human and nonhuman spheres. Such a worldview contributed to the dehumanization of Indigenous people, portraying them instead, if at all, as part of the uncivilized and therefore nonhuman world. This colonial logic extended to the current perception of climate changes. Taking issue with the term Anthropocene, Métis scholar Zoe Todd criticizes the framing of the global ecological crisis as a universal responsibility, presenting it instead as

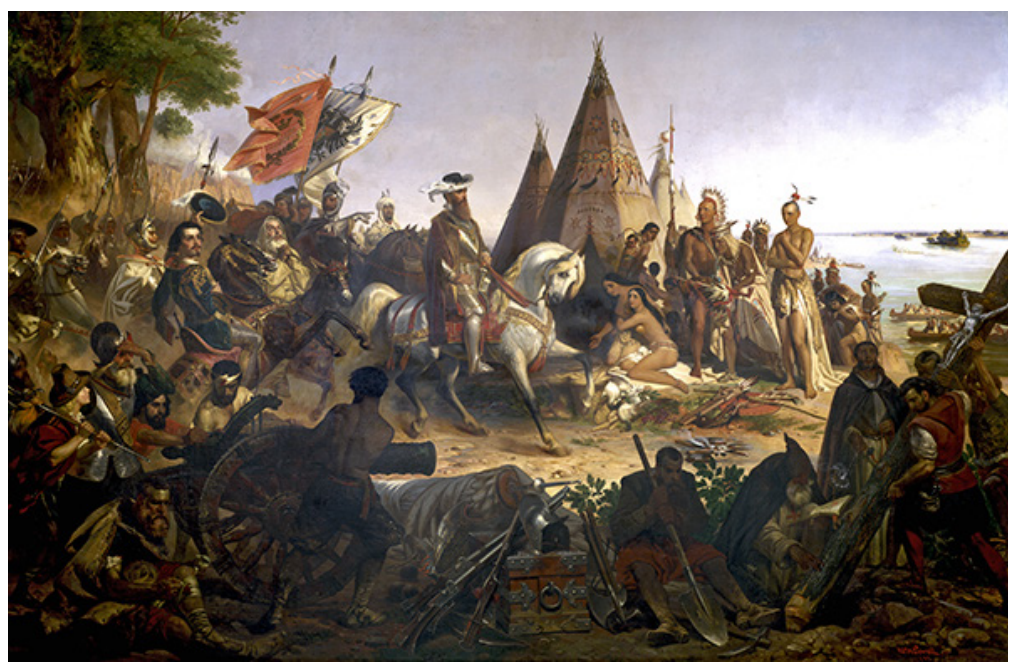

\section{Nonhuman>> That is} not of the human race; not belonging to or possessing the characteristics of a human being.

Figure 3 >> This painting by William H. Powell called the Discovery of the Mississippi by De Soto depicts the type of othering that is so apparent in the Western worldview. 
a result of the mass transformations imposed by European settlers on Indigenous landscapes and people around the globe. In keeping with Todd's ideas, this thesis takes issue with the universal sense of guilt implied by the Anthropocene, focusing instead on the colonial worldviews that enabled the crisis. This othering process simultaneously justified the exploitation of landscapes through technological mastery and gave rise to myths of divine redemption through wilderness encounters. By pitting humans against nonhumans in the settlers' geographical imagination, this worldview contributes, to this day, to the current climate crisis affecting the Canadian landscapes. 


\subsection{2 >> Players, the Game, and its Landscape}

How can a videogame be used to reframe geographical imagination regarding climate changes? After all, games are often critiqued as lacking the credibility attributed to auteur film or literature. Games are often dismissed as "mere tools that exist to entertain or distract."' According to author and game designer lan Bogost, the world of game design, he argues, has "often maintained a separation from other forms of human culture and creativity" in order to come into its own.? This resulted in games having fairly limited reach as a medium, since "encountering games still requires pledging fealty to gamedom." "10 What then can games bring to the

conversation about worldviews that differs from movies or books? Bogost hints to possible answers in his description of games:

They include characters and personas with whom we can identify and empathize, like we might do with a novel or a film. They are composed of forms and designs derived from whole cloth, producing visual, tactile, and locomotive appeal like fashion or painting or furniture. They insert themselves into our lives, weaving within and between our

8 Ian. Bogost, "Anything but Games," in How to Talk about Videogames (University of Minnesota Press, 2015), ix.

9 Bogost, 181.

10 Bogost, 182. 
daily practices, both structuring and disrupting them. They induce feelings and emotions in us, just as art or music or fiction might do. But then, games also extend well beyond the usual payloads of those other media, into frustration, anguish, physical exhaustion, and addictive desperation.

Following Bogost, one can argue that games' analogous nature to other media forms makes them the ultimate support to communicate worldviews, effectively rendering other media forms obsolete. ${ }^{11}$ However, it is perhaps the labelling of games as "Prosthetic Imagination"12 that better renders their true potential.

First coined by game theorist Jim Rossignol and cited by Michael Taylor in his thesis The Prosthetic Imagination, the term refers to the game medium as "... the prothesis that extends our being from the real-world, into the virtual realm of the game-world. "13 Taylor describes a videogame as "active simulations" that "... [allow] the individual to test a situation through the prosthetic imagination." ${ }^{14}$ With their capacity to simulate real space and immerse the player in a virtual space, videogames offer a terrain to test out real world scenarios. With this capacity, games provide the perfect support for

\footnotetext{
11 McLuhan, Understanding Media.

12 Michael Taylor, "The Prosthetic Imagination: Mediations on Virtual Space and Experience in Single Player Computer Role Playing Games" (University of Waterloo, 2011).

13 Michael Taylor, 83.

14 Michael Taylor, 87.
} 
representing changing worldviews through the design of the game world.

In working with such a medium, what then is the role of the architect? Taylor hints at an answer by arguing that "without architecture, there would be no way for the player to understand the space of the game."1s Through interaction with game world architecture, players are able to make sense of the virtual space they occupy and, by extension, of the real world that they inhabit. Architecture suggests a space for human interaction, for scale, for inhabiting or being in place, and as such it provides - in the space of the game - a prosthetic relation to the real world. In this sense, the role of the architect becomes that of a world-builder, organising the game world in reference to the material world. As a world-builder, the architect utilizes game space to reframe imaginaries and make tangible the reality of a changing world. The game then becomes the tool upon which we can project into and imagine the possible futures or realities without limits. This thesis explores the question of images and the prosthetic imagination around a narrative of climate change in Canada, through the space of a video game.

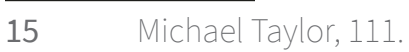




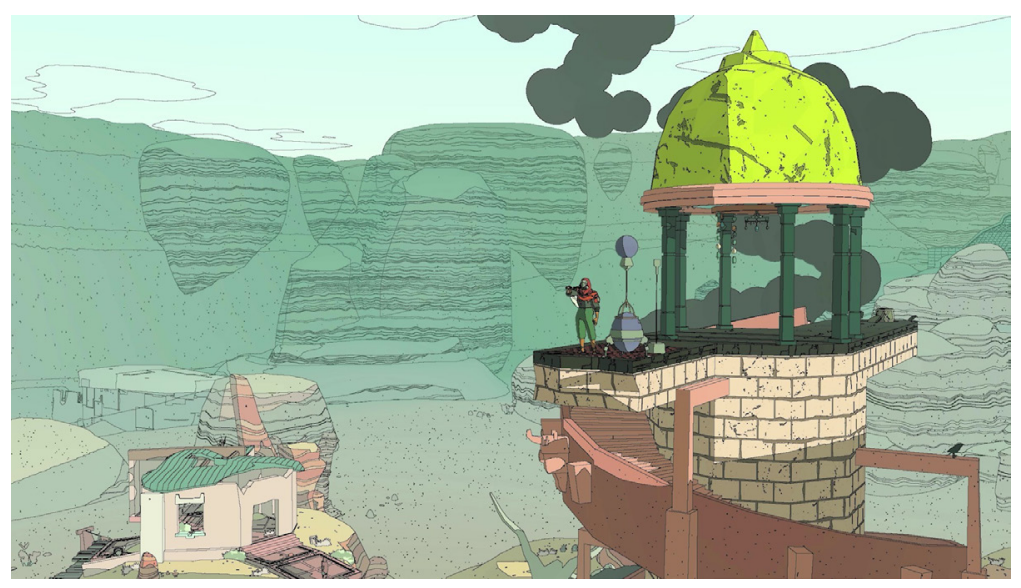

Figure 4-5 >> Video game stills from Sable, an upcoming oper world exploration game that draws inspiration from architectural representation.

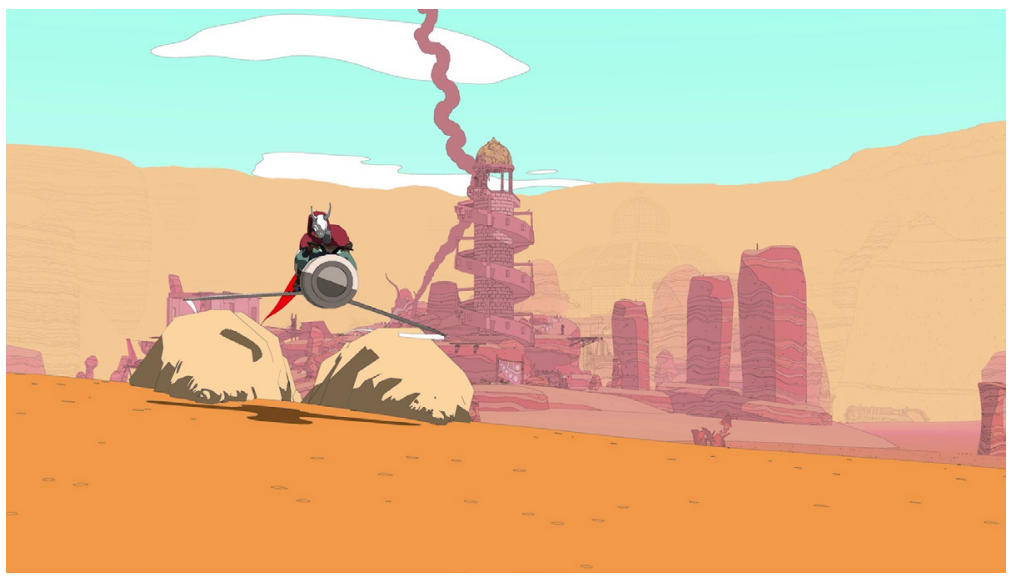




\subsection{3 >> Thesis Structure}

This thesis consists of three parts, following the operations of Seeing >> Imagining >> Worlding.

Seeing traces how a selection of Canadian landscapes came to be perceived through various stages of European settlement, and how Europeans came to impose a material order to reflect a constructed worldview. The study of maps, propaganda posters and landscape paintings grounds this investigation.

Imagining proposes the use of fiction, and particularly of science fiction to reframe geographic imagination in view of environmental changes. A study of science fiction worldbuilding, along with exploratory work, forms the content of this section.

Finally, Worlding proposes the design of a game world, including environments, characters, and props. A playable prototype is created to suggest player interaction with the virtual world and its potential to reframe the agency of representation over territory. 
Part I 



\section{Seeing}

"Take a small but varied company to any convenient viewing place overlooking some portion of city and countryside and have each, in turn, describe the 'landscape' ... to detail what it is composed of and say something about the 'meaning' of what can be seen. It will soon be apparent that even though we gather together and look in the same direction at the same instant, we will not - we cannot - see the same landscape."

- Donald W. Meinig, The Beholding Eye

In The Beholding Eye: Ten Versions of the Same Scene, American geographer Donald Meinig proposes a handful of ways that landscape scenery is perceived. In his essay, Meinig describes landscapes as composed “... not only of what lies before our eyes but what lies in our heads."

Borrowing from Meinig, landscape architect and author Dilip Da Cunha uses the Beholding Eye to explain how European empires perceived the lands that they conquered and how they came to impose their worldview over those territories. Citing Edward Said, Da Cunha attributes this vi-

1 DW (Donald William) Meinig and John Brinckerhoff Jackson, The Interpretation of Ordinary Landscapes: Geographical Essays (New York: Oxford University Press, 1979), 33.

$2 \quad$ Meinig and Jackson, 34. 
sion to Orientalism" "a system of representations framed by a whole set of forces that brought the orient Western learning, Western consciousness, and later Western Empire." ${ }^{\prime \prime}$ n Said's concept, the Westerner's gaze over the oriental other aimed at transforming him to fit a colonial vision. For Da Cunha, this worldview not only "constructed the colonized as it did the colonist," but also "their landscapes and the beholding eye,"s therefore transforming the territories, and perception thereof, of the colonized.

Substituting Canadian landscapes for the Oriental, this research argues that this imperial gaze splintered over the course of territorial annexation to Western consciousness. The Beholding Eye and the various forms it takes, serves to articulate this investigation. In this thesis, this rupture of the imperial gaze and its imagery is explored through four lenses: the Mythological Eye, the Military Eye, the Technological Eye and the Romantic Eye provides insight into the agency of representation in allowing the European worldview to englobe Turtle Island, and the consequences of this vision on environmental imaginary.

3 Edward W. Said, Orientalism, First Vintage (New York: Random House, 1978).

$4 \quad$ Dilip Da Cunha, The Invention of Rivers: Alexander's Eye and Ganga's Descent (Philadelphia: University of Pennsylvania Press, 2019), 16.

5 Da Cunha, 16.

\section{Turtle Island >> In some interpretations of North American Indigenous folklore, Turtle Island refers to the land from which their ancestors originated, and often re- fers to the land of North America.}




\section{1 >> The Mythological Eye}

"The many great gardens of the world, of literature and poetry, of painting and music, of religion and architecture, all make the point as clear as possible: The soul cannot thrive in the absence of a garden. If you don't want paradise, you are not human; and if you are not human, you don't have a soul."

- Sir Thomas More

"We gave ourselves for lost men, and prepared for death. Yet we did lift up our hearts and voices to God above, who "showeth His wonders in the deep"; beseeching Him of His mercy, that as in the beginning He discovered the face of the deep, and brought forth dry land, so He would now discover land to us, that we might not perish."

- Francis Bacon, The New Atlantis

From the onset of the European Age of Discovery, a combination of divinely inspired enchantment and fear defined European imagination of the so-called New World. As mentioned by geographer Denis Cosgrove, early explorers alternate in their descriptions of lands discovered between "Edenic garden landscapes" and "... howling wildernesses of 
tangled forest and swamp, haunted by terrifying creatures, half-man, half-beasts."' ${ }^{\prime}$ These contrasting images of the landscape and metaphors of the Eden and Wilderness are not accidental. They appear frequently as motifs in $16^{\text {th }}$ century European imagery as symbols for the perceived struggle between morality and decadence. Moreover, they reflect a European tendency to see the world divided between order and chaos, a result of their obsession with imposing Eurocentric interpretations of Eden onto all else.

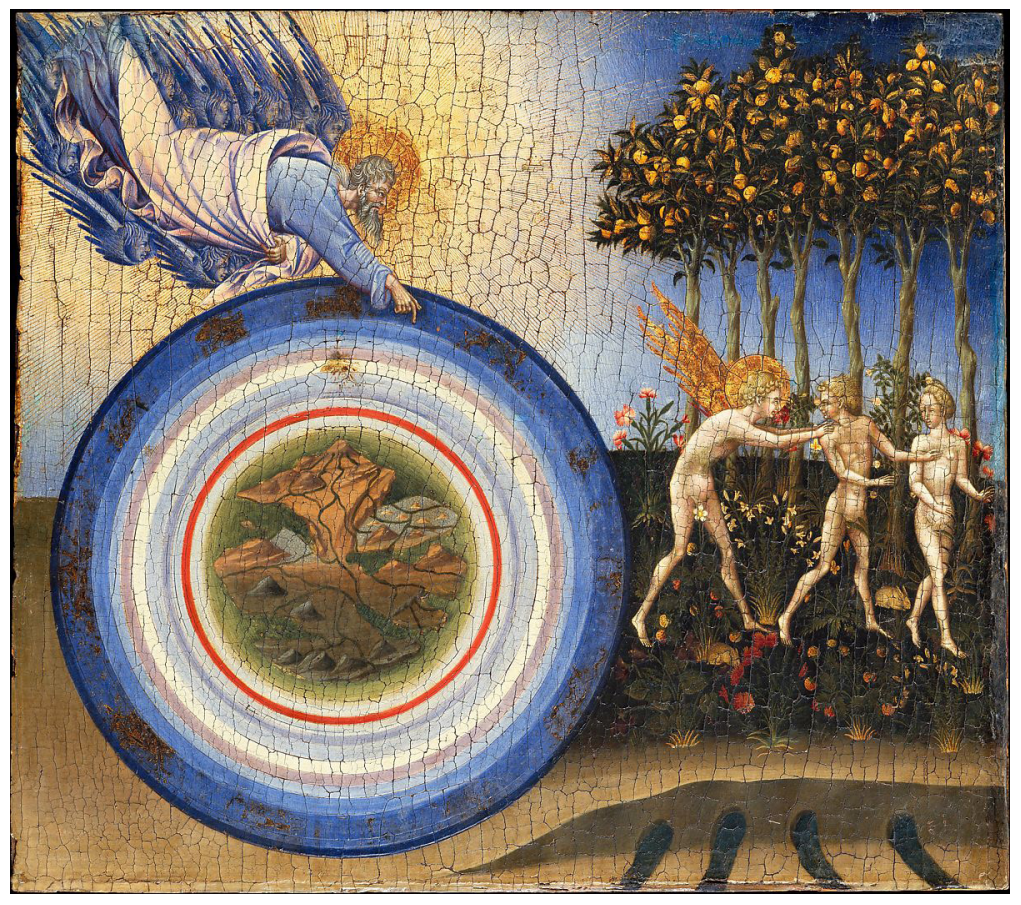

Figure $6>$ The Creation of the World and the Expulsion from Paradise by Giovanni di Paolo.

6 Denis Cosgrove, Geography and Vision: Seeing, Imagining and Representing the World, Geography and Vision: Seeing, Imagining and Representing the World, 2008, 56, https://doi. org/10.5040/9780755620791. 
Early Renaissance imagery is full of references to the Fall of Man and the subsequent expulsion of Adam and Eve from the Garden of Eden. This fall from grace for transgressing divine morality occupies the European imagination during the early Age of Discovery. In The Creation of the World and the Expulsion from Paradise (Figure 6), Giovanni di Paolo represents Adam and Eve being chased from the Garden and into God's newly created world. In the painting, the world is depicted as a mappamondo (a map of the world), a diagram representing the accepted model of the universe at the time. In the diagram, the world is represented as a series of concentric circles (or spheres), with the Earth in the middle surrounded by the four elements, the known planets and the Sun, and the constellations of the zodiac.? Eden is depicted here as existing outside of this diagram, perhaps symbolizing the idea of Eden as an idyllic realm of purity existing outside of the material world.

The depiction of the world with mathematical logic marks a shift in worldview happening in Western Europe at the turn of the $16^{\text {th }}$ century. The introduction of Greek literature to the Latin world under the reign of Mehmet II in Constantinople (1451-1481), and under La Convivencia in Spain and Al-Andalus, infuses European cosmography

$7 \quad$ "The Creation of the World and the Expulsion from Paradise," n.d., https://www.metmuseum.org/art/collection/search/458971.

\footnotetext{
Cosmography >> The science that describes and maps the general features of the universe (both the heavens and earth), without encroaching upon astronomy or geography.
} 
with Platonic concepts of mathematics and geometry in the

late medieval and early Renaissance era. The emergence

of world models featuring Greek numerals and geometric

abstractions reflects this syncretic worldview that likens the

purity of platonic geometry with the divine. This is evi-

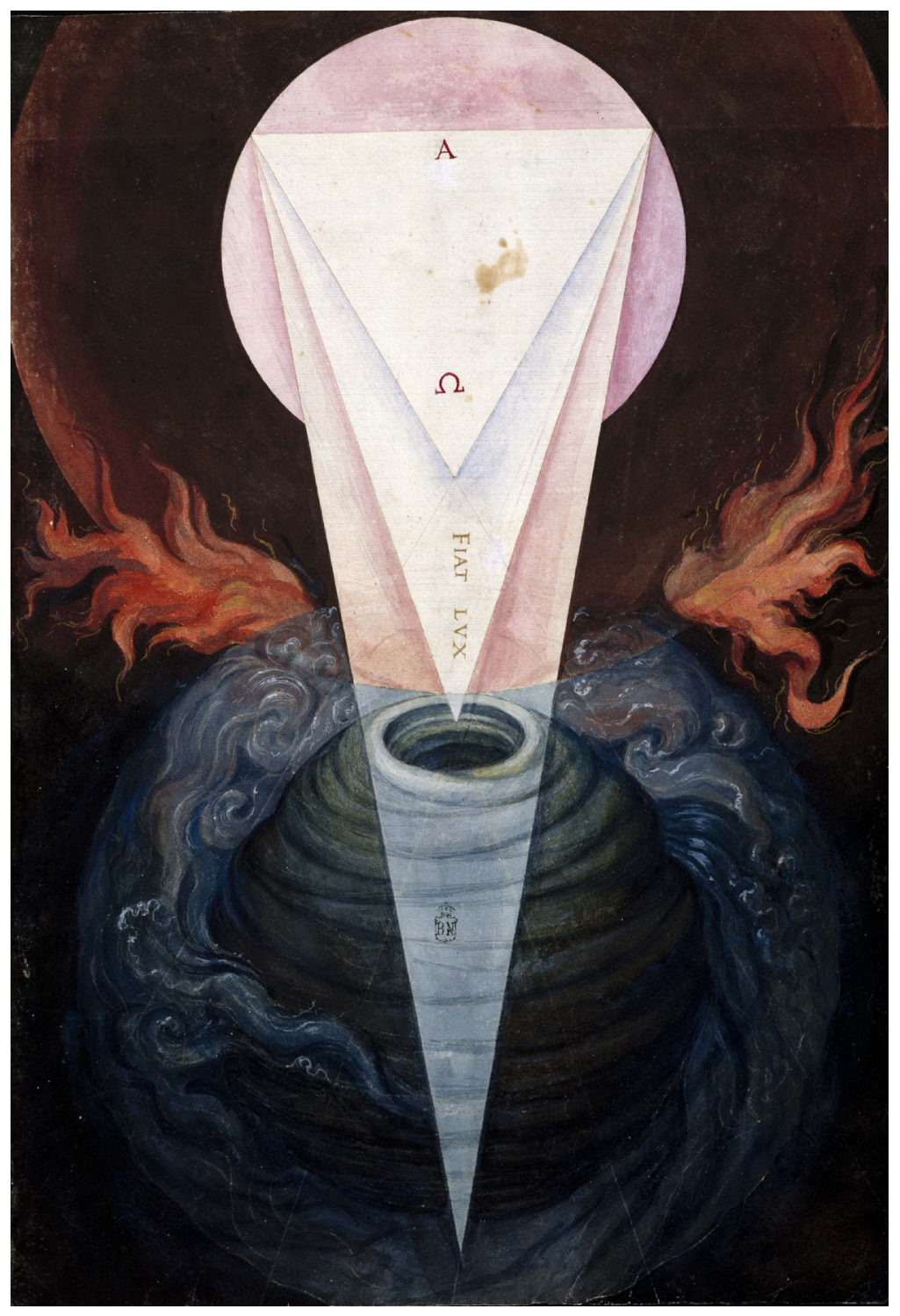

Figure $7>$ The First Day of Cre-

ation by Francisco de Holanda. 
denced most notably in the work of Francisco de Holanda, De Aetatibus Mundi Imagines. The volume depicts the creation of the World, with each biblical day occupying a page accompanied with captions. De Holanda's use of geometry to depict divine genesis, as shown in the First Day of Creation (Figure 7), reflects European cosmography at the time, which according to Cosgrove, preoccupied itself with "the place of human life in an ordered creation."s Evidence of this "cosmic order" was seen notably through the use of Albertian perspective, seen as "the inherent constructional principle of space itself, proof that divine handiwork operated with geometrical consistency at all scales of creation." For Cosgrove, such obsession with an underlying cosmic order influenced Europeans to "inscribe this divine logic onto the terrestrial canvas." "10 Under such a worldview, the New World enters European consciousness as the promised redemption for the lost Eden, whose unruly wilderness must be tamed through the reveal of a certain underlying order.

In contrast with this European cosmography, Indigenous imaginaries reflected a markedly different conception of space compared to European counterparts. Differences are most notable in how the Indigenous concept of person-

\footnotetext{
8 Cosgrove, Geogr. Vis. Seeing, Imagining Represent. World, 38.

9 Cosgrove, 25.

10 Cosgrove, 25.
}

Personhood >> The quality or condition of being a person. The development of one's self or personal identity.

\section{Albertian >> Referring to the Italian Renais- sance man, Leon Battista Alberti, known for using methods of projecting lines on a flat surface to create perspective.}


hood differs from the European notion. Art historian Richard Hill uses examples of the Anishinaabe worldview to explain this vision:

Where a European painter may have seen an empty wilderness landscape, a traditional Anishinaabe artist would have seen a space peopled with relatives. Likewise, one's relationship to the land is not one in which a human agent extracts and manipulates inanimate "natural resources," but a social relationship

Figure 8 >> Androgyny by Norval between human and non-human people.11

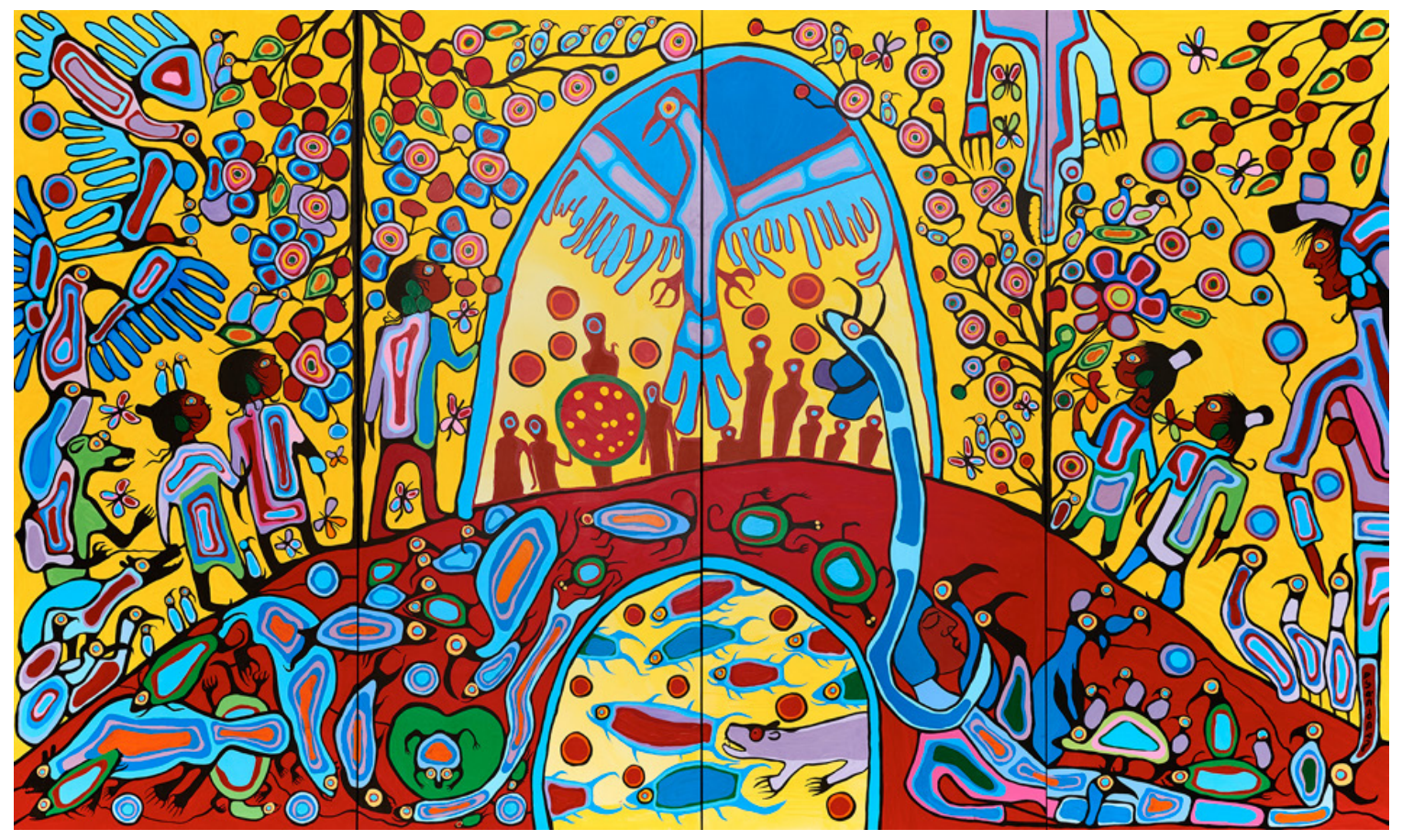

11 Richard Hill, "Too Silent to Be Real," in Expanding Horizons: Painting and Photography of American and Canadian Landscape, 18601918, ed. Hilliard T Goldfarb (Montreal: Montreal Museum of Fine Arts, 2009), 100. 
One such painter was Norval Morrisseau, who is known for illustrating mythological themes from his Anishinaabe culture through his compositions. In his painting Androgyny, Morrisseau provides a glimpse into Anishinaabe worldview through his own interpretation. In the artist's words, Androgyny (Figure 8) depicts "a shaman that is Androgyne in four directions, filled with all parts of nature in Canada, thunderbeings, sacred serpents and turtles, flowers, animals, and we children of Mother Earth. PS. Butterflies and Bumble Bees, too!"12 In the painting, humans and nonhuman beings fill the cosmos. Spirit-beings occupy the center of the composition, including "the snake that reaches from the underworld to the spirit world." ${ }^{13}$ Both humans and nonhumans are painted in the same graphic style, further illustrating the kinship between them.

Morrisseau's work communicates Hill's portrayal of Anishinaabe worldviews as a society formed between humans and nonhumans. The composition and illustrative style render a sense of order and harmony in space, albeit one radically different from the platonic order of the European Renaissance.

12 Carmen Robertson, Norval Morrisseau : Life \& Work (Toronto: Art Canada Institute, 2016), 34-35.

13 Robertson, 34. 


\section{2 > The Military Eye}

"Violence is intrinsic to abstract space and to the act of geographic abstraction itself; it impoverishes "concrete" space and disconnects it from the many relations within which it is embedded."

- Rania Ghosn and El Jazairy, Geostories: Another Architec-

ture for the Environment

The European obsession with geometry, developed during the Renaissance, continued into the Enlightenment. The task of representing space with the utmost precision became synonymous with the values of reason and political equality. ${ }^{14}$ The impulse for the establishment of large-scale

Topographic >> The accurate and detailed delineation and description of any locality.

topographic surveys came from the desire to provide a panoptic view of landscapes for reasons of power, control, ownership, and nationalism, ${ }^{15}$ a view that would guide European imposition of spatial order over conquered lands. In the words of Denis Cosgrove, the most visible trace of European colonization in the global landscapes is "the territorial inscription of cartography. The graticule, geodesy

14 Rachel Hewitt, Map of a Nation (London: Granta Books, 2010), 218.

15 Hewitt, 21. 
and the grid were practical tools of empire and modernity." ${ }^{16}$ In British North America, such a system would follow in the footsteps of the Ordnance Survey of Great Britain.

According to Rachel Hewitt. The Ordnance Survey takes its origins in the Jacobite Rebellion of 1745 . Frustrations with a lack of reliable survey intelligence during the Rebellion led to the commission of a Scottish engineer, William Roy, to produce a military survey of Scotland. Following the Rebellion, Roy would oversee the execution of the triangulation work (Figure 9), which would provide the backbone for the execution of the Ordnance Survey.

Triangulation provided the most reliable system for accurate measuring and would remain the paradigm in land surveying until the development of Global Positioning Systems. Developed centuries before, but greatly refined in $18^{\text {th }}$ century Britain, theodolites (Figure 10) were used as the main instrument to carry out the survey. Capable of measuring both horizontal and vertical angles at high precision over long distances, these 200-pound instruments would be mounted on portable scaffolding by artillerymen to achieve maximum visibility over the landscape. Astronomical instruments, like telescopes and sextants, would be used to measure coordinates and form baselines, along which the

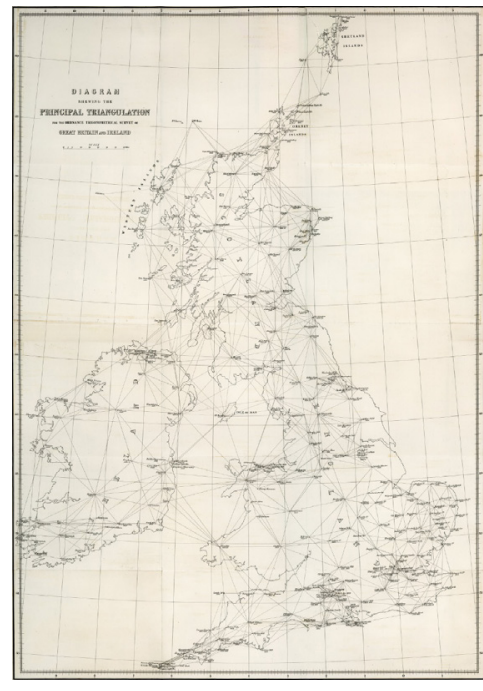

Figure 9 > Alexander Ross Clarke 's triangualtion diagram for the Ordnance Survey, 1858.
Triangulation $>$ The tracing and measurement of a series or network of triangles used to survey and map out a territory or region.

\footnotetext{
Theodolites >> portable surveying instrument, originally for measuring horizontal angles, and consisting essentially of a planisphere or horizontal graduated circular plate, with an alidad or index bearing sights.
} 
Survey would move.

Although a military endeavor, the Ordnance Survey reflected the scientific ideals of European Modernity. In the wake of the French Revolution, the new French Republic saw cartography as the language of reason, "the [embodiment] of the 'esprit géométrique' of the Enlightenment... .' ${ }^{17}$ In England, William Roy himself, animated by scientific ideals, saw in the Royal Survey the potential to create "an accurate image of the natural world." ${ }^{18}$

In British North America, a combination of this ambition to reveal an underlying natural order and the need for adequate knowledge of the territory would play a direct role in the emergence of a geological survey. In 1841, on impulse from the emerging scientific community in Montreal, the first Geological Survey of Canada (GSC) (Figure 11) was established. Although founded and operated by scientists, the GSC followed in the footsteps of European geological surveys with an objective of advancing the mining economy of the colony. ${ }^{19}$ Prior to Confederation, British North America consisted of a series of disparate coastal colonies separated by a vast, largely unpopulated hinterland. Because of this,

\footnotetext{
$17 \quad$ Hewitt, Map of a Nation, 128.

18 Hewitt, 135.

19 C. Vodden; L. A. Frieday, and Niko Block, "Geological Survey of Canada," in The Canadian Encyclopedia, 2007.
}

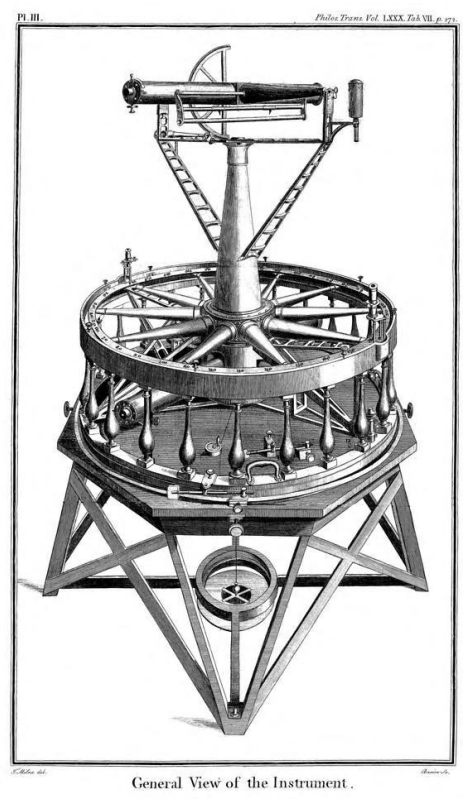

Figure $10>>$ General View of the Instrument depicts a Great Theodolite used during the first days of the Ordnance Survey.

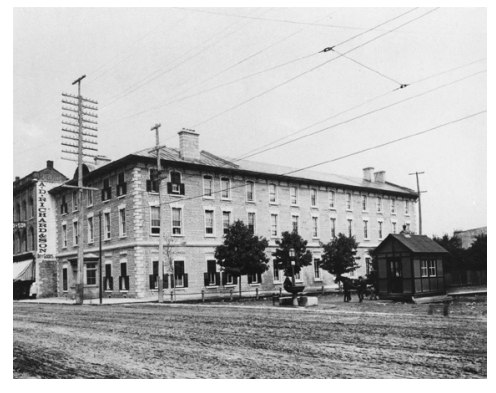

Figure 11 > The first Geological Survey of Canada, located in Montreal. 
accurate surveys were limited to the coastal regions and populated areas, leaving the bulk of the territory uncharted. Following Confederation, the desire to connect the coasts of the newly unified Dominion while guiding colonization of the interiors provided the need for accurate representation of space. Under the directorship of Alfred Selwyn (Figure 12) and then George Dawson (Figure 13), the GSC would explore and survey the western territories for the establishment of the Canadian Pacific Railway. Through their explorations, the GSC would codify the landscape's resources while extending colonial vision to the vast Canadian hinterland.

Maps produced for the Canadian Pacific Railway testify to the fluid but pivotal role the GSC played in extending colonial control westward. Although produced by a civilian agency, the maps' ancestry can be traced back to the Ordnance Survey of Great Britain. They were drawn by Alfred Barlow, apprentice to his father, Robert Barlow, who was the GSC's first chief draftsman. As a topographer, Robert Barlow had previously worked for the Ordnance Survey in Britain for twenty-seven years before his appointment at the GSC. ${ }^{20}$ Act-

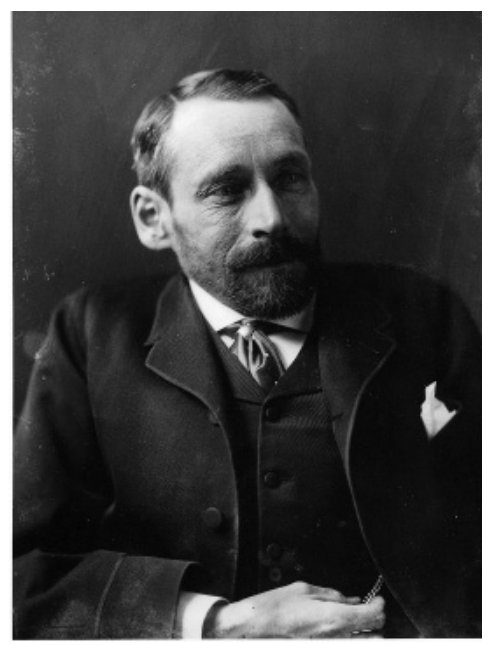

Figure $13>>$ George Dawson ing often as the vanguard for imperial surveying, geologists lacked proper topographic information to display their find-

20 William E. Eagan, "BARLOW, ROBERT," Dictionary of Canadian Biography (University of Toronto/Université Laval), accessed August 14, 2021, http://www.biographi.ca/en/bio/barlow_robert_11E.html. 
ings on. As the first chief draftsman, Barlow's contribution at the GSC largely consisted of the development of a branch for topographic mapping. Although informed by European methods, the techniques used for taking measures across the North American landscape would vary considering the vastness and complexity of the task. Certain areas would be surveyed with the heavy use of instruments (Figures 14, 15, 16), including theodolites, telescopes and measuring tape, while others would be measured manually through pacing. ${ }^{21}$

Drafted by Alfred Barlow, with the involvement of George Dawson as surveyor and later as director, the Reconnaissance Map of the Rocky Mountains and the Geological and Topographical Map of the Northern Part of the Lake of the Woods and Adjacent County reflected the Geological Survey's transition from a scientific enterprise to an arm of colonial expansion. In the Reconnaissance Map (Figure 17), special attention is given to coal outcrops, particularly along the CPR rail corridor in the Bow River Valley. Their "considerable importance due to their proximity to the rail line and excellent quality" is mentioned in the accompanying report

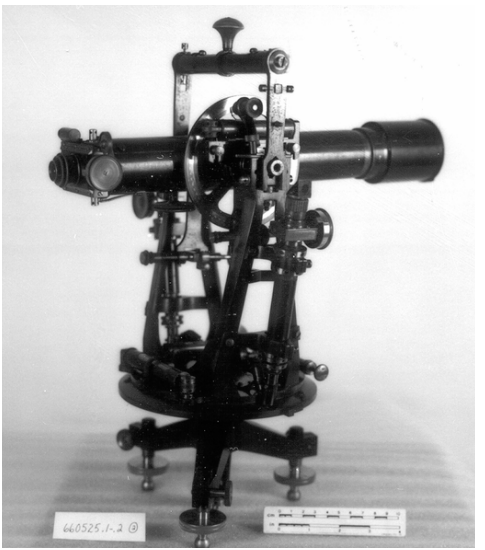

Figure $14>>$ Theodolite

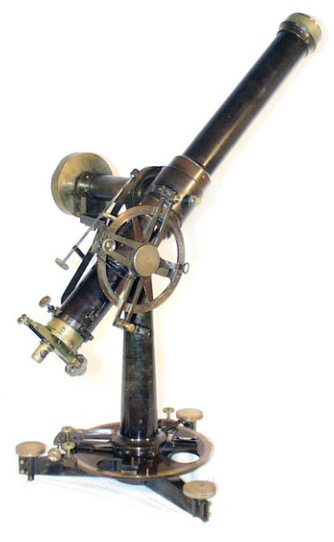

Figure 15 >> Telescope

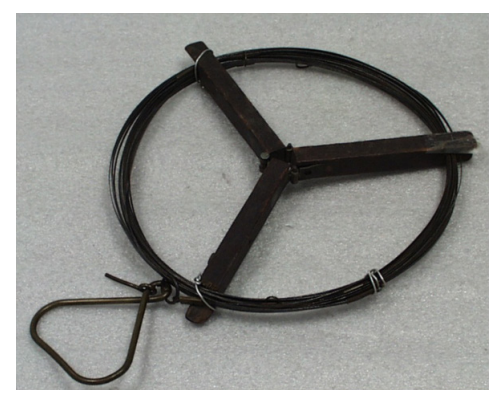

Figure 16 >> Measuring Tape

21 J Burr Tyrrell, "The Topographical Work of the Geological Survey of Canada," The Geographical Journal 10, no. 6 (August 14, 1897): 623-24, https://doi.org/10.2307/1774911. 


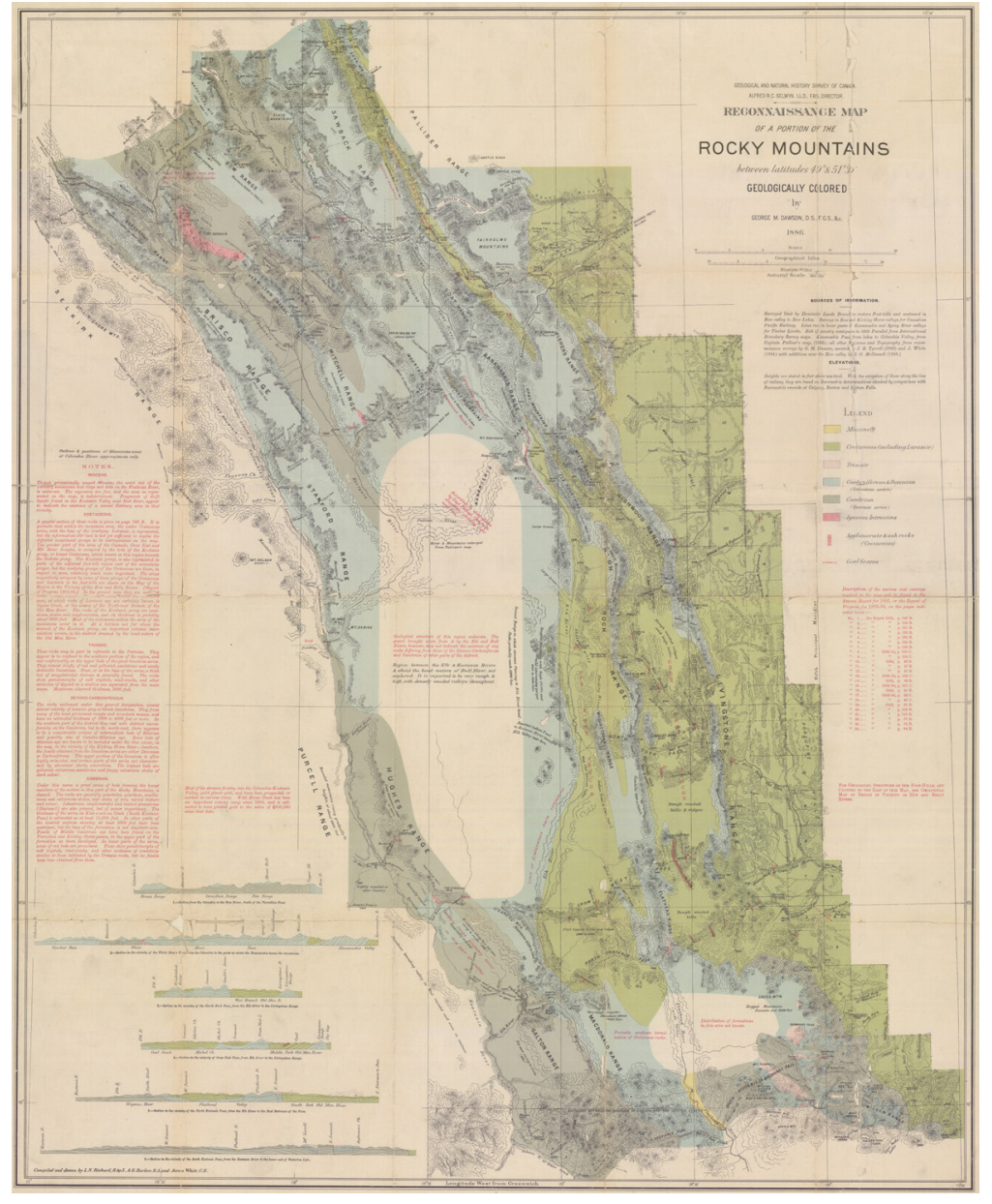

Figure $17 \gg$ The Reconnaissance Map of the Rocky Mountains drafted by Alfred Barlow.

written by Dawson in 1885.22 The Geological and Topographical Map (Figure 18), produced two years later, is more explicit in its role as an agent of exploitative development. While the Reconnaissance Map features some degree of elevation information, the Geological and Topographical Map's topographic information is stripped to a bare minimum, and

22 G. M. Dawson, "Preliminary Report on the Physical and Geological Features of That Portion of the Rocky Mountains, between Latitudes $49^{\circ}$ and $51^{\circ} 30$, " Geological Survey of Canada, Annual Report vol 1 (1886): 133. 


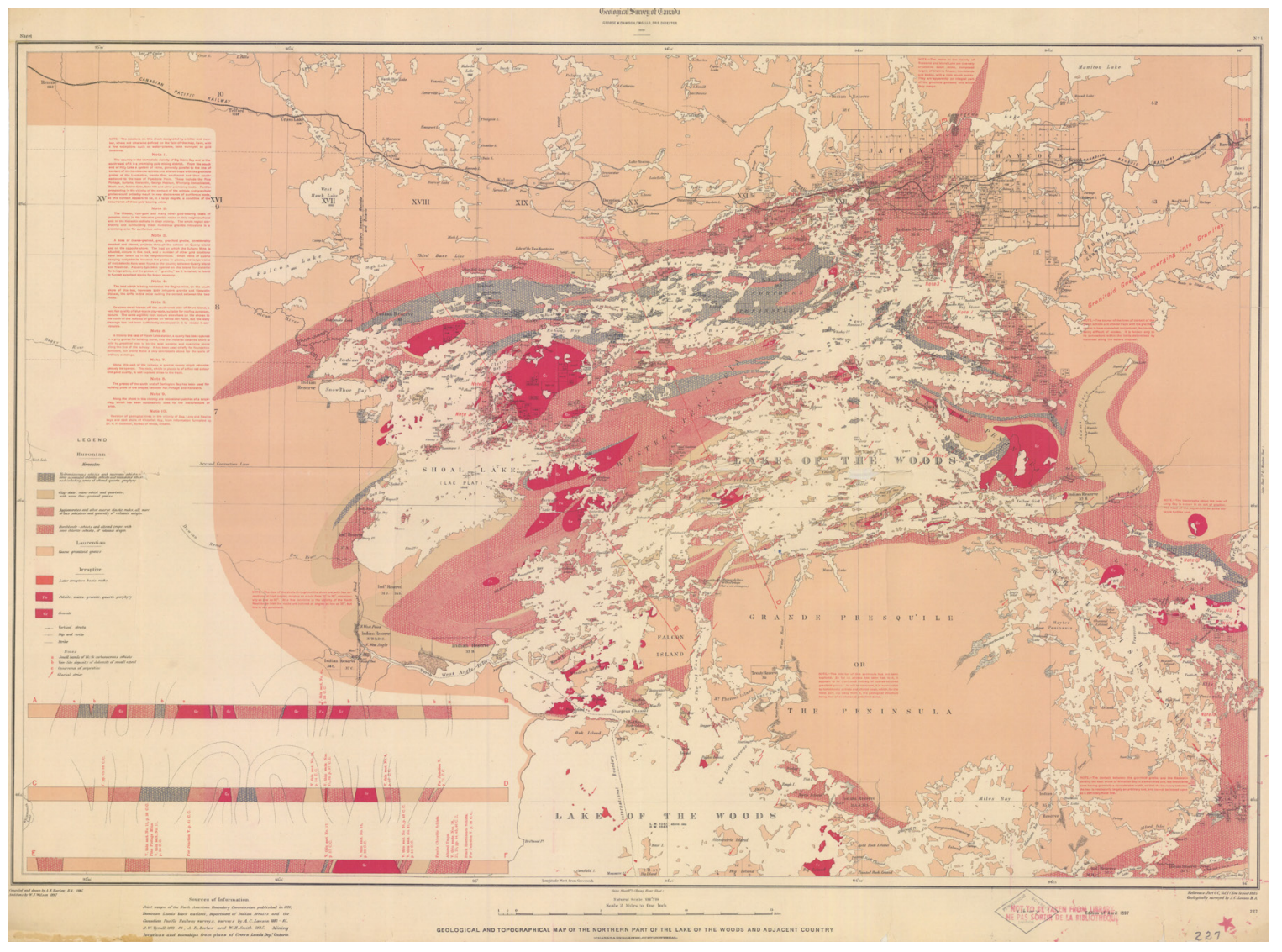

emphasis is put on geologic content. Unlike in the Reconnaissance Map, geologic formations are divided into subgroups identifying their mineral content. Finally, notes on the map explicitly highlight the potential for certain zones to support economic development, going as far as suggesting the opening of a new granite quarry along the existing CPR rail corridor.

The measure of the Dominion's territory in terms of its resources would go on to inform the configuration of its
Figure 18 >> The Geological and Topographical Map of the Northern Part of the Lake of the Woods and Adjacent County drafted by Alfred Barlow. 
settlements, training the colonial eye to look at the land-

scape in terms of extractive or economic potential. Eventually, such potential would allow the modern Canadian state to emancipate itself from colonial Britain, and to become, as Pierre Bélanger calls it, its own Extraction Empire. ${ }^{23}$ 


\section{3 >> The Technological Eye}

"To achieve this dream, the railway was a necessity [...] it would be the spine of empire, an Imperial highway linking the British Isles with the Orient..."

- Pierre Berton, The National Dream

Technology played a crucial role in the formation of the modern Canadian state. While it practically facilitated the settlement of the "hostile" landscape of the country's interior, it also defined settler perceptions of themselves in relation to the lands they were colonizing. Described by media theorist Maurice Charland as Technological Nationalism, this cornerstone of the Canadian imaginary would animate the rhetoric of nation-building that shaped the colonial western expansion, a rhetoric fueled heavily by the use of imagery.

To say that the development of the railroad linking the West Coast to Ontario transformed the Canadian state would be an understatement. Described by Charland as a "space binding technology," the railroad connected the sparsely populated hinterland to the dense urban centers along the coasts, thus expanding the apparatus of the state 
and permitting "the incorporation and dominions of the margins." ${ }^{24}$ For Charland, this new "technological state" provided Canada with its own myth of origin; that of a nation capable of asserting control over its territory through technological mediation. The steam engine itself represented an icon of power, capable of negotiating geographic obstacles to bring the nation together (Figure 19). ${ }^{25}$

As the corporation responsible for this continental connection, the Canadian Pacific Railway contributed largely to this mythos through the use of propaganda images.

The publication of brochures advertising the technological prowess of the CPR reinforced the idea of space rendered accessible through technology. The cover of The New Highway to the Orient: Across the Mountains, Prairies and Rivers of Canada (Figure 20) is a clear example of this. The scene is centered on the Stoney Creek Bridge, a segment of the railway crossing over a steep ravine. The cliff sides that form the ravine fade in the margins, thus reinforcing the effect of the vertical composition. The creek flows off the drawing and into the margin at the bottom, which adds dynamism to the composition. The landscape recedes in the background into the fog, creating a sense of infinity, hinting to the vast ex-

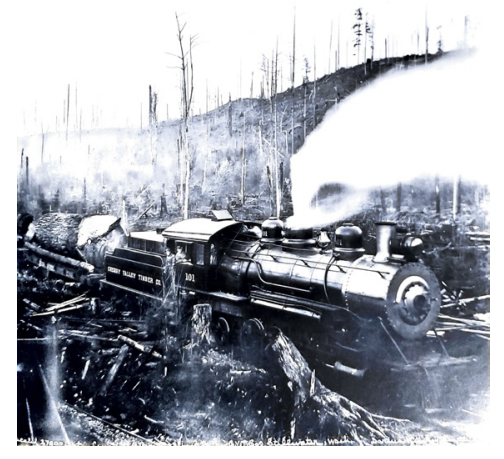

Figure 19 >> Steam Engine Locomotive

24 Maurice Charland, "Technological Nationalism," Canadian Journal of Political and Social Theory X (1986): 199.

25 Charland, 200. 


\section{Ganadian Pacific}

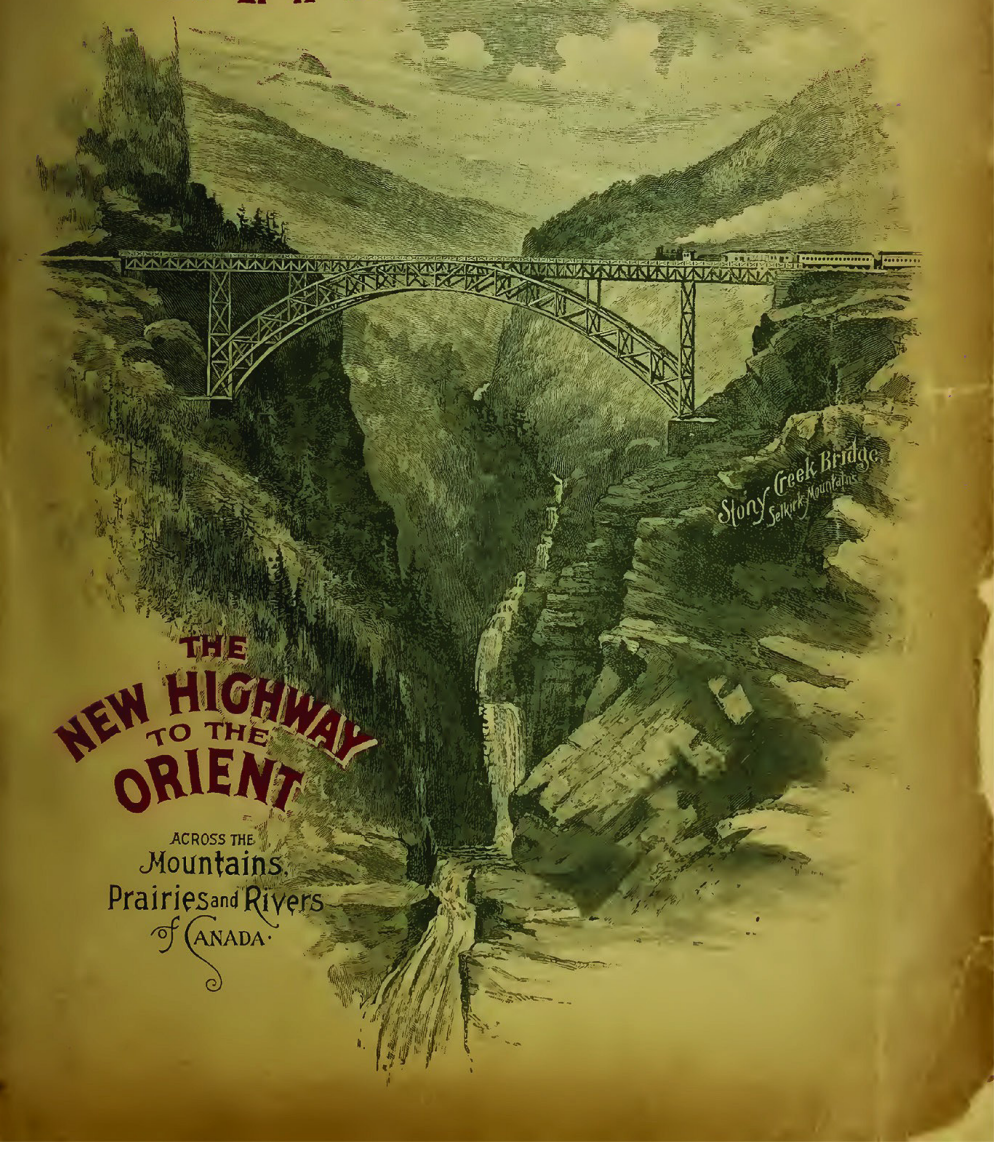

Figure $20>$ > The cover of The New Highway to the Orient: Across the Mountains, Prairies and Rivers of Canada.

panses lying beyond the ravine. In the image, the role of the train is clear. By domesticating this rugged, perilous terrain it opens this vast, empty expanse of land to the enjoyment of the colonial gaze. By opening up for colonization lands otherwise considered as uncharted, far-flung wildernesses, the Canadian Pacific Railway played a crucial role in the devel- 
opment of the Canadian Prairies. Here, technologically-mediated space combined with the CPR's propaganda played a central role in territorial development.

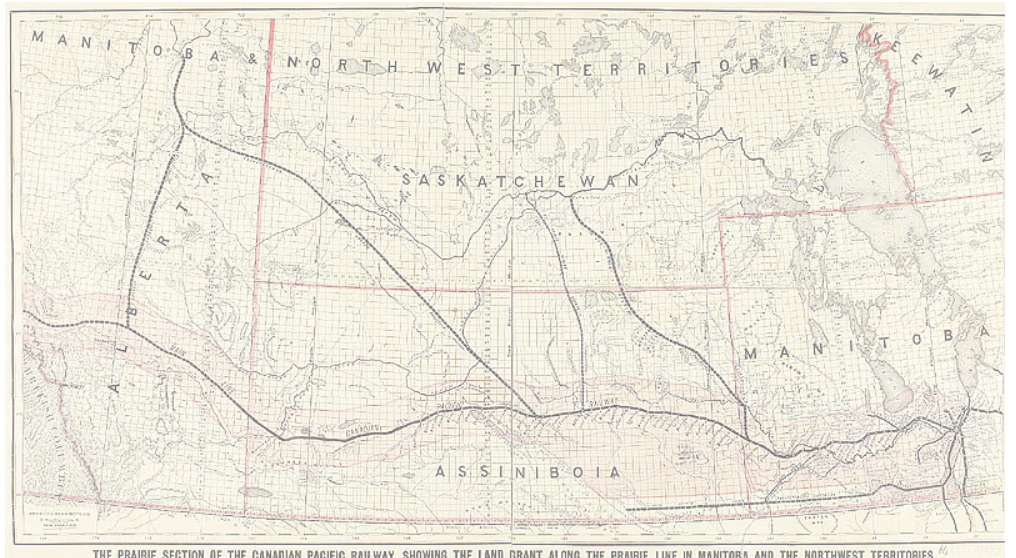

According to architectural writer and historian Elsa

Lam, early explorers and traders described the southwestern Prairies as a desert wasteland. ${ }^{26}$ Known as Pallister's Triangle

(Figure 21), this region encompasses most populated areas of modern-day Alberta, Saskatchewan, and Manitoba. After Confederation, when the Prairies found themselves within the reach of colonial authorities, a group of expansionists would purposefully rebrand Pallister's Triangle as a "promised land" of "fertile, untouched wilderness," (Figure 22) waiting for its full potential to be realized. ${ }^{27}$ Chief among the expansionists was the CPR, whose Southern Line crossed the Triangle, and whose revenue depended largely on the

$26 \quad$ Elsa Lam, "Wilderness Nation: Building Canada's Railway Landscapes, 1885-1929" (Columbia University, 2011), 113.

27 Lam, 113.
Figure 21 > CPR map of Western Canada showing Pallister's Triangle.

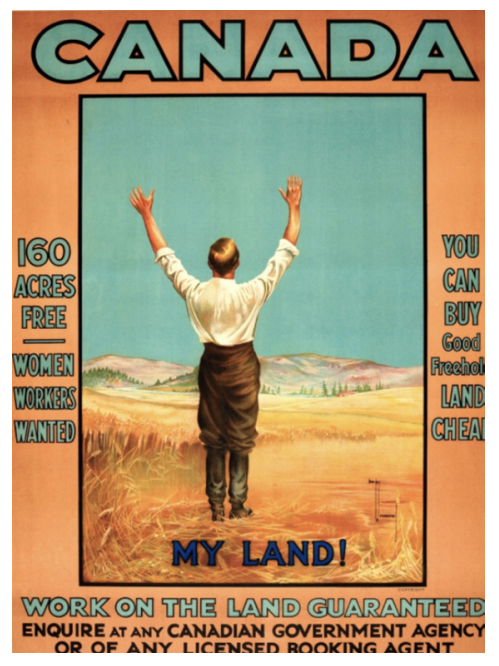

Figure 22 >> CPR poster implying a promised land. 
sales of land along its tracks. Following popular wisdom that "rain follows the plow," the CPR would develop massive irrigation districts through the construction of dams, reservoirs, and canals, thus activating the "latent productivity of the apparently desolate terrain." ${ }^{28}$ The districts would then be parceled into plots of land and marketed for settlers "of British descent" back in Europe.29 Here again, the CPR's propaganda apparatus would play a crucial role in realizing this vision by appealing most notably to British picturesque sensibilities (described further in the next section, The Romantic Eye). Through promotional brochures, the CPR would advertise picturesque farmsteads in natural settings, with the underlying irrigation technology "not far removed from being cast as a natural act." ${ }^{30}$

The cover of the brochure Irrigation Farming in Sunny

Naturalism $\gg>$ The idea Alberta (Figure 23) depicts a farmer gently guiding water through a system of irrigation channels. The lush, verdant pasture and overall naturalism of the scenery testify to the ideals of the picturesque promoted by the CPR. A water dam is shown in an overlay, subtly hinting to the role of technology in making the realization of this Edenic garden possible. and forces operate within the world.

Picturesque $>>$ An aesthetic category alongside beauty and sublimity, associated with the roughness and irregularity of nature harmonised by composition.

$\begin{array}{ll}28 & \text { Lam, } 118 . \\ 29 & \text { Lam, 122. } \\ 30 & \text { Lam, 119. }\end{array}$




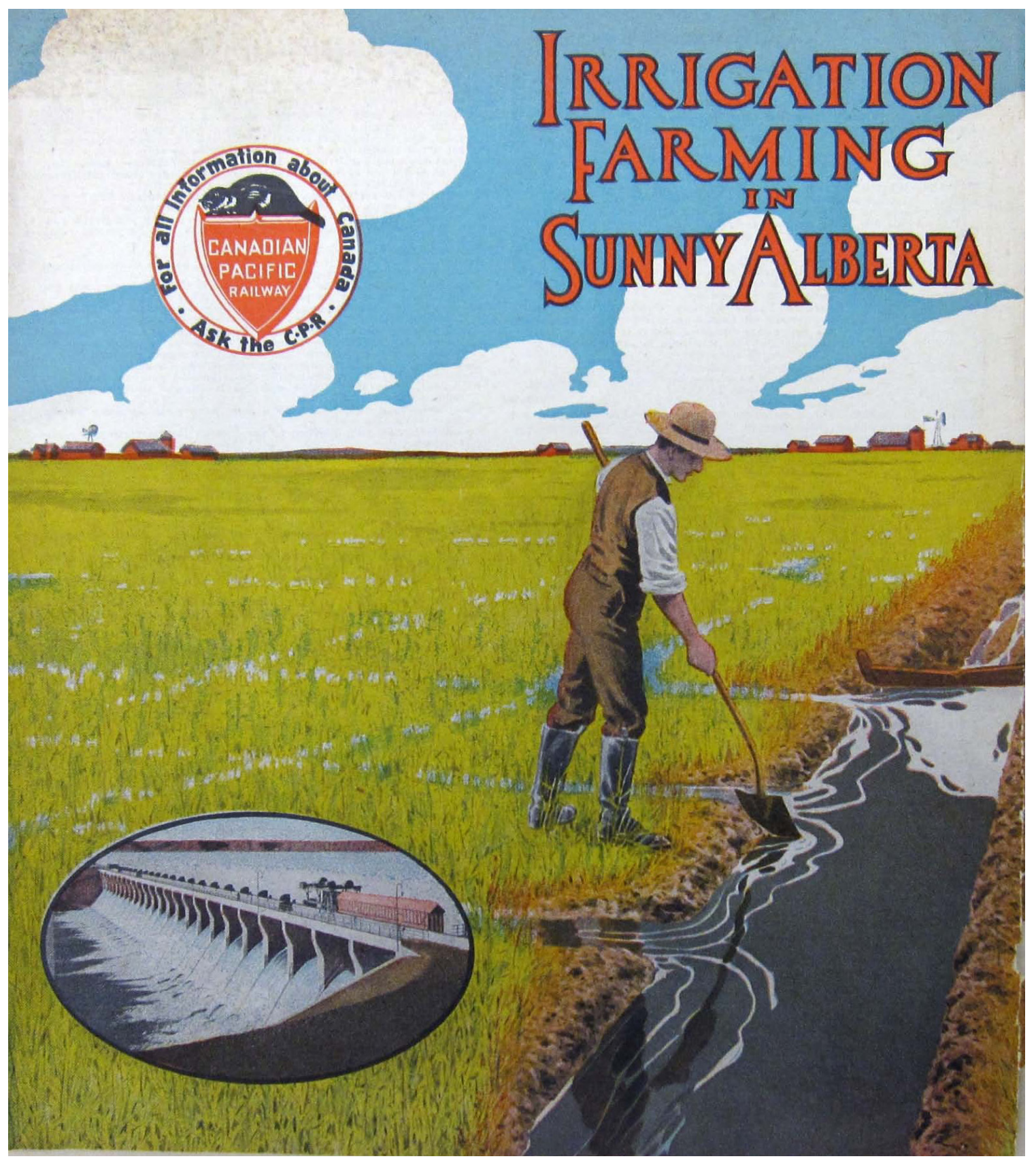

Figure 23 >> The cover of the brochure Irrigation Farming in Sunny Alberta. 
As argued by Lam, this depiction of the picturesque farm remains key within Canadian national culture. ${ }^{31} \mathrm{Al}$ though the naturally semi-arid terrain of Pallister's Triangle is commonly prone to episodes of severe drought, its identity as pastoral landscape has been ingrained in the collective imaginary through images of grain elevators (Figure 24) and cattle farms. By downplaying the threat presented by the barren-looking grasslands, and rebranding the Prairies as a "fertile wilderness," the CPR directly contributed to their transformation into a technologically mediated space. Technology, representation and mythmaking are combined, and "Nature" is rendered non-human, and separate - and therefore, can be tamed.

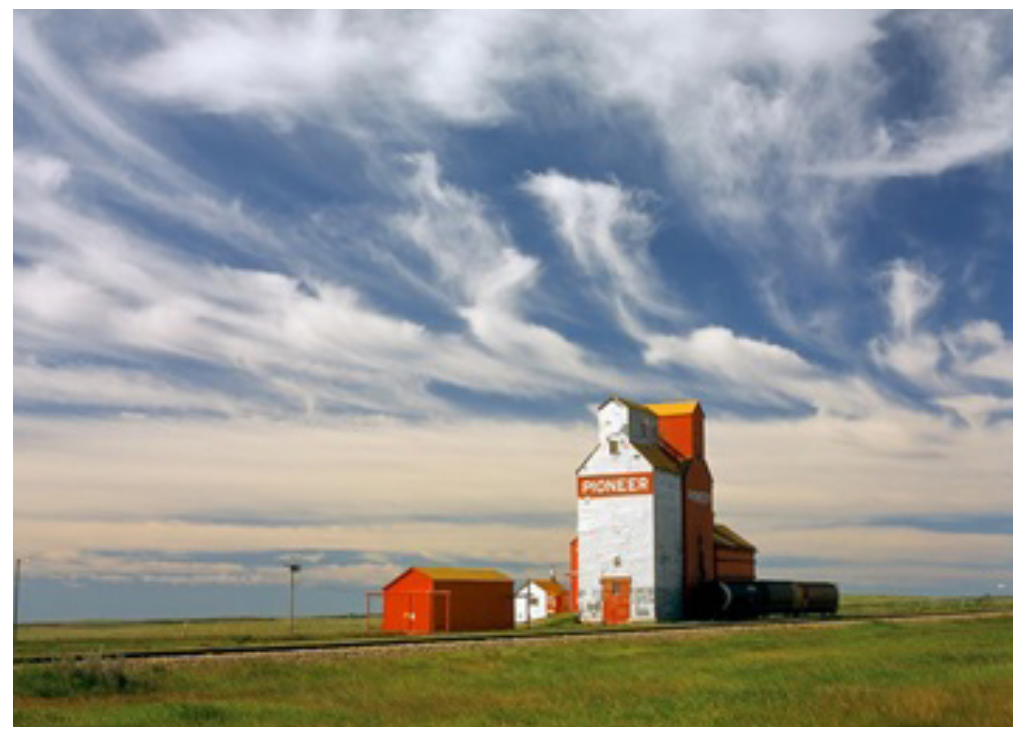

Figure 24 >> Prairie grain elevator. 


\section{4 > The Romantic Eye}

"In wildness is the preservation of the world."

- Henry David Thoreau, Walking

Aesthetics contributed greatly to defining perception

of nonhuman. Techniques and compositions associated

with Picturesque and Romantic ideals dominated the visual landscape of the Victorian era. Such principles would go on to influence the fields of the natural sciences and play a crucial role in the emergence of the contemporary environmental conservation movement. These aesthetic sensibilities would percolate through Canadian cultural memory and influence the development of a national identity.

Before the establishment of standardized survey systems, accurate recordings of space were created by artists known as topographic painters. Described as "topographic" because of its accuracy, this style was largely associated with military draftsmanship, and was notably taught in England at the Woolwich Royal Military Academy.32 To achieve spatial

32 Pierre-simon Doyon, "Topographic Painters," in The Canadian Encyclopedia, 2009. 
accuracy, painters would routinely make use of a pinhole camera (Figure 25), an optical device allowing artists to project the image of a landscape onto a flat surface for tracing. In the $18^{\text {th }}$ century, such a device consisted of a series of lenses within a box, which made it portable enough for artists to carry on extensive expeditions. Despite its military origins, this representational style was ultimately destined for art galleries. Through this, the style developed under the influence of the artistic canons of the British Picturesque, influencing artists to use a degree of creative freedom to fit certain aesthetic standards in their compositions.

The use of pinhole cameras to capture a scene would often result in a blurry foreground due to lens refraction. For this reason, topographic painters would often compensate for this with an invented scenery, populated with rugged elements typical of a picturesque aesthetic, but also with characters, giving a sense of realism and relatability. The work of George Fisher, for instance, communicates the use of these techniques in early depictions of the Canadian landscapes. Although there is no direct proof that Fisher used a pinhole camera, his depiction of the Fall of Montmorenci (Figure 26) testifies to the use of such compositional devices. A darkened swathe of land populated with rockeries and characters occupies the foreground, a method

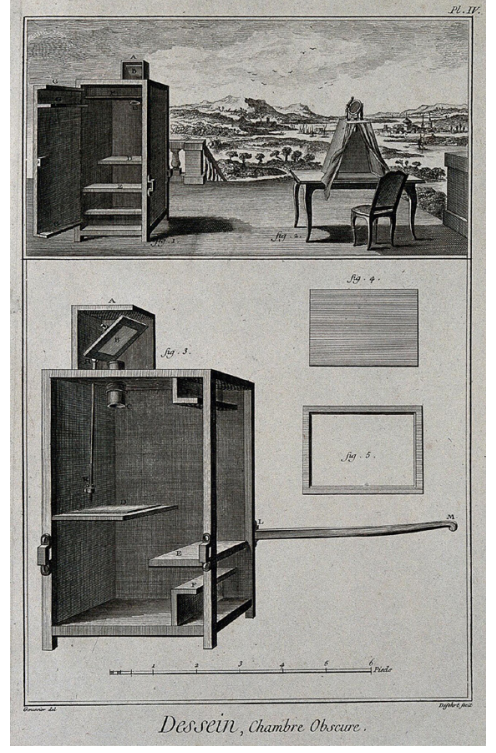

Figure 25 >> Engraving of a pinhole camera by Louis-Jacques Goussier. 


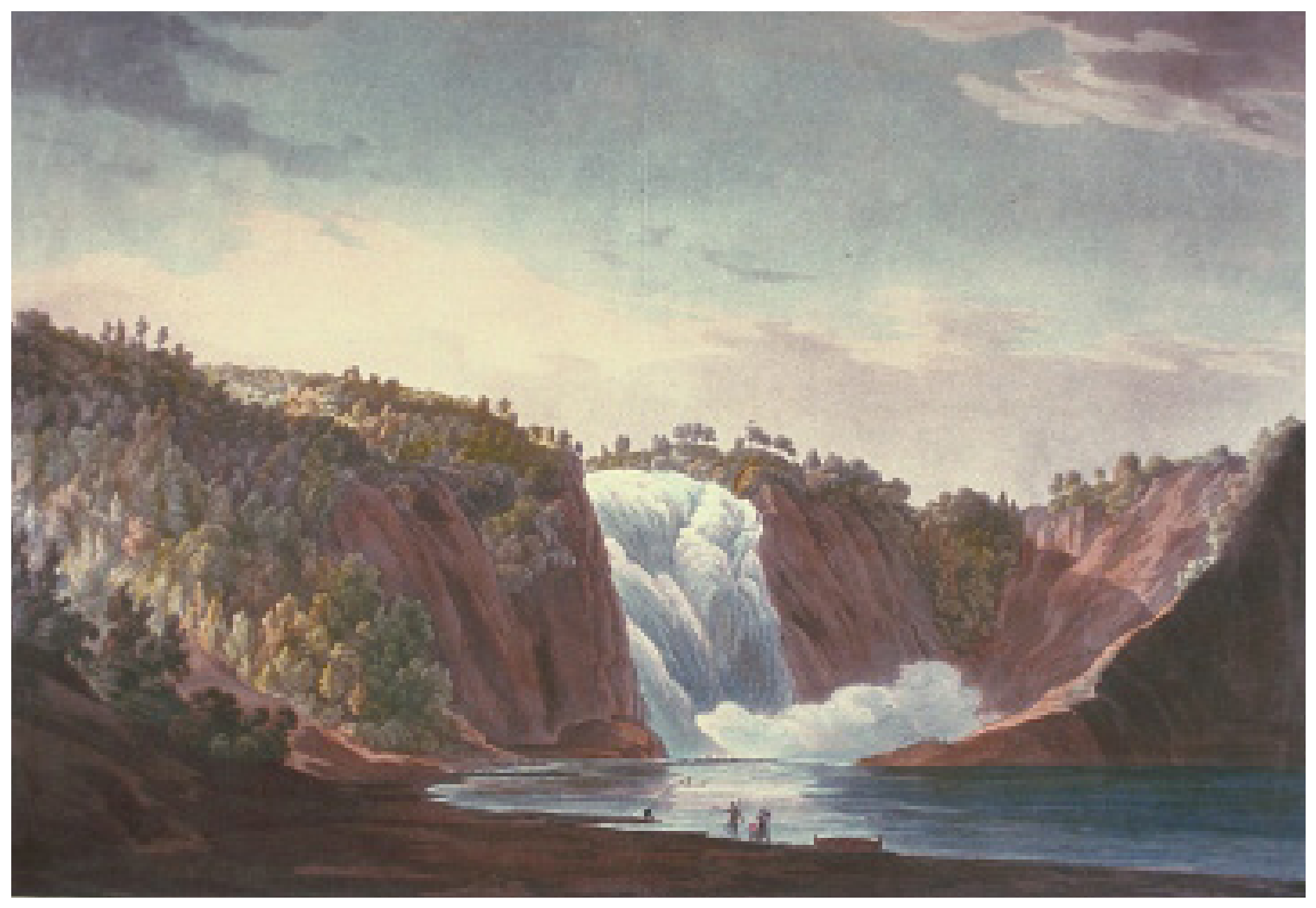

commonly used to provide depth to the composition and to

Figure 26 >> Fall of Montmorenci compensate for optical aberrations. ${ }^{33}$

Such fascination with landscape scenery would eventually spill out of art galleries. The construction of pavilions containing panoramic paintings, such as the one at Leicester Square in London, grew in popularity throughout the Victorian era (Figure 27), allowing urbanites to experience remote locations in immersive and picturesque environments. Picturesque scenery would also come to define

33 Michael Collins, "The Ground Glass: Landscape Art, the Camera Obscura and Photography," accessed August 15, 2021, https://www. bl.uk/picturing-places/articles/the-ground-glass-landscape-art-the-camera-obscura-and-photography-coll-items-missing. 
the composition of museum dioramas (Figure 28), and by extension the aesthetics associated with natural history museums and collections. Most importantly, excitement for the Picturesque would encourage urbanites to seek a direct experience of the scenes pictured in these images, giving rise to a vibrant tourism industry.

The aesthetic of the Picturesque would take a supernatural undertone through the paintings of the Romantic movement. According to William Cronon, explorers and artists would come to see particular landscapes as "those rare places on earth where one had more chances than elsewhere to glimpse the face of God." ${ }^{34}$ Important landmarks became perceived through the doctrine of the sublime, as described by the theories of Edmund Burke, Immanuel Kant and others. Qualities such as power, vastness, magnificence and suddenness would come to define the aesthetics of the sublime. ${ }^{35}$ In Canada, the depiction of dramatic scenery across the country's vast expanses of land was a way to represent the sublime.

Chief among Canadian representations of the sublime is the work of Lucius O'Brien. His painting Sunrise on the

$34 \quad$ William Cronon, "The Trouble with Wilderness: Or, Getting Back to the Wrong Nature," Environmental History 1, no. 1 (1996): 4, https://doi. org/10.2307/3985059.

35 Lam, "Wilderness Nation: Building Canada's Railway Landscapes, 1885-1929," 50.

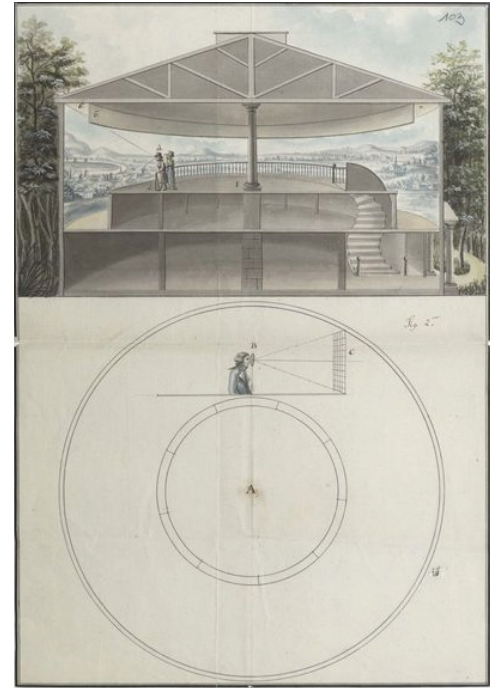

Figure 27 > Victorian Panorama

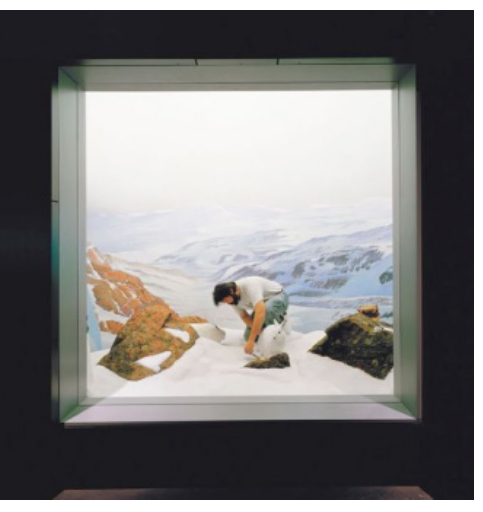

Figure 28 >> Museum Diorama

Romantic >> An artistic movement that made use of legendary, exotic, or imaginary settings, typically to explore the conflict between man and nature or the supernatural. 


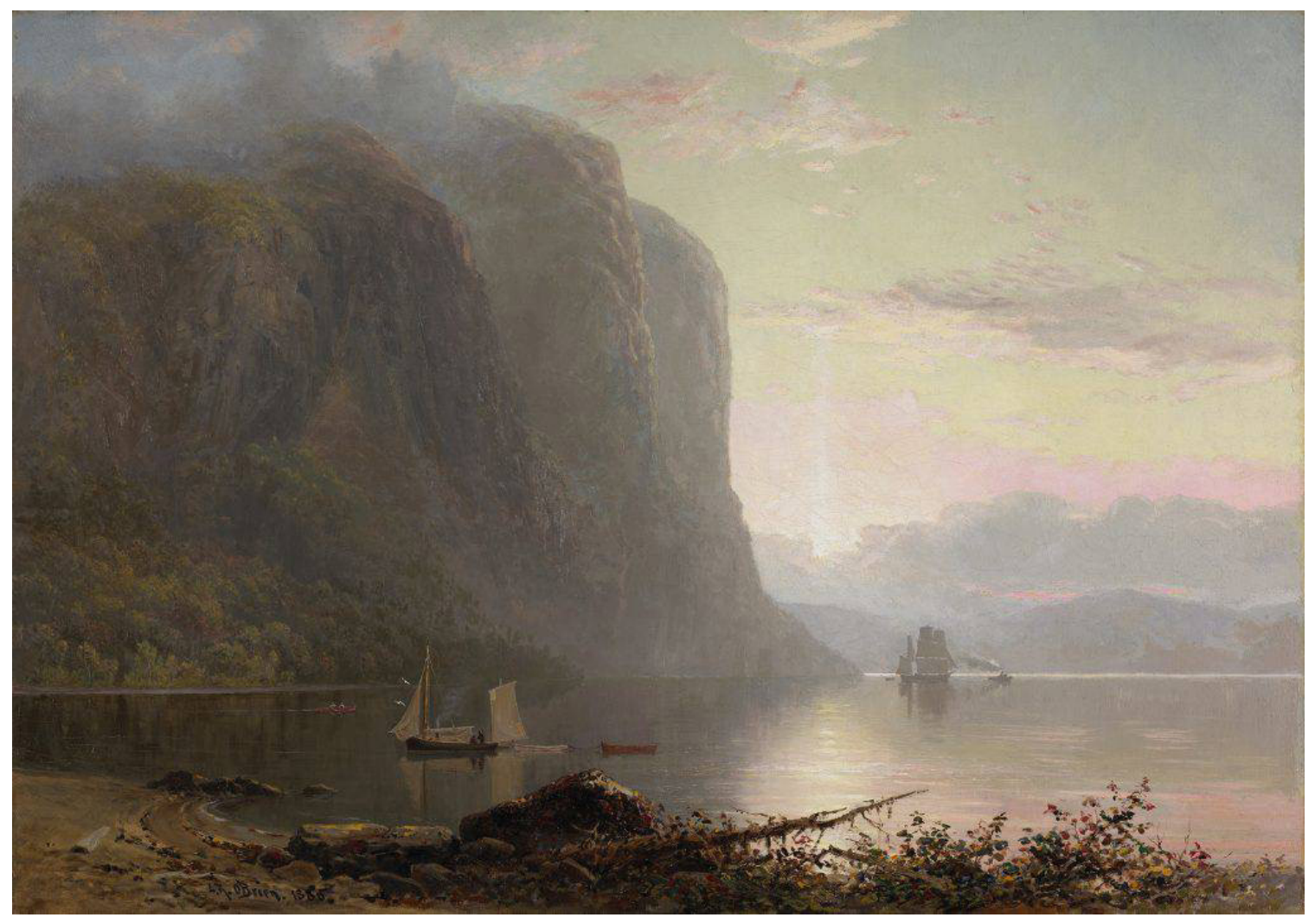

Saguenay (Figure 29) captures a sense of vastness and powFigure 29 >> Sunrise on the Saer, along with the mysticism associated with aesthetics of the sublime. The juxtaposition of the towering cliffs with the minute skiffs alludes to the fragility of Man against the power of Nature. In contrast with the clear, jagged illustration of Fisher's to pographic style, O'Brien's painting renders the enveloping atmosphere and illumination through complex fades.

Transcendentalists >>

The composition and complex play of light in O'Brien's painting are intended to suggest the spiritual charguenay by Lucas O'Brien. ing beyond the bounds of any single category, often made synonymous with the metaphysical. 
acter of landscape representation in the romantic period. Such ideals reflected the writings of American transcendentalists such as Ralph Waldo Emerson and Henry David Thoreau, who advocated for "a child-like approach to the untouched natural world in order to discover its inherent divinity." ${ }^{36}$ Inspired by such writings was also American writer and environmentalist John Muir, whose influence would lead to the creation of Yellowstone National Park, and to key ideas of the American environmentalism movement. Taking issue with the movement's focus on the preservation of a perceived wilderness, William Cronon traces the origin of the concept of wilderness to American and Christian mythology. According to Cronon, "wilderness came to embody the national frontier myth," a reaction to the "ugly artificiality of modern civilization." ${ }^{37}$ The concept also takes origin in the Judeo-Christian belief that "Wilderness is the natural, unfallen antithesis of an unnatural civilization that has lost its soul." ${ }^{38}$ Through their carefully crafted scenes and experiences, National Parks came to embody this perceived wilderness, bringing to life the highly mannered landscapes represented by Fisher and O’Brien.

Ultimately, landscape painting in Canada would

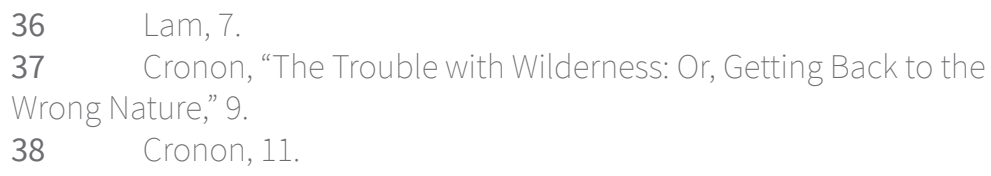


come to reflect a nationalist tendency. Borrowing from the themes of the Romantic painters, the members of the Group of Seven would represent the Canadian landscapes with a modern approach in the 1920 s and 30s. Critical of the naturalism of academic intellectualized art, they would paint their scenery in the outdoors and employ modern techniques associated with the post-impressionists and focus on communicating their feelings towards the scenery. ${ }^{39}$
Figure 30 > Untitled Alberta landscape by A.Y. Jackson.

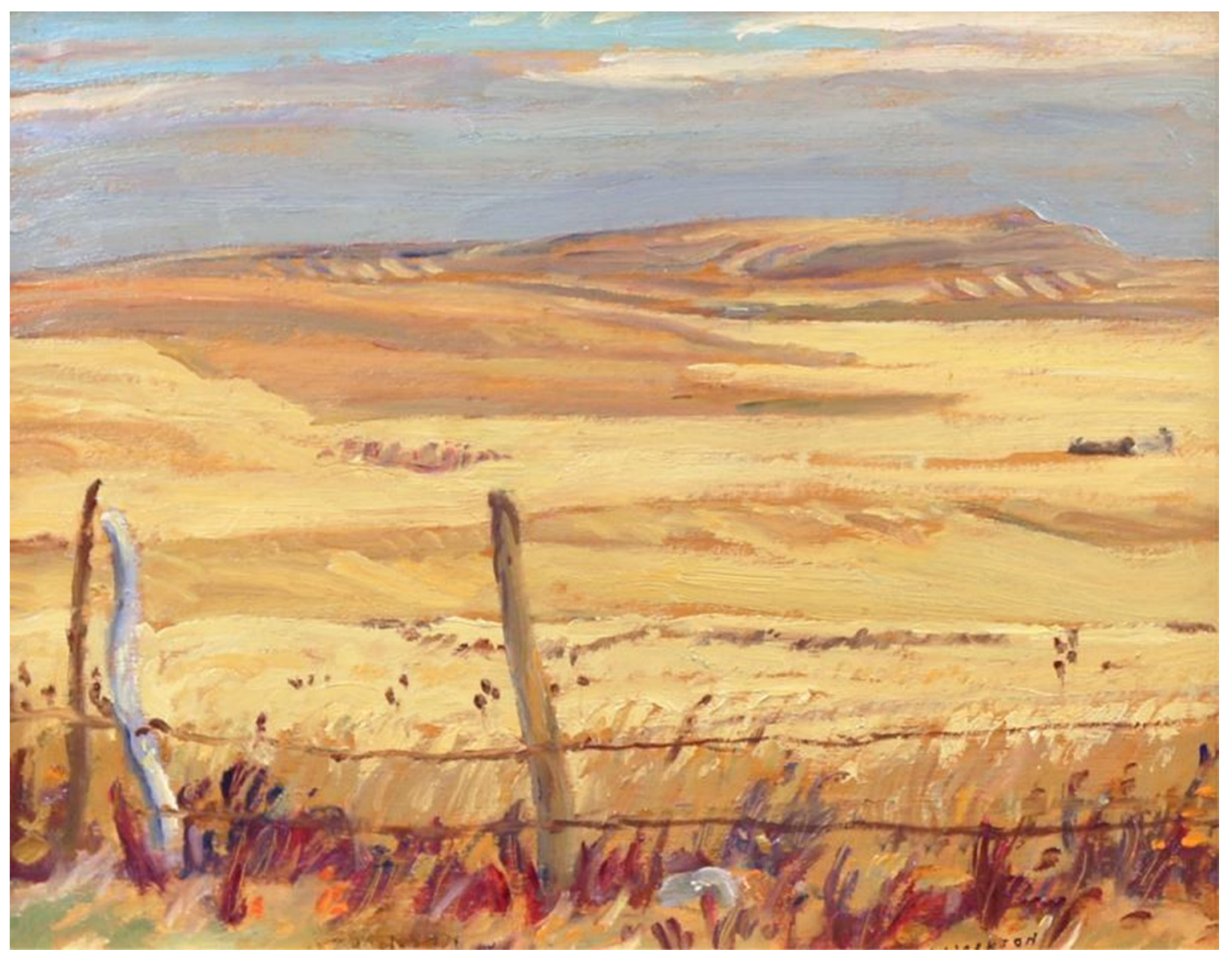

39 Christopher Varley and Russell Bingham, "Group of Seven," in The Canadian Encyclopedia, 2013, https://doi.org/10.1093/ gao/9781884446054.article.t035135. 
Among the Group of 7 (which originally included:

Franklin Carmichael, Lawren Harris, Frank Johnson, Arthur Lismer, J.E.H. MacDonald, and Frederick Varley), A. Y. Jackson's paintings of Alberta's landscapes are especially evocative of these ideals (Figure 30).

Although the representation of landscape scenery in Canadian consciousness has transformed over time, the framing of it as "pristine Nature" has remained somewhat consistent. Successive generations of explorers, artists, writers, and tourists have produced vistas showcasing a landscape to be worshipped, measured, exploited, and feared. These images reflect and construct the Canadian beholding eye, just as they reflected and constructed the territory that they captured. This beholding eye, however, remains myopic, as we fail to grasp the reality of environmental changes that this gaze misses. 


\section{5 >> Disrupting Vision}

Through constructing colonial vision, each lens and their associated imageries contribute in a way to define the current geographic imagination of Canadian settlers, as expressed through various attitudes towards the Canadian territory. These attitudes, in turn, contribute to obscuring the interconnectivity between humans and their physical environment, and by extension, to the environmental catastrophes that increasingly affect Canadian locales.

Through the Mythological Eye, the Natural World is constructed as subservient to the needs of settlers, which justified the development of exploitative infrastructures across the country. The establishment of a cartographic system through the Military Eye enabled the parcelling of the land into concessions, while simultaneously allowing for the scientific monitoring of territories through a range of instruments and data models. Through the Technological Eye, set-

tlers saw the need to manipulate their surroundings through technological means, a vision that extends to the technological manipulation of the climate at local scales. Finally, the Romantic Eye projects an incentive to protect an idealized Nature, resulting in the creation of a network of protected zones, 
and an uneven distribution of conservation efforts.

In constructing the geographic imagination, these attitudes reflect how settlers in Canada perceive the relationships that exist between them and the territory they occupy. Although this vision remains largely stable, the occurrence of unexpected climate events can create the necessary slippages that question the established perceptions. As argued by philosopher Maurice Halbwachs, "the bonds attaching a group to a physical locale gain greater clarity in the very moment of their destruction.40" In Canada, such major events include the 2013 Alberta floods, and the Fort McMurray wildfires of 2016.

In 2013, a combination of both meteorological and hydrological factors led to an extreme flooding event in the Bow River basin. Known as Alberta's Flood of Floods, the event resulted in the displacement of almost a hundred thousand people and caused nearly \$6 billion in damage, making it the costliest natural disaster in Canada to that date. ${ }^{41}$ The increase in human-induced green house gases emissions over the decades leading up to the event was demonstrat-

40 Maurice Halbwachs, "Space and the Collective Memory," The Collective Memory, 1941, 2.

$41 \quad$ Xuebin Zhang et al., "Temperature and Precipitation Across Canada," in Canada's Changing Climate Report: Temperature and Precipitation Across Canada, ed. Editors Bush, E. and Lemmen, D.S, 2019, 179. 
ed to have increased the likelihood of extreme precipitation events in southern Alberta, a region typically known for its arid climate. $^{42}$

During the spring of 2016, a raging wildfire burned through almost six hundred thousand hectares in the vicinity of Fort McMurray, Alberta. While the fire resulted in the evacuation of the entire town, it also interrupted production in the oil sands industry, taking a blow to the economy. ${ }^{43}$ It was demonstrated that increasing temperatures due to anthropogenic emissions lead to drier timber and a longer fire season, resulting in the extreme intensity and duration of the wildfire. ${ }^{44}$ Through their disruptive effect, these events offered a moment of clarity and an increased reckoning with the impact of human activities on the frequency of extreme climate events. This reckoning is expressed by architect Paulo Tavares, who argues that these extreme events are never simply natural phenomenon. For Tavares, such events "are immediately embedded within a historical-political terrain formed both by environmental forces and by social cleavages, local ecologies and global vectors of power and capital, and, crucially, by the

$\begin{array}{ll}42 & \text { Zhang et al., } 180 . \\ 43 & \text { Zhang et al., } 181 . \\ 44 & \text { Zhang et al., } 181 .\end{array}$


frictions and relations established between them.” ${ }^{45}$

While such a reckoning offers clarity in the Canadian situation, it arrives too late to produce any lasting changes to the origins of anthropogenic disturbances. As argued by Tavares, "the historical failure in establishing a political solution to the problem of anthropogenic-induced global warming thus forced us to consider the undesirable but unavoidable possibility of deploying a technological fix in the global climate." ${ }^{46}$

This focus on technological mediation of the climate to insure long-term human survival has been expressed in Canada, largely through the development of carbon reduction projects. Most notably, the implementation of direct air capture technologies allows for the removal of carbon dioxide from the atmosphere through a chemical process. The carbon is then combined with hydrogen and oxygen to create fuel. ${ }^{47}$ While the development of such technological fixes represents a step forward to reduce the impact of climate changes, the application of such fixes largely follows the colonial

45 Paulo Tavares, "Stratoshield," in Textures of the Anthropocene: Grain Vapor Ray, ed. Katrin Klingan et al. (Cambridge, Massachusetts \& London, England: MIT Press, 2015), 67.

46 Tavares, 66.

47 Bob Weber, "B.C. Company Says It Is Sucking Carbon from Air, Making Fuel," The Canadian Press, 2018, https://www.cbc.ca/news/ canada/british-columbia/b-c-company-says-it-is-sucking-carbon-fromair-making-fuel-1.4696817. 
logic of resources extraction. In Alberta, the development of a Carbon Conversion Technology Center provides consultancy for oilsands companies wishing to profit from their carbon emissions by converting them to fuel and monetizing them. ${ }^{48}$

While the extreme climate events that plagued western Canada offered a moment of clarity on the impact of humans on the climate, the reaction to those events remains a continuation of the colonial vision defined by the Beholding Eye. The rise in a reliance on technological fixes calls for new frames of conceptualization. While the end goal remains political mobilization, there remains a need for a deeper reorientation of the geographical imagination, one that challenges how Canadians view and occupy their territory. To support this mobilization, the development of a fictional Canada explored through a videogame is proposed.

$48 \quad$ Kyle Bakx, "New Centre Aims to Capture CO2 and Monetize the Emissions," CBC News, 2018, https://www.cbc.ca/news/business/acctcshepard-xprize-co2-1.4676527. 
Part II 



\section{Imagining}

"In urgent times, many of us are tempted to address trouble in terms of making an imagined future safe [...] Staying with the trouble does not require such a relationship to times called the future. In fact, staying with the trouble requires learning to be truly present, not as a vanishing pivot between awful or Edenic pasts and apocalyptic or salvific

futures, but as mortal critters entwined in myriad unfinished configurations of places, times, matters, meanings."

- Donna Haraway, Staying with the Trouble

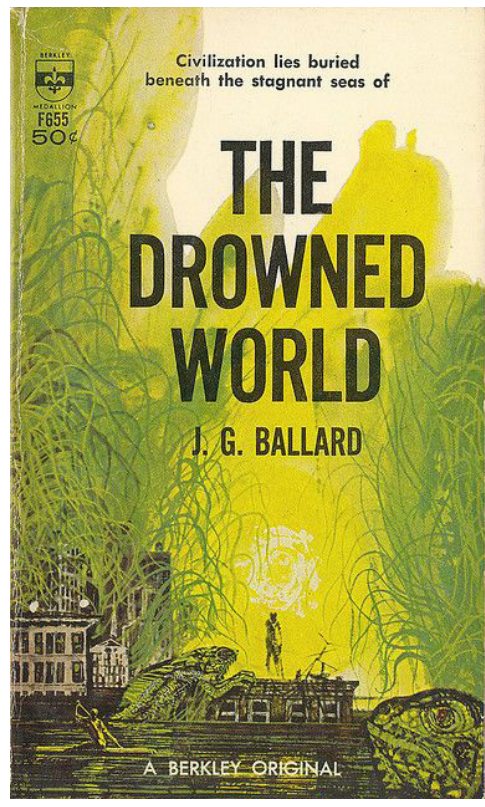

Figure 31 > Cover of The Drowned World, by J.G. Ballard.

According to writer and novelist Amitav Ghosh, a distinctive trait of the human species is its "ability to experience the world through stories." Whether expressed through literature, film, or images, stories reflect how human societies perceive themselves in and operate their world(s). Through stories, we construct our collective imaginaries, or, as described by Sheila Jasanoff and Sang-Hyun Kim, our "collectively held and performed visions of the future, animated by shared understandings of forms of social life and order."2 Imaginaries form out of a collective understanding of past and present

$1 \quad$ Amitav Ghosh, "Wild Fictions," n.d., 1.

2 Jacob Boswell, "Notes from the Wasteland: Competing Climatic Imaginaries in the Post-Apocalyptic Landscape," in Climates : Architecture and the Planetary Imaginary, ed. James Graham et al., The Avery (Lars Müller Publishers, 2016), 49.

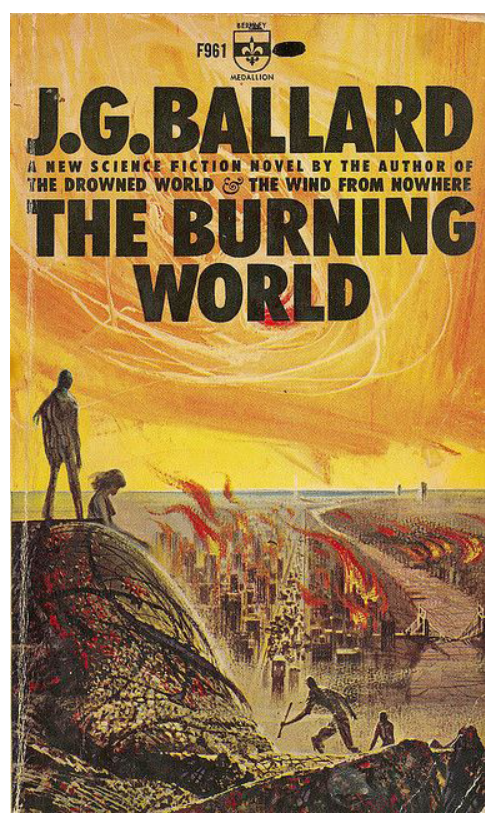

Figure 32 >> Cover of The Burning World, as The Drought was known. 
events, which are then enacted into reality. Fiction, meanwhile, crystallizes those worldviews, simultaneously perpetuating and expanding mythologies. As a paradigm of Western worldviews, the Canadian imaginary is one of technological hubris, resource extraction, and Edenic scenery. It celebrates a mythologized past and defines the nonhuman as a static entity, separate from human cultures.

With the increasing prevalence of climate catastrophes, apocalyptic scenarios have gained some prominence in collective imagination. A common trope in Western fiction, the Apocalypse rests on a rich history of precedent in the dystopian genre. From J.G. Ballard's The Drowned World (Figure 32) and The Drought (Figure 33) to Cormac McCarthy's The Road (Figure 34), scenarios of civilizational collapse have revealed dire consequences of a failing climate. Yet, such scenarios rely heavily on similar tropes of "Man versus Nature," (Figure 35) while simply pushing them to their logical conclusion. With its fatalist undertones and focus on the aftermath, the Apocalypse fails to provide a roadmap for concrete action. There remains a collective sense of apathy resulting in a failure to grasp the urgency of the situation until catastrophe comes knocking at the door.

In contemporary "Canada", we witness annually hubris >> Presumption, originally towards the gods; pride, excessive self-confidence.

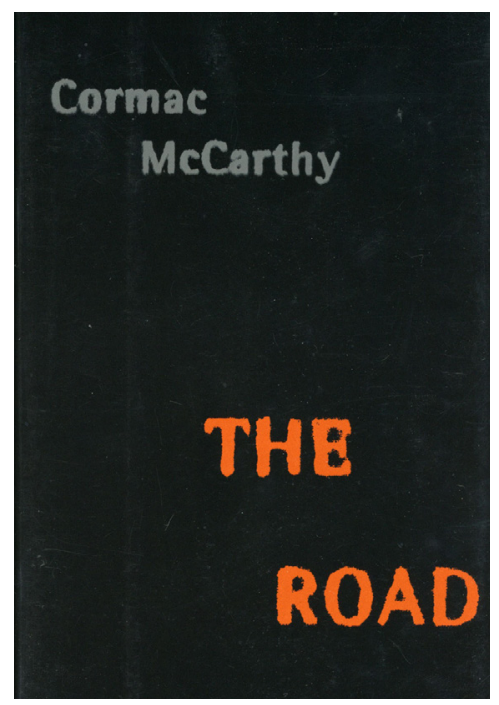

Figure 33 >> Cover of Cormac McCarthy's The Road.

Dystopian >> Of an imaginary place or condition in which everything is as bad as possible; opposed to utopian.

Trope $>>$ A significant or recurrent theme, esp. in a literary or cultural context; a motif.

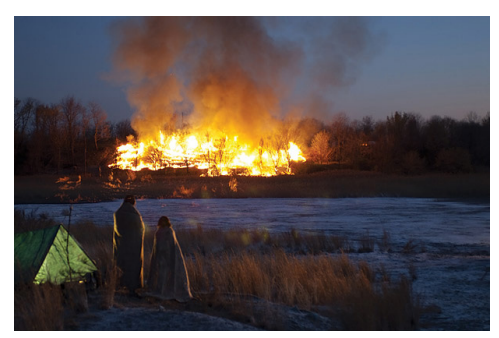

Figure 34 > The Road's "Man versus Nature". 
smoke from raging wildfires cloud the skies of Vancouver, Calgary, Toronto, and Montreal, lengthy droughts weakening the Prairies' food production, tornadoes tearing through Central Ontario and Quebec, and rising sea levels that threaten the coastal communities of the Maritimes. These catastrophes make it increasingly clear that the world has changed beyond a point of return. Yet, we continue to negate our role as agents. In response, this thesis seeks to take Donna Haraway's advice to "stay with the trouble," and, through Amitav Ghosh's fictive imperative, to critically examine our present through fiction, stories and storytelling. Alternating between critical reflection and visual production, this section attempts to offer alternative ways to imagine a changing, and plummeting, world. 


\section{1 >> Thinking in Aggregate}

"It is a fact that the contemporary novel has become ever more radically centered on the individual psyche while the collective - "men in the aggregate" - has receded, both in the cultural and the fictional imagination." - Amitav Ghosh, The Great Derangement

In The Great Derangement, Amitav Ghosh laments the focus on the "individual moral adventure" to the detriment of collective scenarios in contemporary fiction. Citing Bruno Latour, Ghosh attributes this partitioning to modernity's obsession with separating the natural from the cultural, and the dismissal of mythological associations in the natural sciences. ${ }^{3}$ Still following Latour, this dismissal of Nature-Culture hybrids resulted, as a side effect, in the partitioning of literature into a "serious fiction" concerned with well-defined characters, and less serious fiction concerned with "men in the aggregate." ${ }^{\prime 4}$

Yet, as Ghosh rightly points out, this focus on individ-

3 Amitav Ghosh, The Great Derangement, The Great Derangement (The University of Chicago Press, 2018), 68, https://doi. org/10.7208/chicago/9780226323176.001.0001.

$4 \quad$ Ghosh, 77.

\begin{abstract}
Modernity $\gg$ An intellectual tendency or social perspective characterized by departure from or repudiation of traditional ideas, doctrines, and cultural values in favour of contemporary or radical values and beliefs (chiefly those of scientific rationalism and liberalism).
\end{abstract}

Natural > A natural thing or object; something having its basis in the natural world or in the usual course of nature.

Cultural >> Of, belonging to, or relating to the culture of a particular society, people, or period.

Mythological >> of a body or collection of myths, esp. those relating to a particular person or thing, or belonging to a particular religious or cultural tradition.

Aggreate $>$ Constituted by the collection of many particles or units into one body, mass, or amount; collective, whole, total. 
ual narratives fails to capture the ubiquity of environmental changes. The uncanniness of a seemingly inanimate nature "suddenly coming to life" thrust back into light the "elements of agency and consciousness" that humans share with the nonhuman, effectively shattering the partitions between the Natural and Cultural.5 This sharing of agency is perhaps better understood as being what philosopher Timothy Morton's defines as an Hyperobject. For Morton, Hyperobjects are so "massively distributed in space and time" that they can ever only be grasped in bits through localized events. ${ }^{6}$ Yet, in their ubiquity, such objects become "sticky," and the more we try to shake them off, to distinguish ourselves from them, the more we realize that we simply cannot.?

Science fiction provides the necessary thinking "in aggregate" to tackle the scale of these Hyperobjects. For critic and philosopher Fredric Jameson, science fiction as a genre concerns itself less with "the extrapolation of forms of individual destiny onto collective history" than with "the mediation of space itself." ${ }^{\prime}$ With this prioritization of space over time, science fiction not only presents itself as a genre capable of engaging with the vastness of climate catastrophe, but it can

\footnotetext{
$5 \quad$ Ghosh, 63.

6 Timothy Morton, "What Are Hyperobjects ?," 2019, 48.

7 Morton, 36.

8 Fredric Jameson, Archaeologies of the Future: The Desire

Called Utopia and Other Science Fictions, 2005, 312-13, https://doi. org/10.1057/palgrave.cpt.9300288.
} 
also effectively address its urgency. Jameson, in the end, suggests that science fiction does not attempt to imagine "real" futures, but rather mock futures that "[transform] our own present into the determinate past of something yet to come." Science fiction becomes an active means of creation and reflection. Moreover, with its capacity to mediate space, science fiction holds the potential to animate game worlds.

It is this quality of science fiction as a "spatial genre" that defines it as a suitable medium for architectural practice, allowing designers to act beyond the built environment and reflect critically on the complexities of worldly phenomena including in and through media such as videogames. Such an ambition is pursued in the visual storytelling practices of Rania Ghosn and El Hadi Jazairy's Design Earth. In their anthology Geostories (Figure 36), Ghosn and Jazairy "draw specifically on science fiction and its persistent engagement with technological questions in relation to the planet."10 Described as an "architecture with externalities," their work uses architectural representation to "bring the Earth into matters of concern" and engage "actors and scales otherwise unaddressed." "11 They describe their drawings as "tableaux vi-

9 Jameson, 288.

10 Rania Ghosn and El Hadi Jazairy, Geostories: Another Architecture for the Environment (New York, Barcelona: Actar Publishers, 2018), 21.

11 Ghosn and Jazairy, 22.

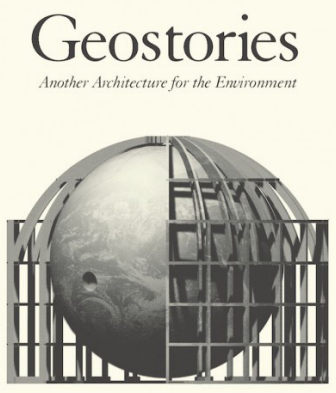

DESIGN EARTH

Figure 35 >> Cover of Geostories: Another Architecture for the Environment.

Tableaux Vivants $>$ A person or group of people forming striking or picturesque scenes. 
vants," miniaturized worlds that aim to capture the scales of environmental changes (Figure 37). ${ }^{12}$

Through their drawings, Ghosn and Jazairy follow Amitav Ghosh's suggestion that future fictions will reflect on the human impact on the environment not in words, but in images. Such fictions "makes possible the imagining of possibilities" by addressing the infinitely large, making it possible to address the nature/culture coexistence challenge posed by the climate crisis.

Figure $36>>$ Pacific Aquarium, an example of the "tableaux vivants" of Design Earth.

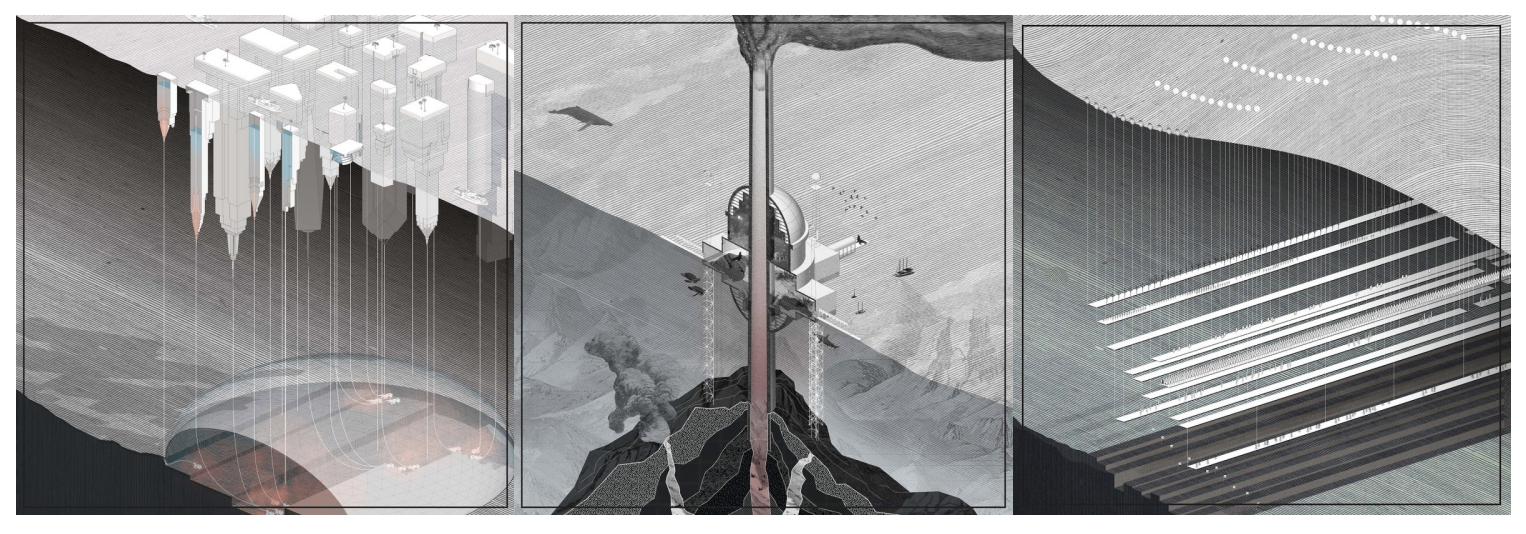




\section{2 >> Shrinking the Trouble}

Design Earth's approach to the "tableaux vivants" inspired a visual case study in this thesis into the building and representation of Canadian landscapes. The work was informed by themes of Professor Lisa Moffitt's seminar Miniaturizing the Gigantic, which explored the miniaturization of gigantic landscapes affected by climate change through various forms of architectural representations within model form.

Following the research in Part I of this thesis, a series of models were produced that reflect on the agency of the Mythological, Military, Technological, and Romantic visions in defining the Canadian imaginary. Inspired by representational devices such as maps, dioramas, and landscape paintings, five display vitrines were created to correspond to the five selected ecoregions of Canada (Grasslands, Boreal Forest, Arctic Tundra, Temperate Forest, and Maritimes) (Figures 38, 39).

Each vitrine is conceptualized as a terrarium (a miniature world), and filled with organic material corresponding to each region. The vitrines, built out of acrylic and sitting upon CNC-milled topographic models, were extracted as samples of the Canadian National Topographic Survey, the 


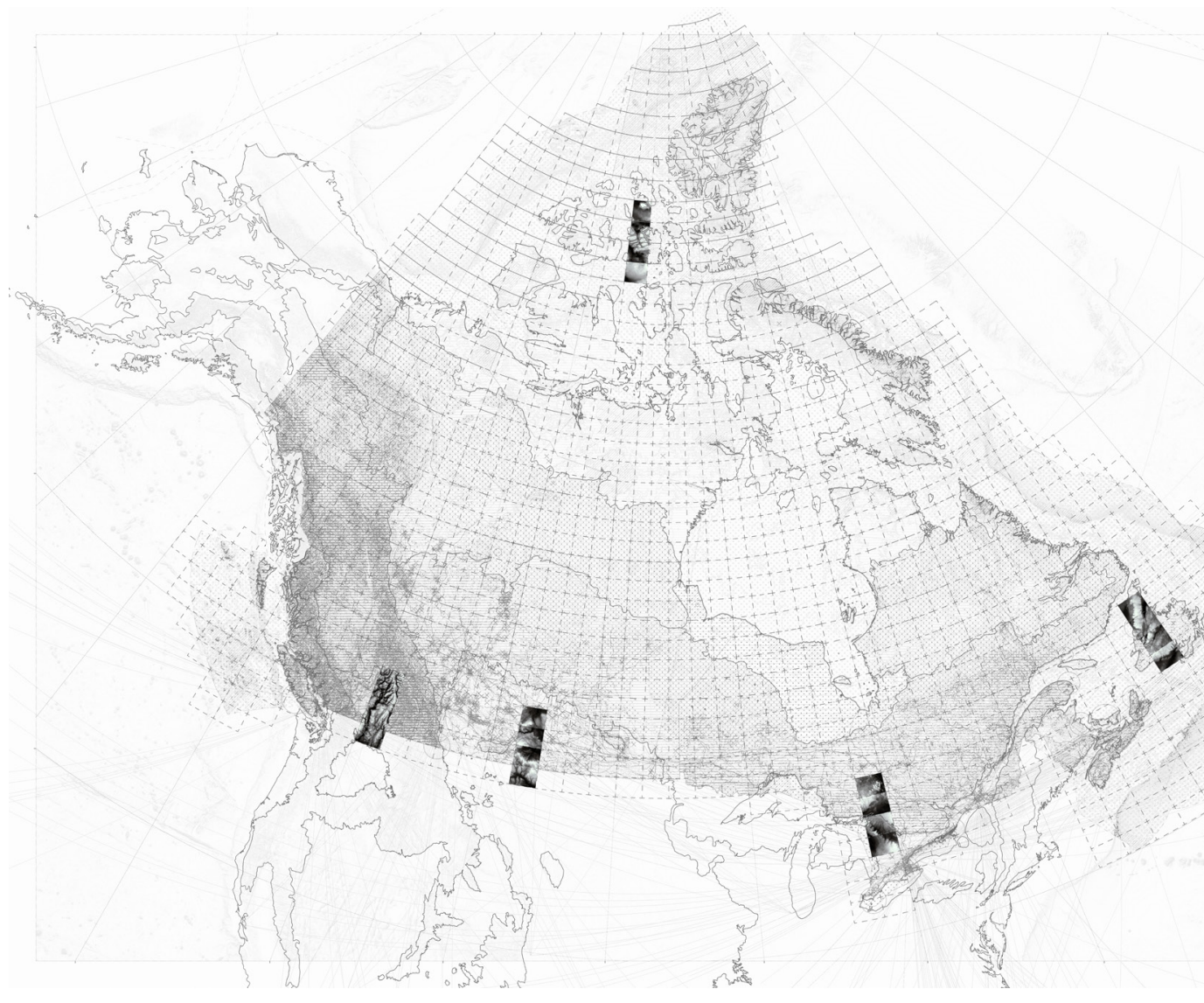

Figure 37 > Map of ecoregion sample locations. Each swatch corresponds to a vitrine.

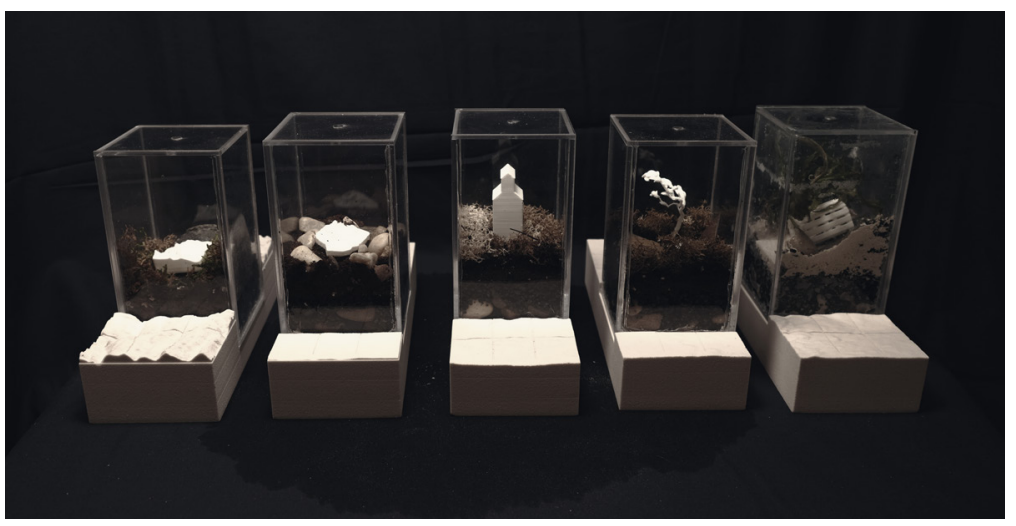

Figure $38>>$ Front view of the five 
main source of information for Canadian cartography. Each vitrine contains an iconic object; a digital artefact of 3D printed white plastic. Each artefact represents an icon, natural or cultural, reflecting a piece of Canadians' inherent geographic imagination. They are the grain elevator for the Grasslands, the mountain peak for the Boreal Forest, the jackpine tree for the Temperate Forest, the crab net for the Martimes, and the iceberg for the Arctic Tundra (Figures 40, 41, 42, 43).

The vitrines can be read separately, or nested within a fish tank. When collected in the tank, they allude to the creation of specimen catalogues, and the fascination with natural history. Understanding scale as "a tool to understand relationships, negotiations and tensions between actors in space," ${ }^{13}$ the juxtaposition of objects of varying magnitude attempts to make legible the ubiquity of hyperobjects (Figure 44).

Taking advantage of this perspective, the vitrines were subjected to a series of experiments producing particulate clouds. The vitrines were filled with water to simulate atmospheric conditions and injected with a non-Newtonian fluid solution. The clouding of the vitrines disrupts the picturesque quality of their representation, while alluding to the ominous
Iconic >> Designating a person or thing regarded as representative of a culture or movement; important or influential in a particular (cultural) context. 
aesthetics of the sublime (Figures 45, 46, 47, 48). The juxtaposition between the icon and the cloud is meant not to be read as an admittance of apocalyptic fatalism, but rather as an attempt at "translat[ing] the vast, invisible atmospheric domain"14 of the emissions that our activities generate, and their impact on the pristine vistas of our imaginaries .

Figures 39, 40, 41, 42 >> Vitrine
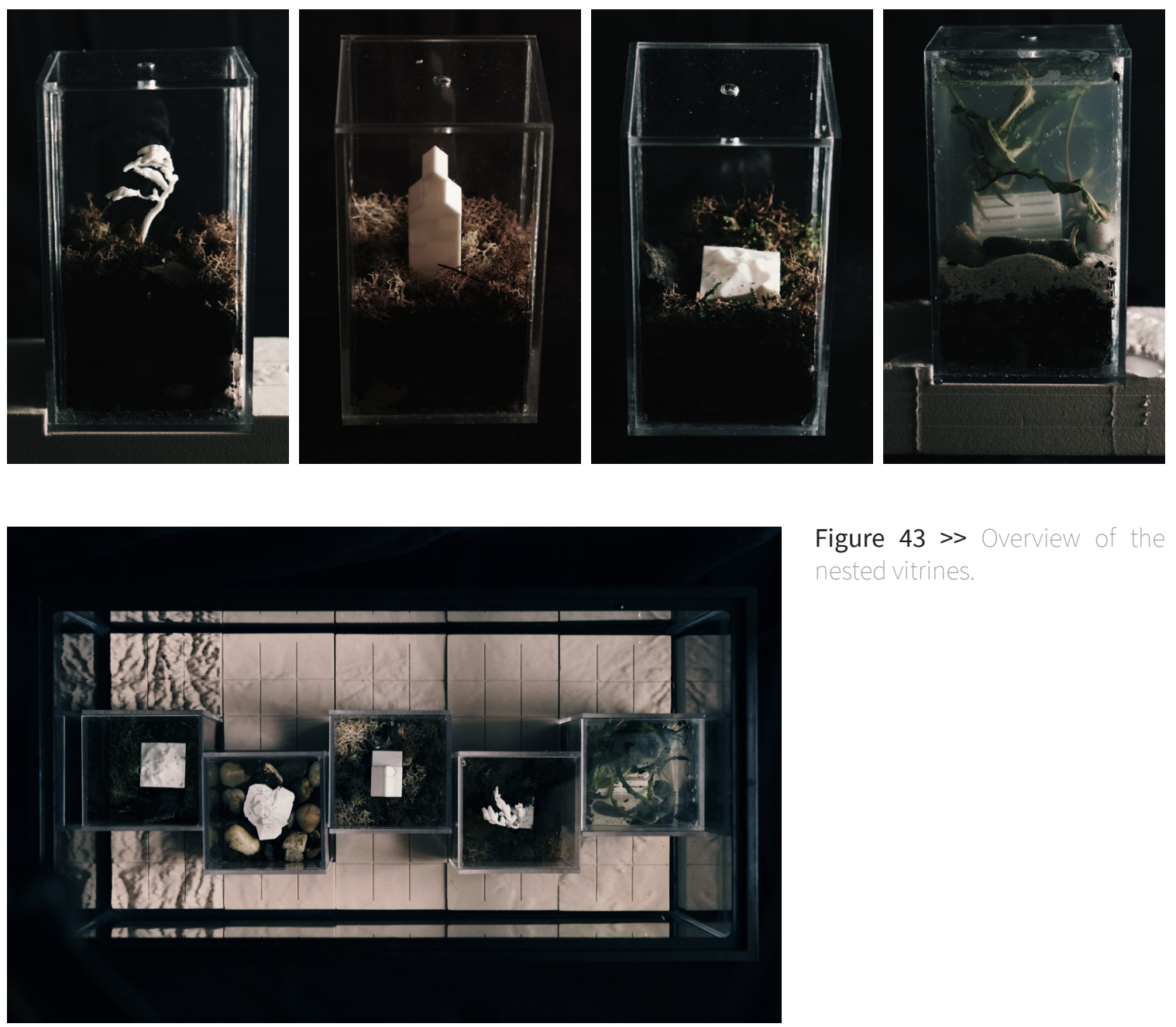

Figure 43 >> Overview of the nested vitrines.

14 Lisa Moffitt, "Streamlines and Vortices," in Architecture's Model Environments (UCL Press, n.d.), 4. 


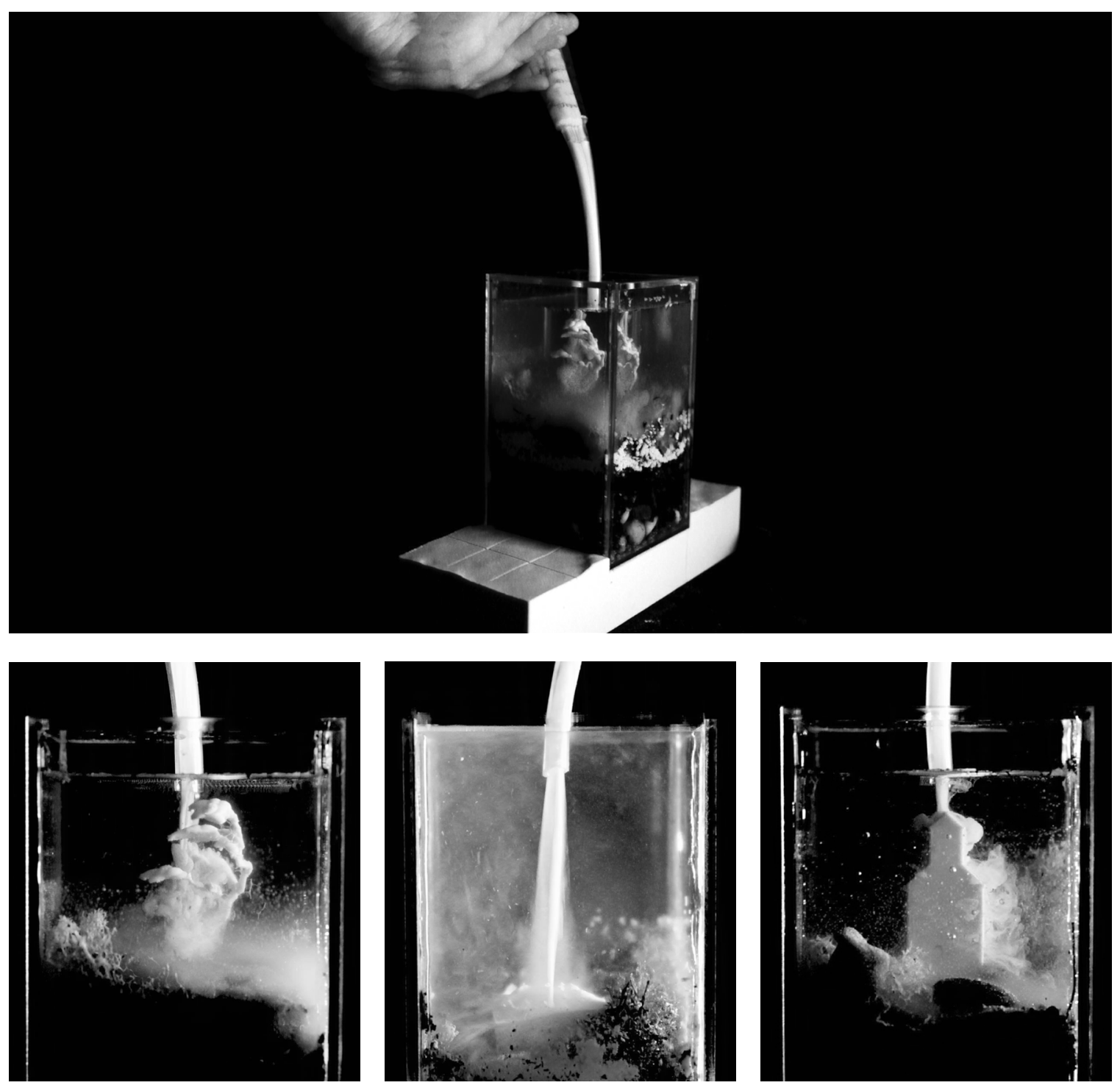

Figures 44, 45, 46, 47 >> Particulate cloud experimentations. 


\section{3 >> Transitioning Terra}

"Foresight, on the other hand, seeks to engage with the future for strategic purpose. Foresight is "the ability to create and sustain a variety of high quality images and understand-

ings about futures and apply these in a range of socially useful ways; for example, to develop policy, guide strategy, [and] avoid or mitigate disasters". In the context of collective preferred futures, we may engage in civilization foresight."

- Leah Zaidi, Brave New Worlds: Science Fiction and

Transition Design

Leah Zaidi's definition of foresight encapsulates the transitional thinking needed to tackle impending environmental doom. It implies that fictions which are collectively held can be manipulated and mobilized into projects for concrete change. Most importantly, it suggests that corresponding worldviews, like the images that inform them, can be carefully crafted.

According to Zaidi, what distinguishes foresight from the writing of science fiction are the implications of desired 
outcomes, be it a strategy, policy or design. ${ }^{15}$ Foresight is practiced through worldbuilding, namely the "creation of imaginary worlds with coherent geographic, social, cultural and other features." ${ }^{16}$ For Zaidi, the act of worldbuilding involves the design of systems, and can inform practices of Transition Design, which she qualifies as "design within radically new socio-economic and political paradigms" and "design-led societal transition." ${ }^{17}$

Transition Design, as defined by Zaidi, offers new possibilities for the agency of architecture and design. Rather than reacting to or challenging existing paradigms, architects could design desired societal outcomes and the roadmap to help achieve them. In short, Transition Design is the design of worldviews. Applied to the current climate crisis, the methods of Transition Design and its focus on systemic thinking could prove crucial in tackling the climate crisis, especially if applied to the use of technology. Such effort must break away from technological hubris, for it risks perpetuating the so-called nature-culture dichotomy.

As a point of contact between humans and their environments, technology has largely been portrayed and

15 Leah Zaidi, "Brave New Worlds: Science Fiction and Transition Design," SSRN Electronic Journal (OCAD University, 2018), 11, https:// doi.org/10.2139/ssrn.3217423.

16 Zaidi, 15.

17 Zaidi, 17. 
employed in ways that reinforce this dichotomy. It is understandable, therefore, that some, like Donna Haraway, are skeptical of an overreliance on "technofixes"18 such as geoengineering to combat the current crisis. For others, including Rania Ghosn and El Hadi Jazairy, geoengineering (Figure 49) is problematic when presented as a feat in "the great history of human emancipation and technological mastery" over nature. ${ }^{19}$ Above all, geoengineering can potentially create conflict terrains, as an approach suited for one country might be detrimental to another's localized climates. ${ }^{20}$ Yet, despite all of its problematic implications, methods involving geoengineering and becoming increasingly accepted as a short-term solution to stabilize climates.

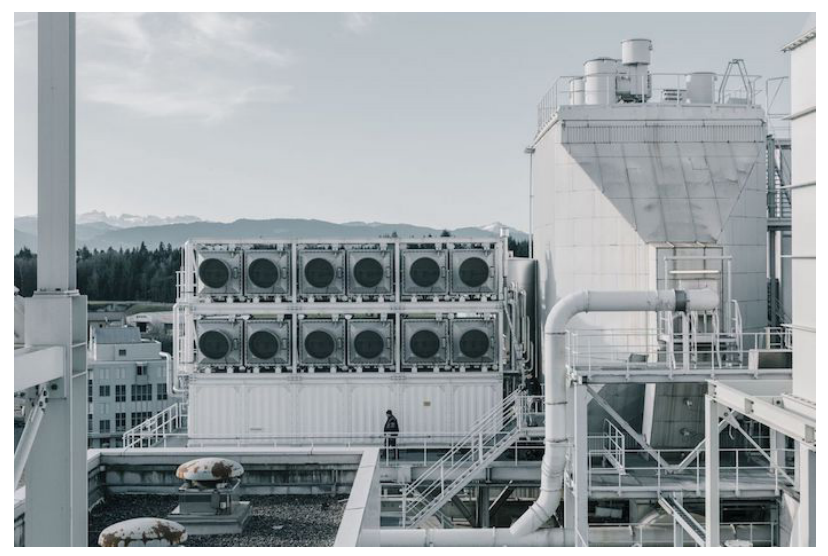

18 Donna J. Haraway, Staying with the Trouble, Staying with the Trouble (Duke University Press, 2016), 3.

19 Ghosn and Jazairy, Geostories: Another Architecture for the Environment, 16.

20 "It That Cannot Be Named : Geoengineering Is Conspicuously Absent from the IPCC's Report," The Economist, 2021, https://www. economist.com/science-and-technology/2021/08/14/geoengineering-is-conspicuously-absent-from-the-ipccs-report.
Geoengineering >> The modification of the global environment or the climate in order to counter or ameliorate climate change.

Figure 48 >> Carbon capture, a common geoengineering strategy. 
In the face of such ethical concerns, how can worldbuilding methods of systemic design be leveraged without the risk of upholding technological tropes? Harkening back to Amitav Ghosh, a potential solution would promote the reintroduction of myth in the depiction of such technofixes, a solution that resonates with the work of Liam Young (Figure 50). As a self-described speculative architect, Young frames his practice one that 'ask questions and that identify new arenas for operation rather than just finding solutions." ${ }^{21}$ In Architectural Monsterologies, Young argues that mythology has long played a role in how humans have dealt with unknown phenomena and expresses his desire to develop an "engineering folklore" to think about how we might relate to emerging technologies.22 Inspired by Young's proposal, I decided to investigate projected changes to the Canadian Grasslands, and the use of technofixes to mitigate them, through collage. The use of iconic landscape imagery as a backdrop, and of natural-cultural hybrids, attempts to realize a new mythology that questions the tropes of technological mastery.

21 Liam Young and Geoff Manaugh, "Architectural Monsterology : An Interview with Liam Young," in Landscape Futures: Instruments, Devices and Architectural Inventions, ed. Geoff Manaugh, vol. 2007 (Actar Publishers, 2013), 120.

22 Young and Manaugh, 118. 


\subsection{1 >> Grasslands}

Although annual mean precipitation is projected to increase globally, they are set to decrease over the Canadian Prairies through climate projections from Environment Canada. Increasing temperatures and decreasing precipitation leads to severe episodes of drought, which are exacerbated by a decrease in river streamflow due to glacial decrease. ${ }^{23}$ In response, proposals are made at the reintroduction of the plain bison. Described as a keystone species, bison play a central role in shaping the ecology of the grasslands. Their grazing patterns combine with wildfires to create a diversity of habitats for varied species. In addition, their habit of wallowing creates depressions in the ground, which collect rainwater and runoff, effectively forming reservoirs where wild life proliferates, offering a solution for water retention. ${ }^{24}$

As droughts increase in severity, a new keystone spe-

cies is introduced to reproduce the role of the bison through technological means. Parts collected from now useless mining equipment are combined with artificial intelligence sys-

23 D.S. Bush, E. and Lemmen, ed., Canada's Changing Climate Report (Ottawa, ON.: Government of Canada, 2019).

24 Parks Canada, "Plains Bison," accessed August 18, 2021, https://www.pc.gc.ca/en/pn-np/sk/grasslands/nature/faune-wildlife/ bison?fbclid=IwAR2fau7BvfDTYbP44P-xB9mckOkx7VGtGKfbsYVDx9PG3u75QStZjOBSW3g.

\section{Keystone Species >> A \\ species exerting a major influence on an ecosys- tem, esp. one on whose activities the survival of other species depends.}


tems to create autonomous robotic bison (Figure 51). Due to the scale of the repurposed mining equipment. These new techno-bovinae are enormous, completely disturbing the scale of "grazing and wallowing," of the original species. The new scale of wallowing turns into terraforming, creating lakes for water retention and fostering other conditions of environmental systems.

In an attempt to mitigate the disruptions in precipitation patterns, the use of carbon capture technology is introduced to decommissioned grain elevators, transforming this rare vertical element into a towering structure of stain-less metallic fans. 


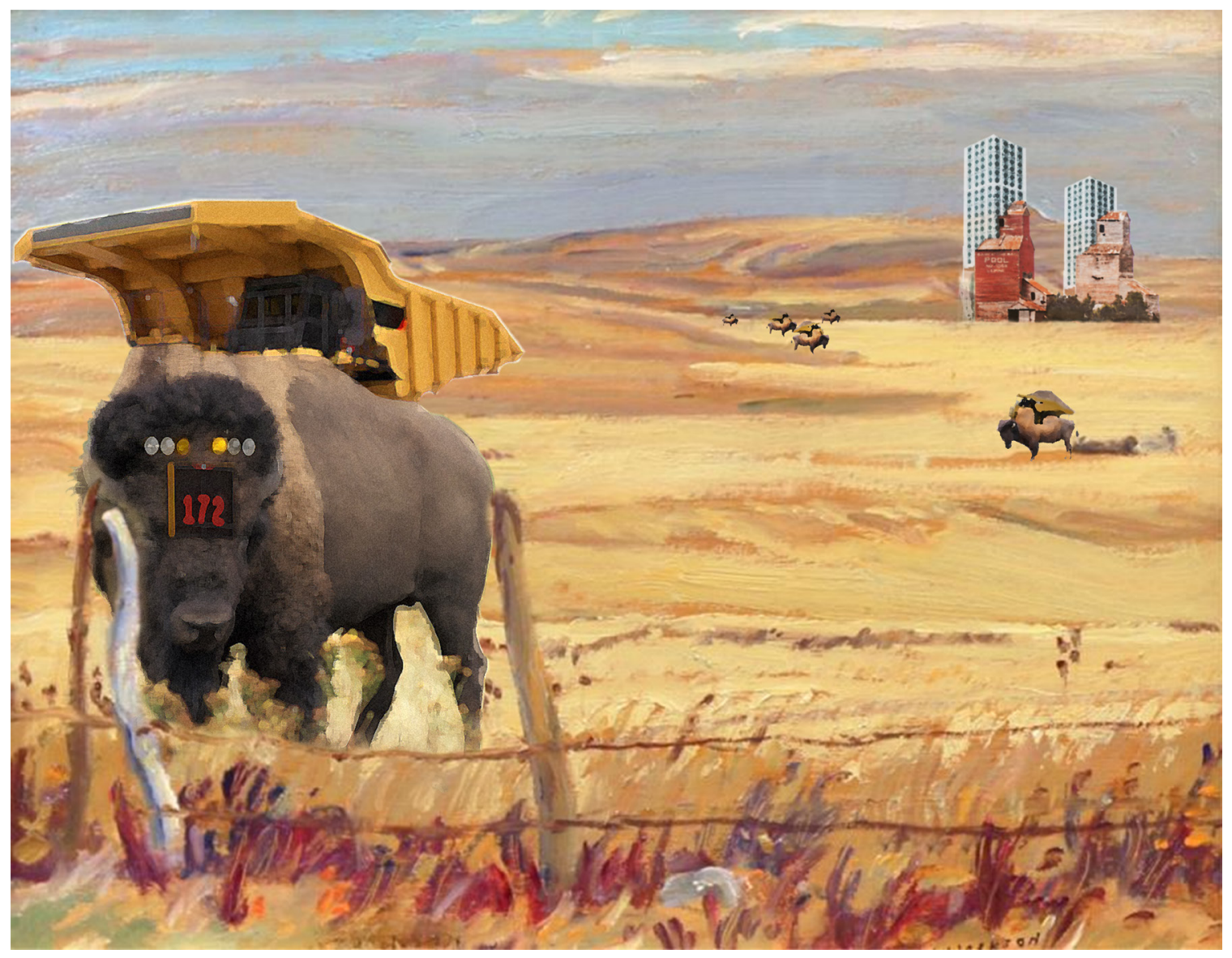

Figure 50 >> Grasslands - Techno-Bovidae and Stainless Towers 


\subsection{2 >> Moving Forward}

In its construction and composition, the collaged scene speaks to the folklore that defines Canadian perception of the Grasslands, while simultaneously suggesting how it may transform over time. In doing so, the drawing shatters the visions of a static nature perpetuated by picturesque imagery and its associated fictions. Moreover, it illustrates the objects and systems that will form the game world. 



\section{Worlding}

"It matters what stories we tell to tell other stories with; it matters what concepts we think to think other concepts with. It matters wherehow Ouroboros swallows its tale, again. That's how worlding gets on with itself in dragon

time."

- Donna Haraway, Staying with the Trouble

In Staying with the Trouble, Donna Haraway uses the term worlding to describe her approach to fiction, borrowing from Ursula LeGuin's Carrier Bag theory of fiction to illustrates her idea of a 'world.' In LeGuin's work, focus is given not on the development of central characters, but rather on the creation of a sound narrative 'container' to "carry" those stories forward, in short, a world. For Haraway, LeGuin's attention to detail produces worlds with the capacity for "collecting, carrying and telling the stuff of the living." 1 This ontological richness in LeGuin's work offers the potential for collective thinking that characterize Haraway's worlding. Worlding, for Haraway, implies a process of "becoming-with,"2 a reframing one's perception of their being in the world through interacting with the nonhuman. That is what this thesis seeks to offer

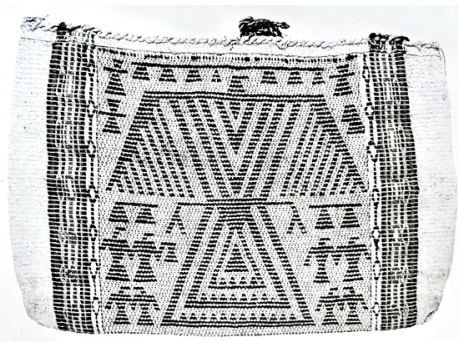

Figure 51 >> Carrying bag representing Anishinaabe worldview.

1 Donna J. Haraway, Staying with the Trouble, Staying with the Trouble (Duke University Press, 2016), 118.

2 Haraway, 13. 


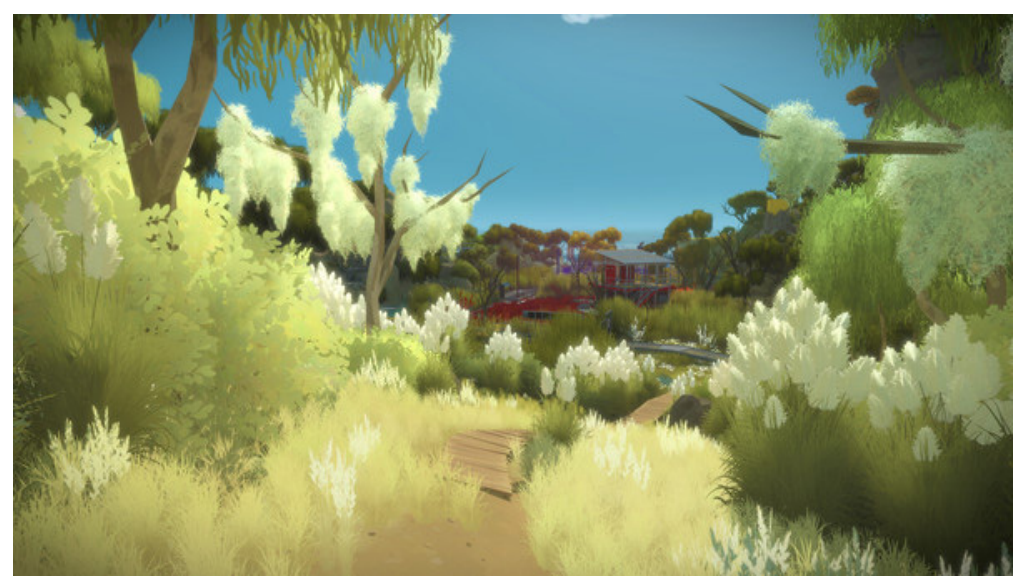

through a videogame.

Gaming offers the opportunities for this process of "becoming-with." Like novels, films and paintings, games rely on the use of visual referents to convey narratives. However, unlike other media, games, especially in the open world genre, are meant to be interacted with and experienced in an open rather than linear progression, allowing the audience to explore narrative content in rather unstructured ways. In certain games, such as The Witness (Figure 56), the gameplay revolves solely on interactions with game world props, environments and architectures, and the uncovering of narratives as a result. This makes the design of game environments all the more essential to maintain the suspension of disbelief and explains game theorist's Henry Jenkins' notion that games are "narrative architecture." For Jenkins, game worlds provide spatial stories with "much more immersive and com-
Figure $52>>$ Video game still from The Witness.

\section{Suspension of Disbelief > Coleridge's phrase for the voluntary with- holding of scepticism on the part of the reader with regard to incredible characters and events.}


pelling representation of their narrative worlds"3 than non-interactive media. Game worlds, in a sense, are like LeGuin's carrier bag fictions, in that they carry the potential to tell "the stuff of the living."

Through the design of their environments and in interacting with them, game worlds can provide the space for the critical reframing of the sense of being in the world. Drawing on these theories, this section focuses on the creation of a game prototype consisting of a single level, and on the design of props, environments and gameplay, that contribute to the narratives they convey. Through the design of the game prototype, the thesis hopes to facilitate meaningful interaction with tropes that define nature-culture dichotomies, and to challenge the colonial gaze of the Mythological, Military, Technological and Romantic Eyes on the Canadian landscapes.

$3 \quad H e n r y$ Jenkins, "Game Design as Narrative Architecture," in First Person : New Media as Story, Performance, and Game (Cambridge: MIT Press, 2004), 122. 


\section{1 >> Embracing Hybridity: The Cyborg as a Trope}

"We are as ignorant of the meaning of the dragon as we are

of the meaning of the universe, but there is something in the dragon's image that appeals to the human imagination, and so we find the dragon in quite distinct places and times. It is, so to speak, a necessary monster..."

- Jorge Luis Borges, The Book of Imaginary Beings

Borges' musings on 'necessary monsters' speak of a time when superstition and myth defined the methods through which humans made sense of the world, of phenomena that couldn't be explained otherwise. While it remains difficult to communicate the breadth of climate changes and their consequences, this thesis advocates for a return of myth, not to invent solutions, but rather to illustrate the uncanniness of a complex situation, and to ask useful questions and new grounds for possible interventions. This ambition calls for a return to hybrid modes of thinking.

Hybridity is a recurring theme in this thesis. Whether referring to the imbrication of fact and fiction, nature and

Hybridity >> Hybrid condition, where two animals or plants of different species, or elements from heterogeneous sources, form one entity. 
culture or animal and machine to name a few, mentions of hybridity in the work attempt break barriers between dichotomies. If the current concerns with climate changes is starting to reveal our dependency on various natural and cultural systems for survival, then perhaps a hybrid figure, a cyborg of sorts, best encapsulates the anxiety of our times. Cyborgs are double hybrids. Being both an assemblage of "machine and organism," and "creatures of social reality as well as creatures of fiction," cyborgs are the perfect figure to represent our sense of being in the world. They are our time's "necessary monsters."

The motif of the cyborg is recurrent throughout the design of the game world. Through processes of hybridization, elements of the Mythological, Military, Technological and Romantic themes are spliced and reassembled to form new entities. This follows Donna Haraway's belief in sympoiesis, the act of "making-with." ${ }^{4}$ For Haraway, nothing is truly autopoietic, or self-organizing. ${ }^{5}$ Rather, she argues that tackling the seriousness of our environment requires to "make oddkin," unexpected collaborations and combinations between seemingly at odds. ${ }^{6}$ To create these tropes, the design employs methods of kitbashing (Figure 57), a model-making

$4 \quad$ Haraway, Stay. with Troubl., 58.

5 Haraway, 58.

6 Haraway, 4. 
process that combines parts from various model kits to create a feeling of "used futures." By creating a landscape of hybridity, the design of the game world hopes to provide the space for meaningful interactions, and for new worldviews to emerge. $x x$

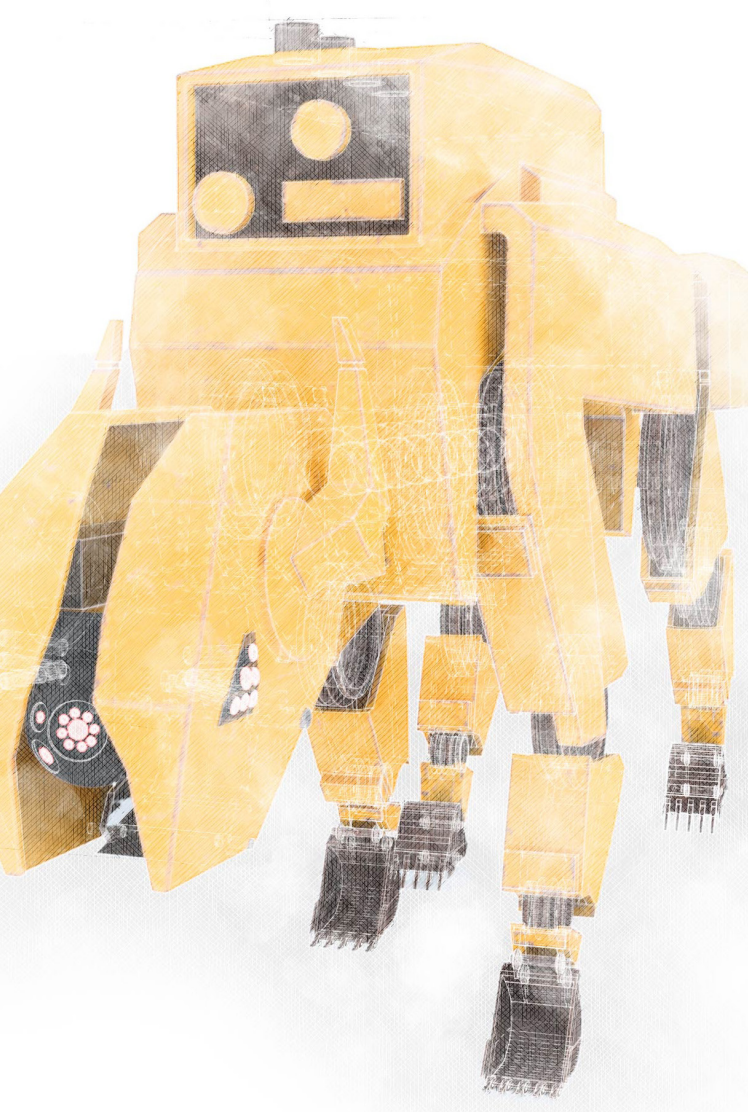

Figure 53 >> Techno-Bovidae Kitbash

$7 \quad$ Ryan Lambie, "Greebles: How Tiny Details Make a Huge Star Wars Universe," Den of Geek, n.d., https://www.denofgeek.com/movies/greebles-how-tiny-details-make-a-huge-star-wars-universe/. 


\section{2 >> Game Prototype: Design Documents}

The ambition of this thesis is to create a game environment that can challenge perceptions of climate change through interaction with a game world. In response, the proposed game is conceptualized as an exploration game focused on the discovery and documentation of fictitious future Canadian landscapes. Know pejoratively as 'walking simulator,' this style of gameplay tends to focus heavily on the storytelling aspect of a game, while lacking any sort of puzzle to solve or enemies to fight?

In the proposed game, the player takes up the role of a field agent tasked with recording and documenting the altered Canadian landscapes post-climate changes. Using a special vision apparatus, the agent can access and control cybernetic animals in the game ecoregions, allowing him to see and record the world from their perspective. The player's findings are catalogued in a logbook and marked on a map, which alludes to the process through which early European explorers would document their understanding of the landscapes that they encountered.

7 Nicole Clark, "A Brief History of the 'Walking Simulator,' Gaming's Most Detested Genre," Salon, 2017, https://www.salon. com/2017/11/11/a-brief-history-of-the-walking-simulator-gamingsmost-detested-genre/. 
The game structure is articulated around five levels corresponding to the main Canadian ecoregions, namely the Grasslands, Boreal Forest, Arctic, Deciduous Forest, and Maritimes. A museum gallery space serves as a 'hub world,' from which the player can access each level. In the gallery, the ecoregions are presented as large dioramas, and act as portals through which the player can walk to access the level.

While the proposed game suggests the design of five ecoregion levels, this prototype focuses on the development of the Grasslands level as a proof of concept. The following pages contain process images and design documents produced in the making of said game prototype.

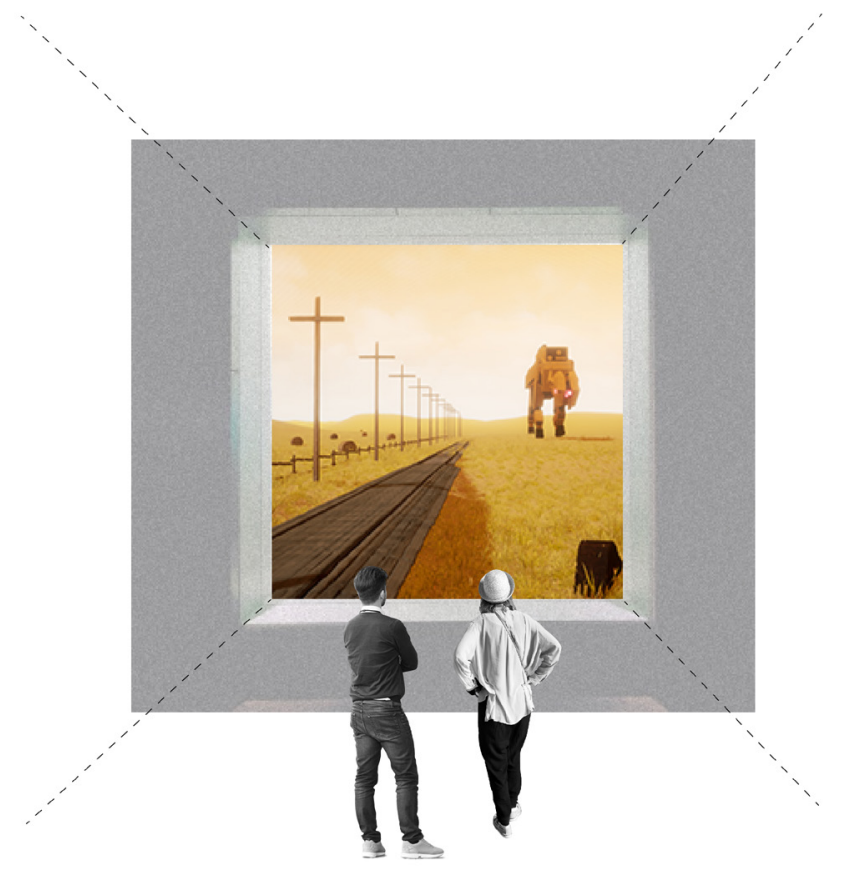

Figure 54 >> Conceptual collage showing the diorama concept. 


\subsection{1 >> Environments}

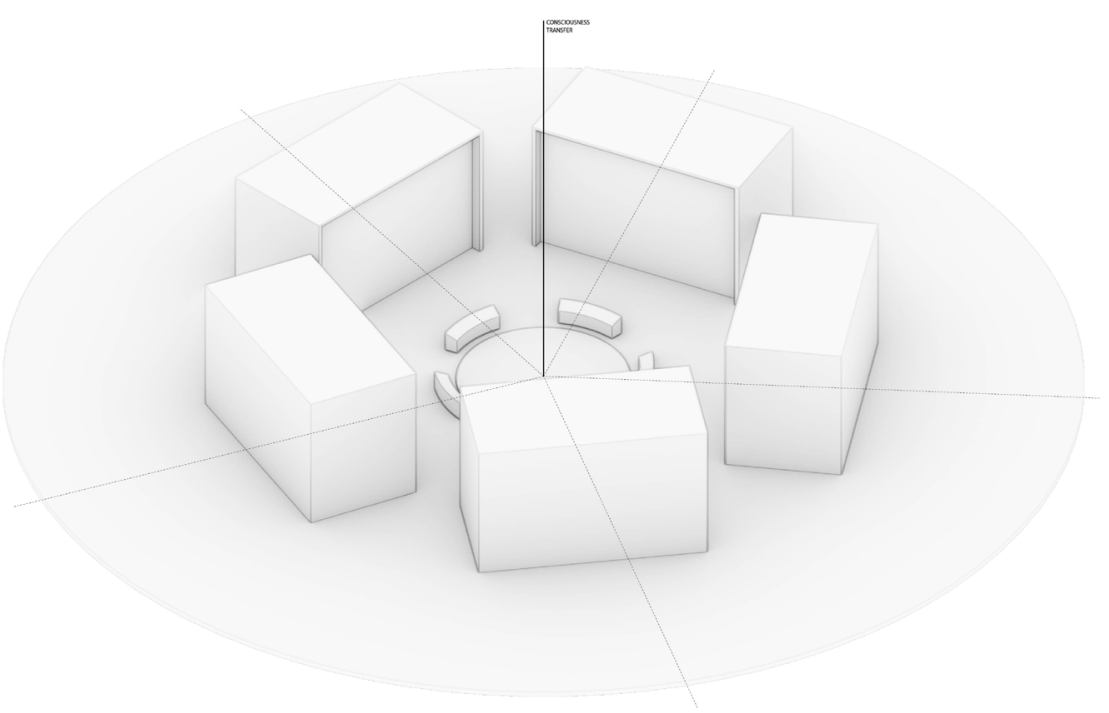

Figure 55 >> Diagram depicting the museum gallery hub world.

Figure 56, 57, 58 >> Topographical surface

This surface was prepared for Unreal Engine in the software Terresculpter. The elevation information was obtained from Natural Resources Canada, and corresponds to a Grasslands Ecoregions. The dryness of the vegetation and orange atmospheric haze allude to changes in the ecoregion.The dryness of the vegetation and orange atmospheric haze allude to changes in the ecoregion.The texture script was created using the engine's visual scripting interface. Which does not require coding knowledge. 

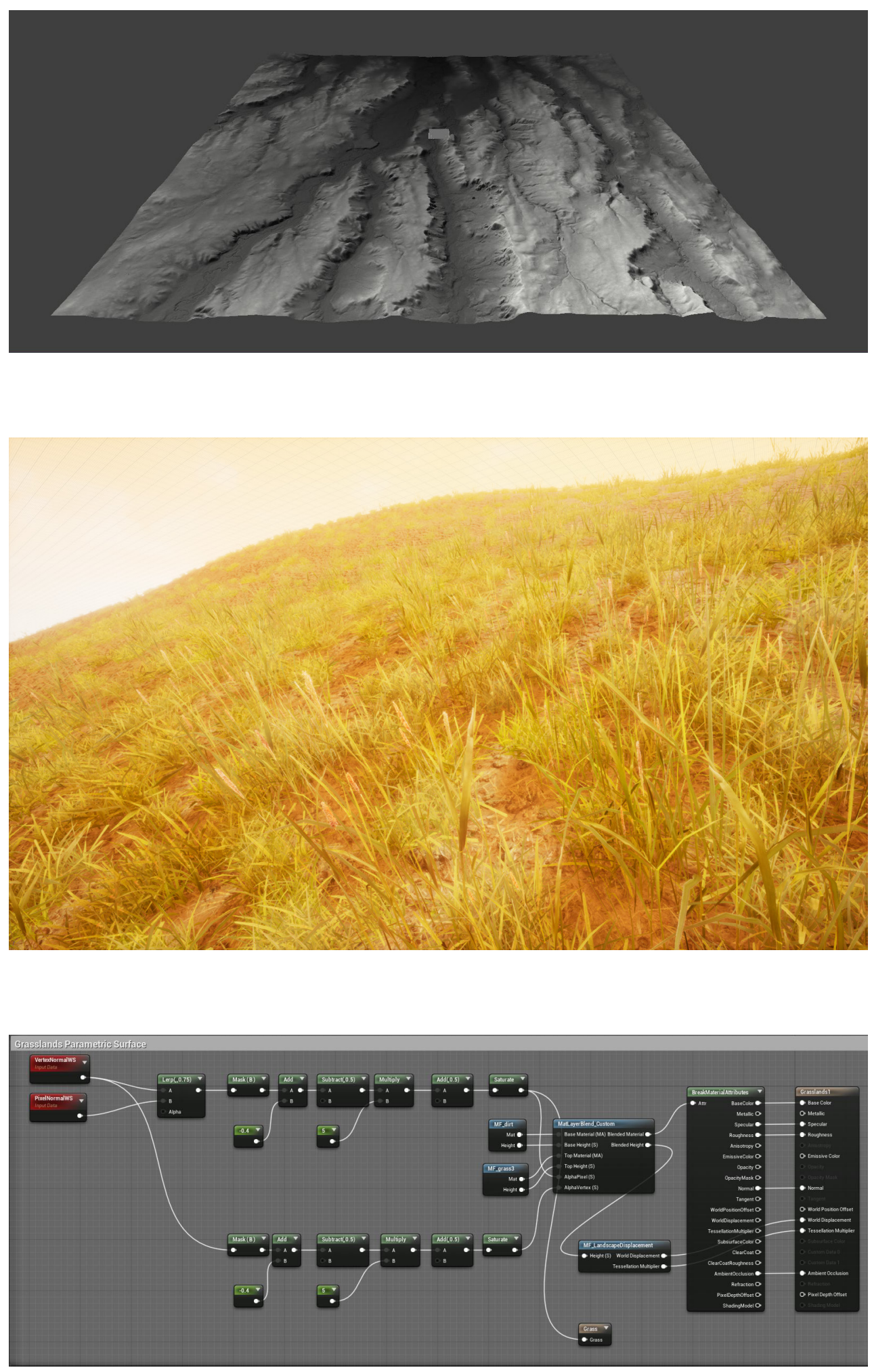


\subsection{2 >> Characters}
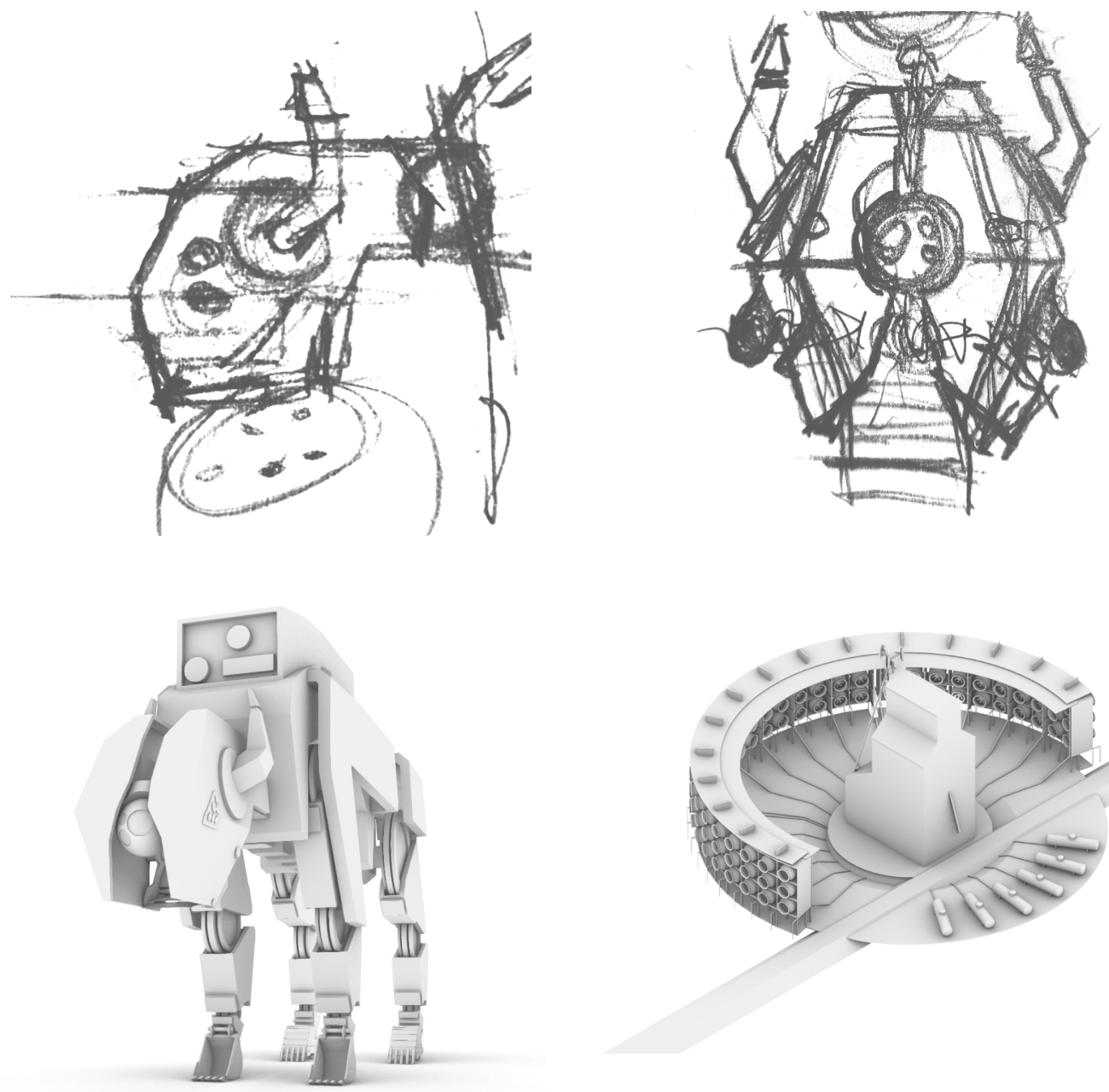

Figures 59, 60, 61, 62 >>

Conceptual Sketches/Clay renders for Techno-Bovidae and Carbon Elevators

Figures 63, 64 >> Techno-Bovidae Development

The animation was based on a mix between mechanical and animal joints movement and uses a typical quadruped animation skeleton.

Texturing in Quixel Mixerwas used to enhance the worldbuilding and to give credit to the Techno-Bovidae's mechanical origins. 

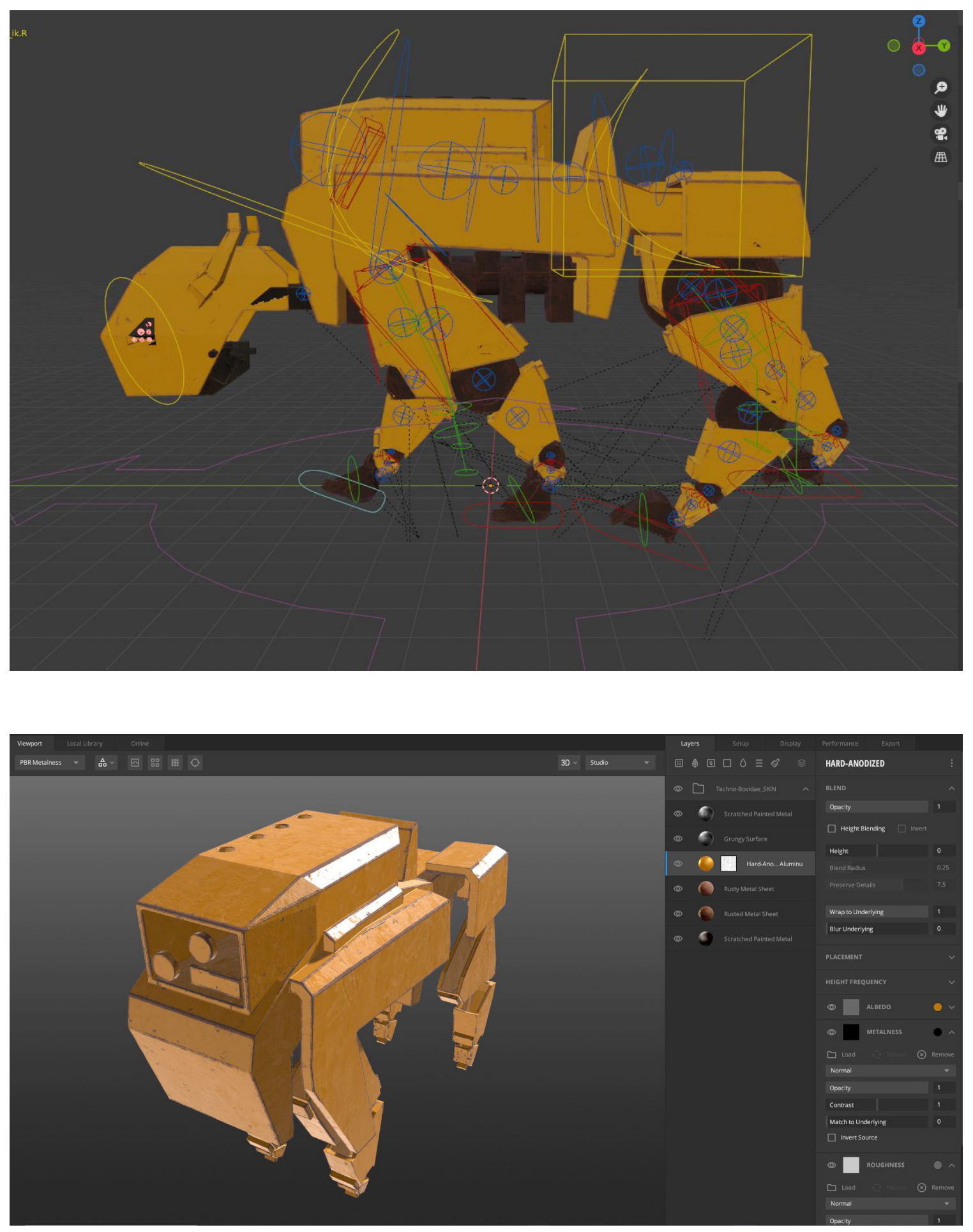


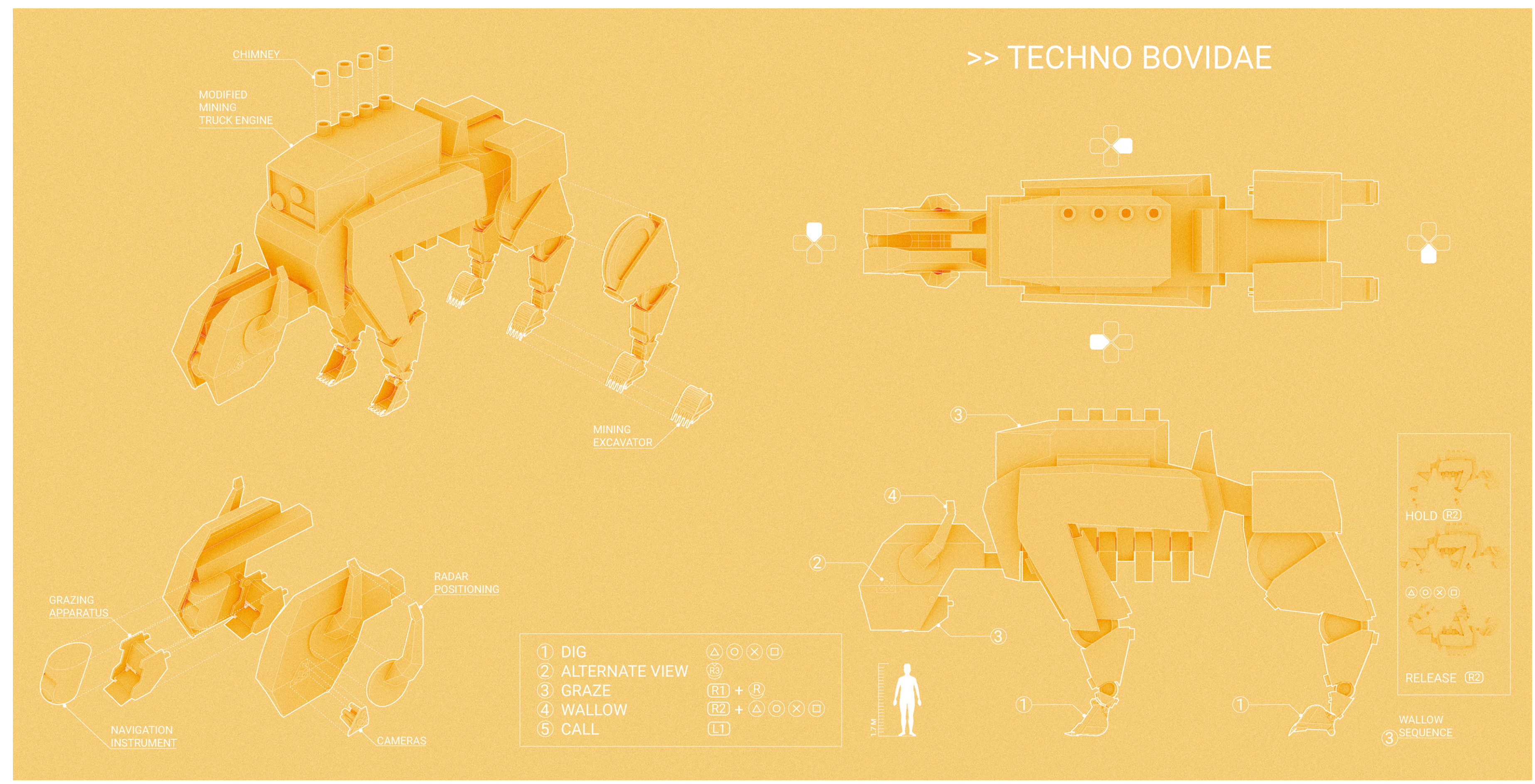

Figure 65 > B Blueprint drawing for the Techno-Bovidae

The drawing for the Techno-Bovidae details the components of which this mechanical bison is made, including recycled mining equipment parts. The head diagram details the navigation instruments that form the character's vision. Finally, dia grams on the right delalls the gameplay assoclated with this character, including algging and wallowing to create pudd les. 


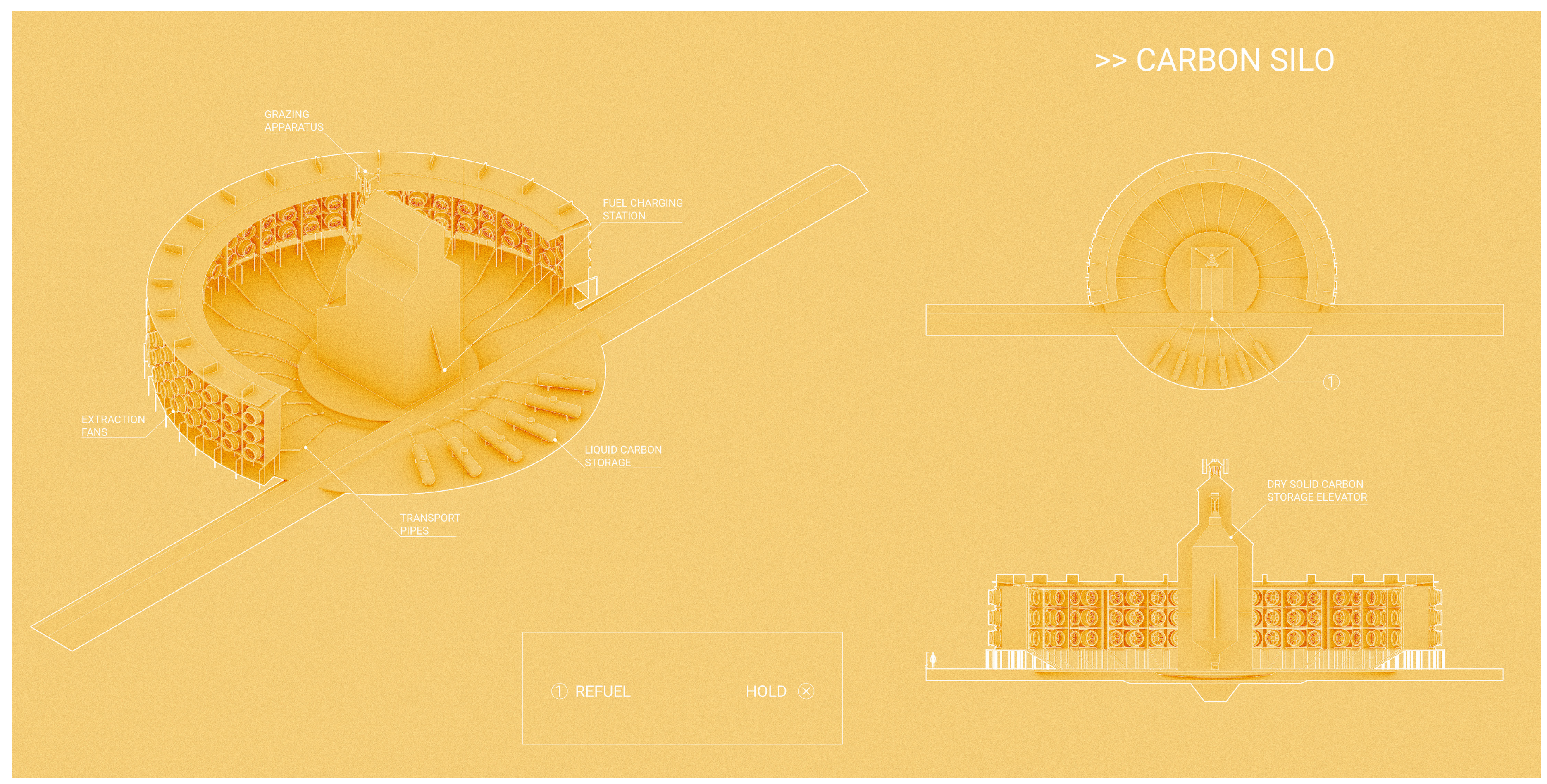

Figure 66 >> Blueprint drawing for the Carbon Elevators

The second blueprint details grain elevators that have been repurposed as carbon capture factories. The diagram on the left details the main systems of the exterior shell, while the diagrams on the right represent a proposed refuelling system for the rechno-Bovidae inspired by the existing grain elevator system in the Canadian Praires. 


\subsection{3 > Gameplay}

The decision to provide walking simulator inspired by landscape exploration stems from the research on vision, and on the production of landscape imagery. By providing the player with the opportunity to create their own recordings, the gameplay reflects critically on the biases and instruments that contribute to this visual production. The follow-

ing series suggest a typical gameplay sequence that includes Head-up Display $>$ A display of flight, navigation, attack, or other information superimposed upon the pilot's The first series is presented as a storyboard, which depicts forward field of view. a typical walkthrough of the game and covers several interactions with the game world through the player's head-up display (HUD) interface.

The last four drawings are detailed representations of types of fieldwork performed through the game, each taking a different point of view on the game world. 


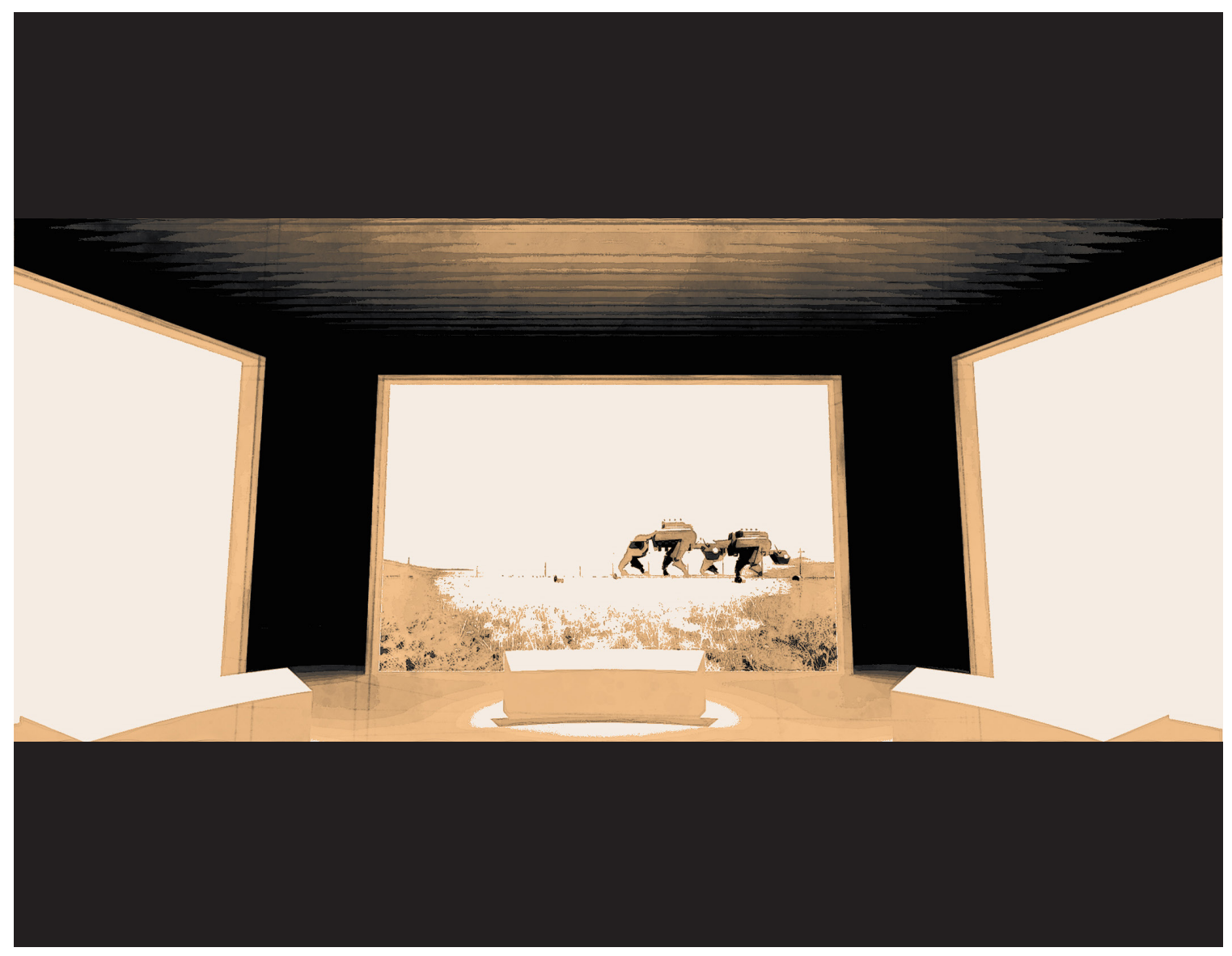

Figure 67 >> Storyboard Frame

Player start in the museum gallery hub world. 


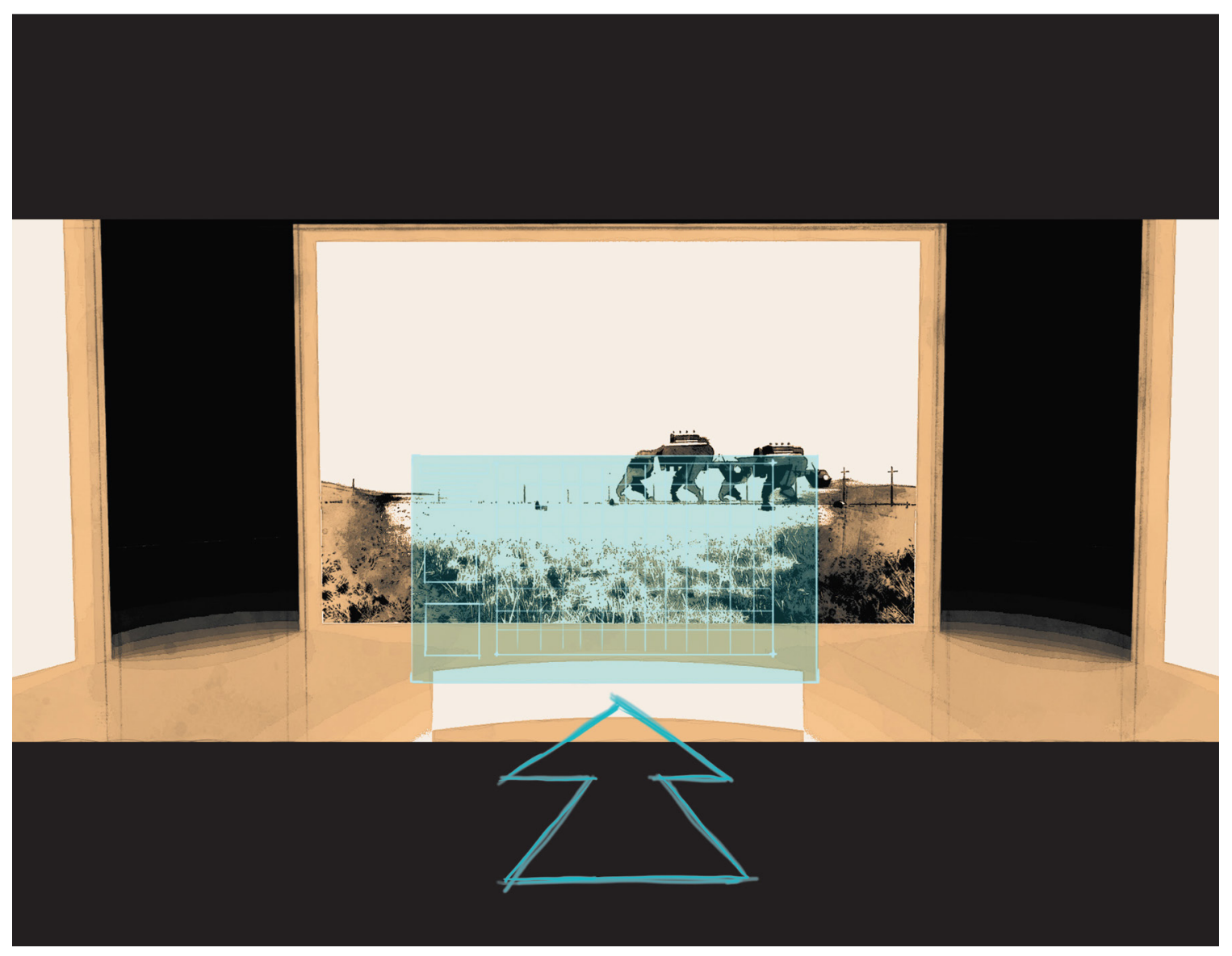

Figure $68>>$ Storyboard Frame 02

Level selection - The player walks up to one of the dioramas displays. A holographic billboard depicting a map of the player's progress through the ecoregion appears. 


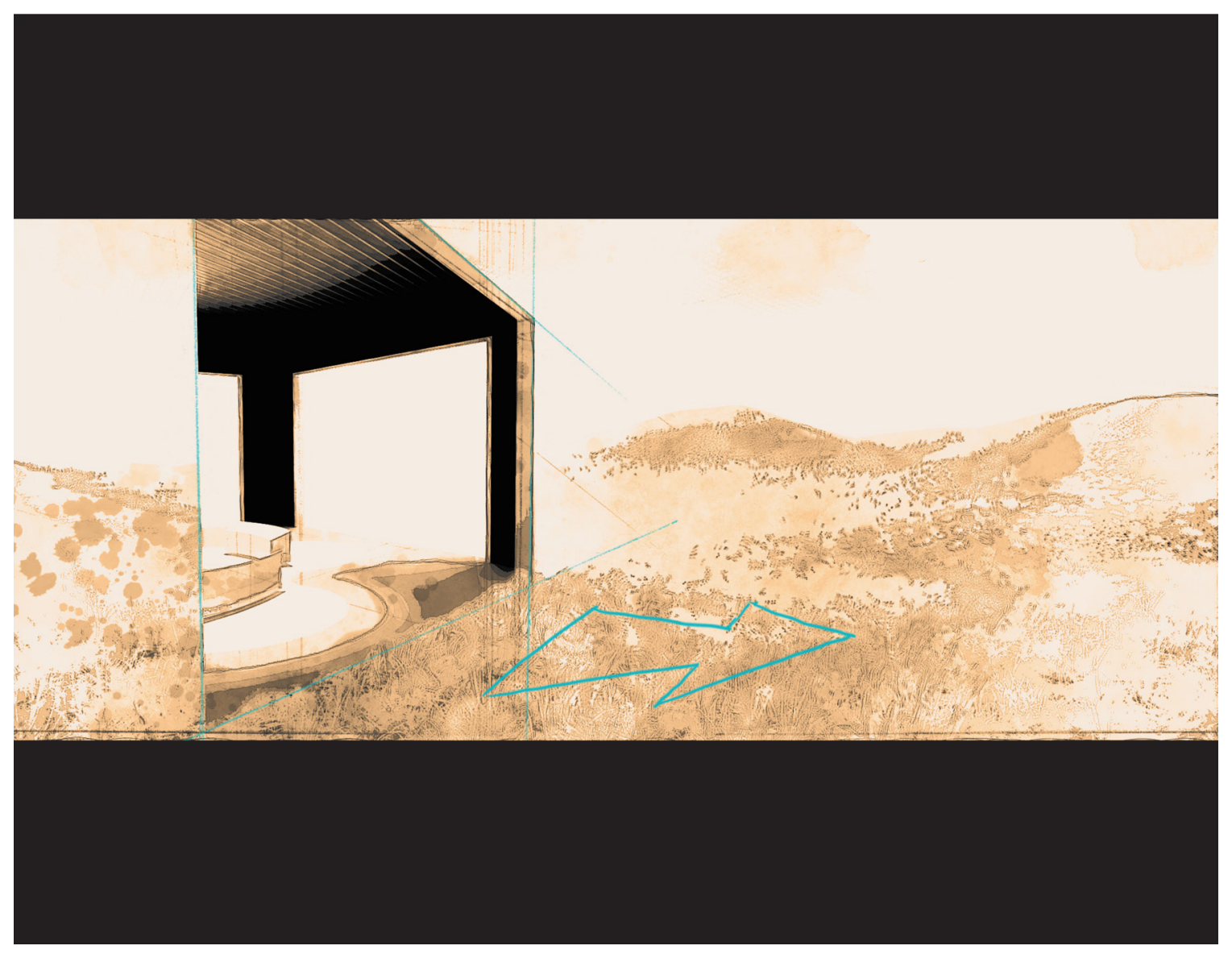

Figure $69>>$ Storyboard Frame

The player walks through the diorama portal and enters the Grasslands ecoregion level. 


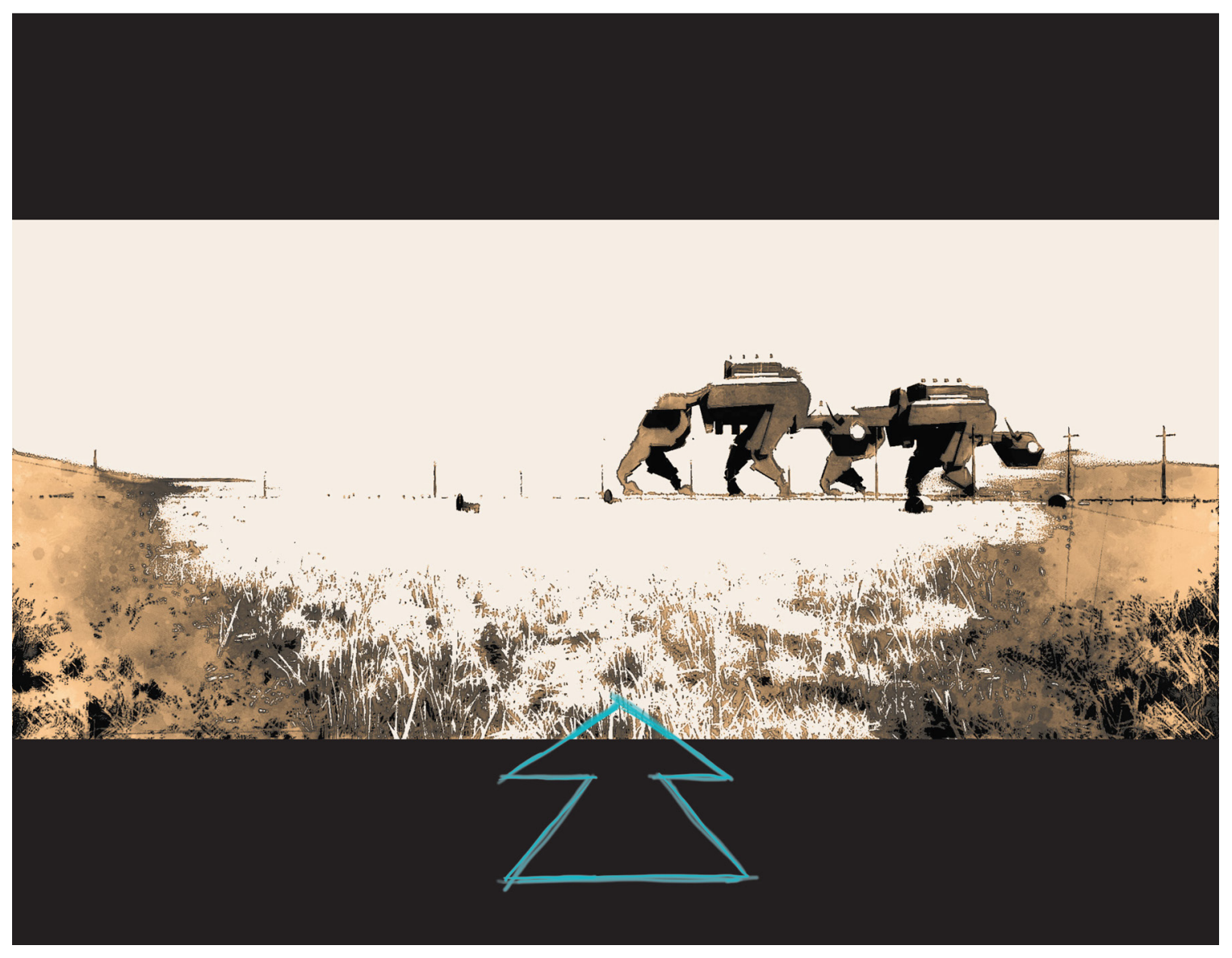

Figure 70 >> Storyboard Frame 04

The player looks at the surroundings and spots a heard of Techno-Bovidae in the distance. 


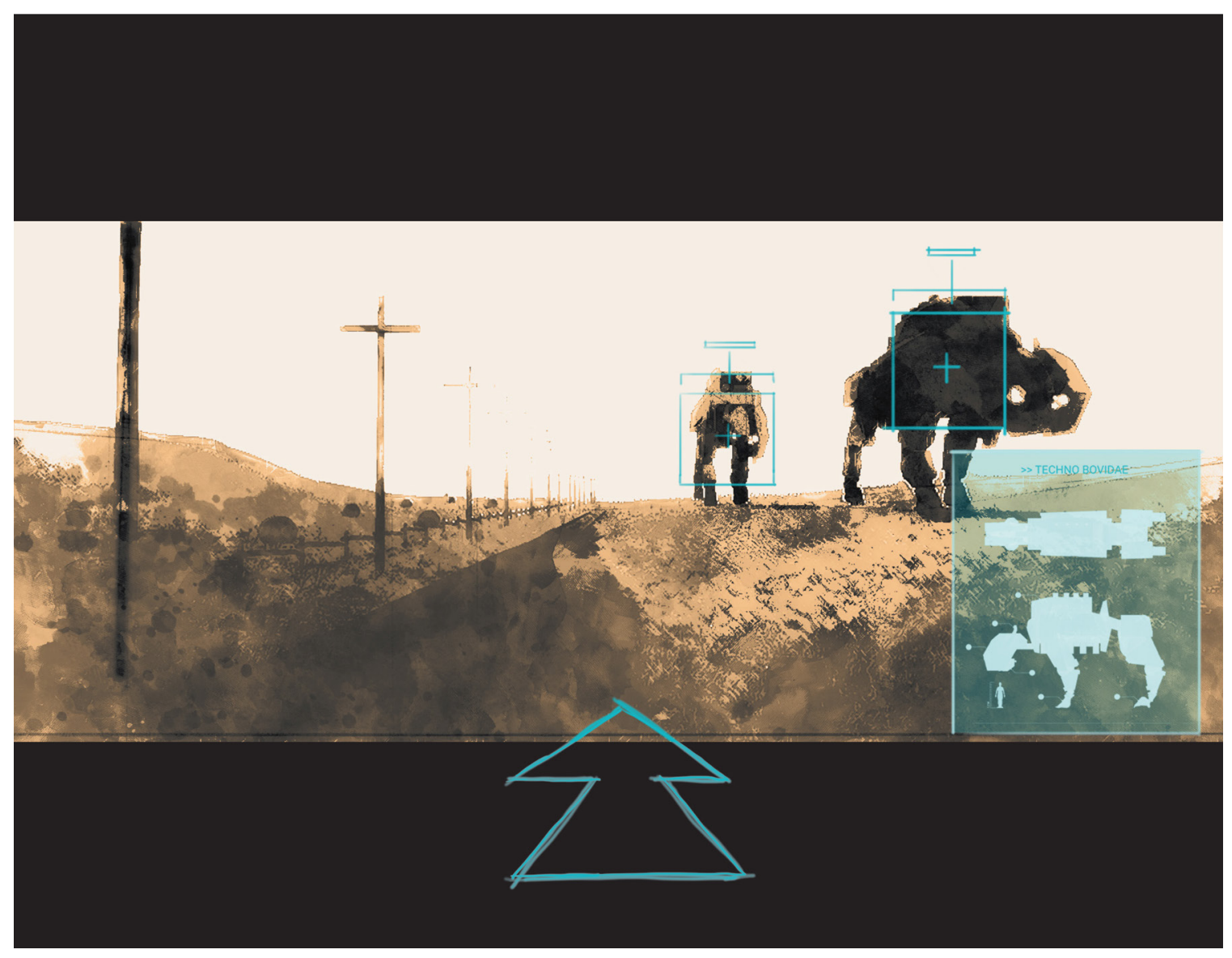

Figure $71>>$ Storyboard Frame

The player walks towards the Techno-Bovidae. As he approaches the heard, an information card appears in the HUD, with option to add as an entry to the logbook. 


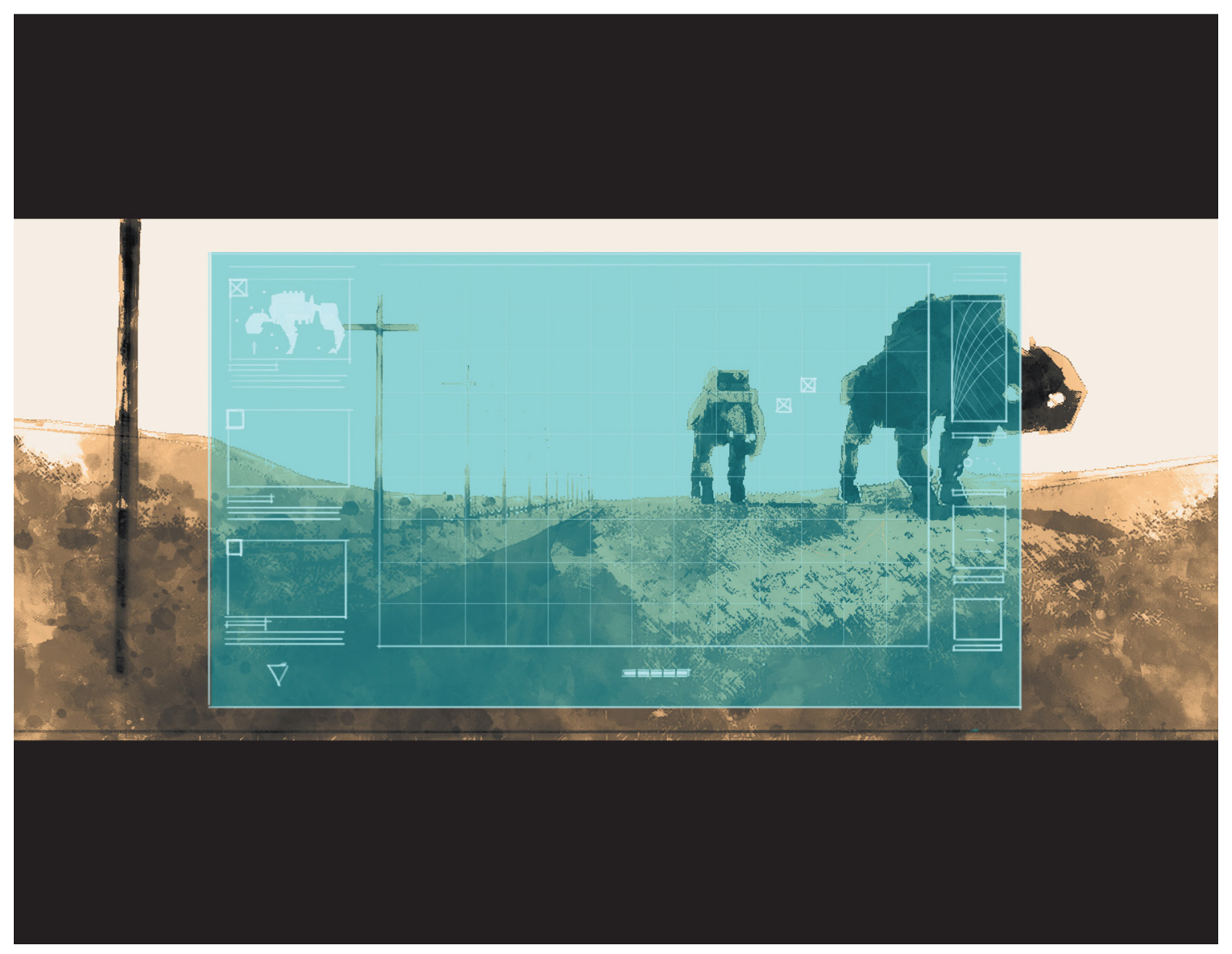

Figure $72>>$ Storyboard Frame 06

The player accesses the logbook menu. A billboard display appears, showing the annotated map, along with recent logbook entries and current weather information. 


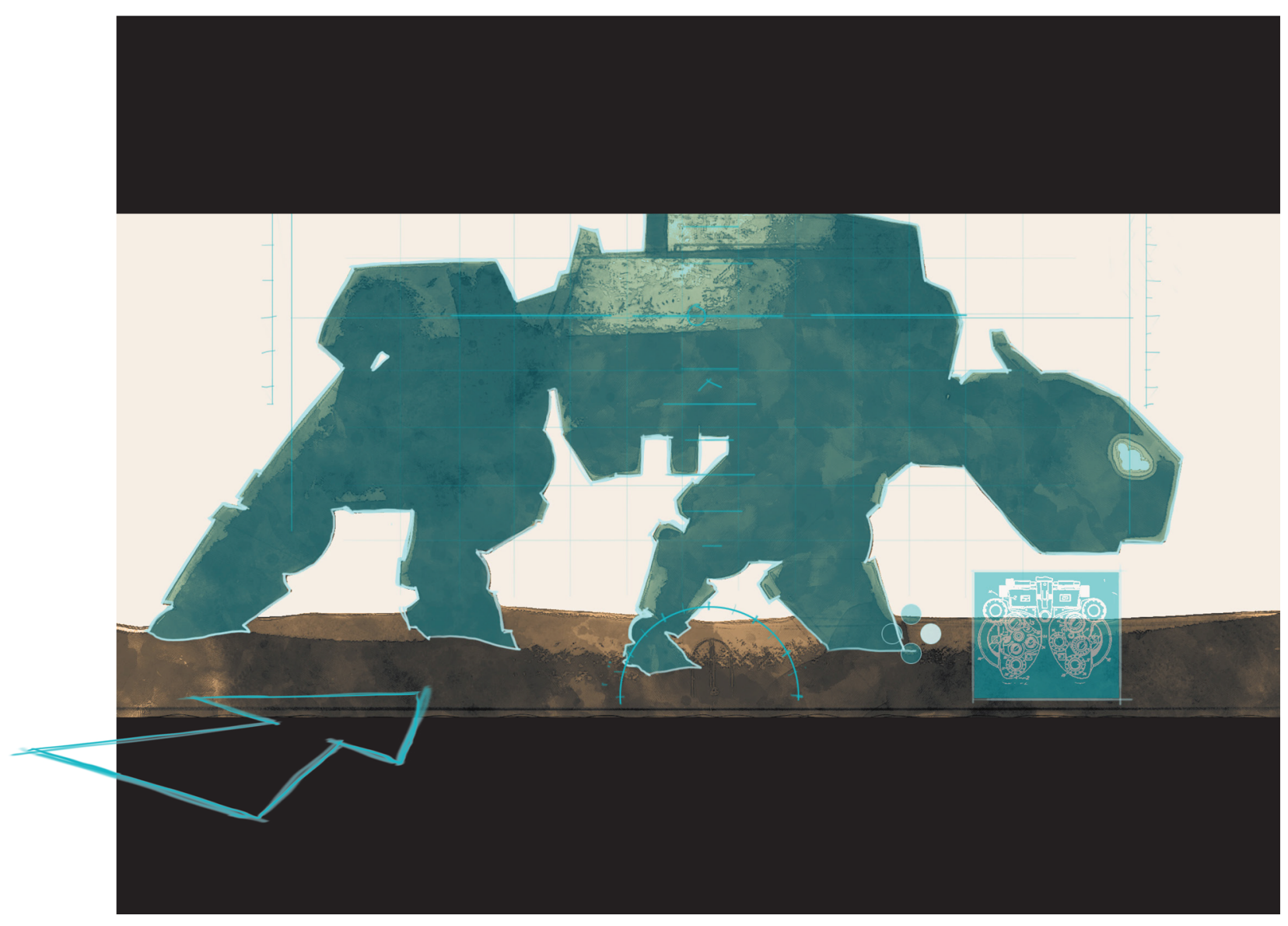

Figure 73 >> Storyboard Frame

The player activates his vision apparatus. A navigational interface appears in the HUD, along with a card showing the vision apparatus. The Techno-Bovidae becomes highlighted in the interface. Once the player locks his gaze on the Bovidae, an option for remote control appears. 


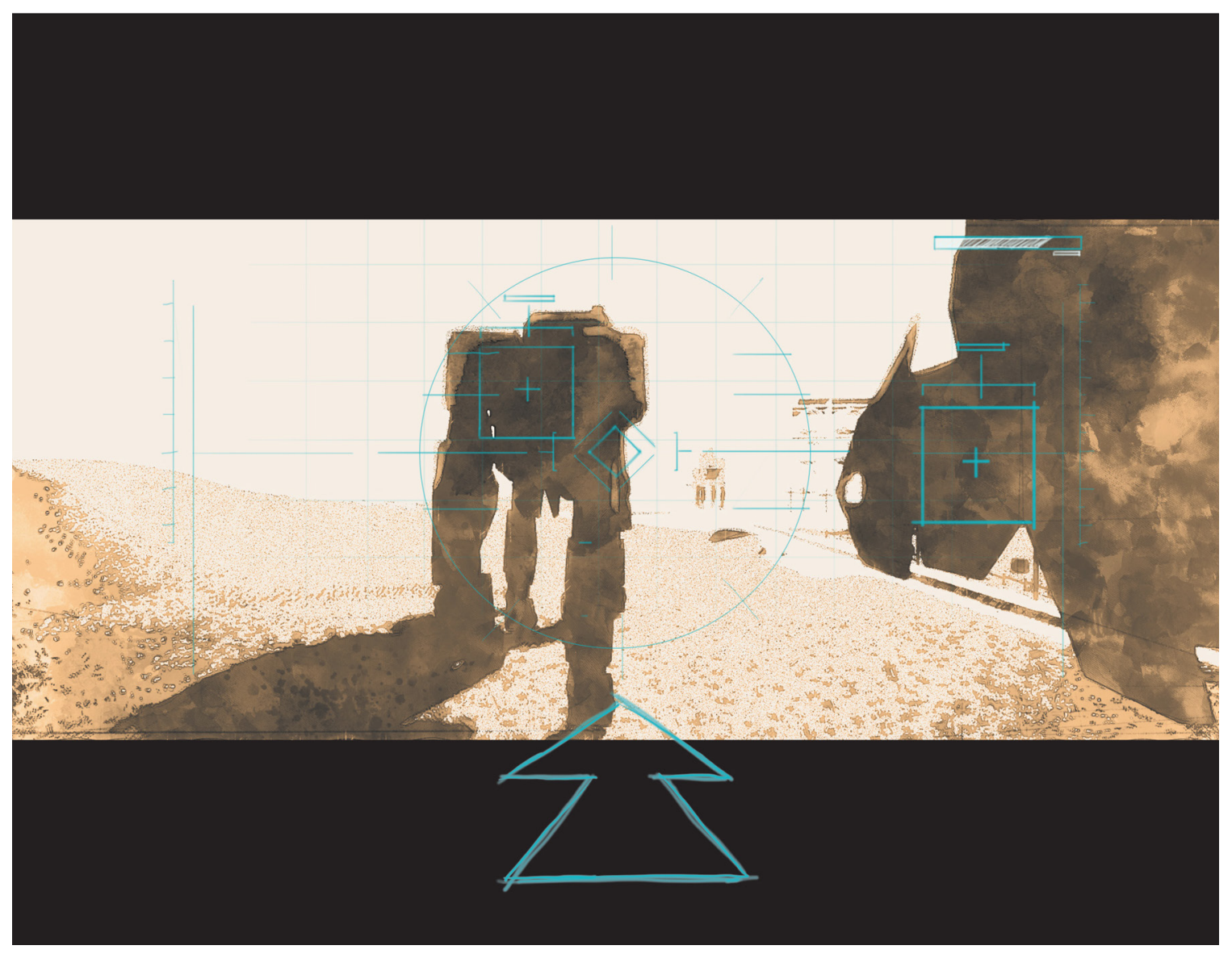

Figure $74>>$ Storyboard Frame

The player takes control of the Techno-Bovidae. At that moment, the player's HUD changes to match the Bovidae's perspective. The navigational interface also changes, and an energy status bar appears in the top right of the HUD. 


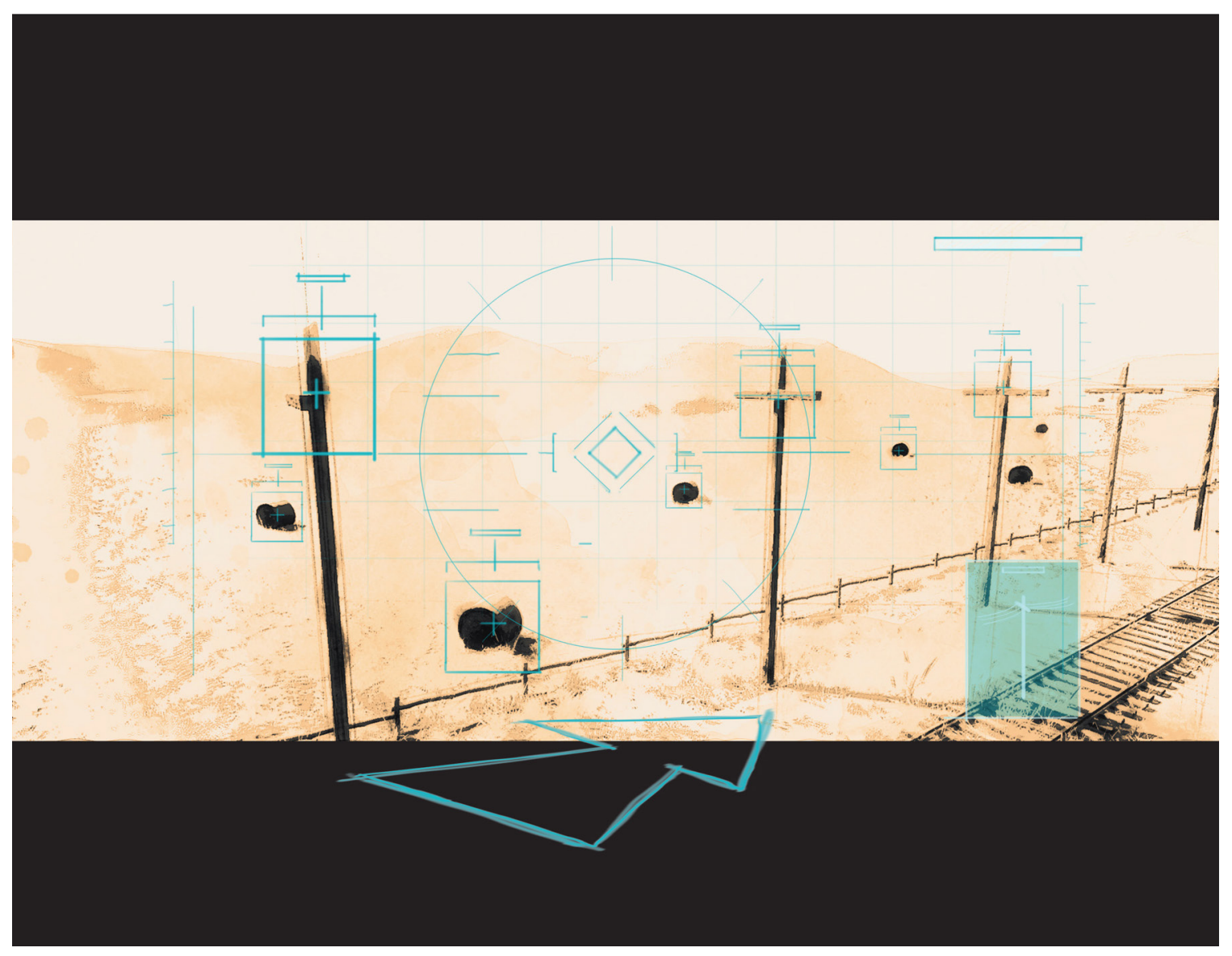

Figure 75 >> Storyboard Frame

The player moves the Bovidae to observe the landscape. As objects come into view, they are marked and labelled in the HUD. As the player locks his gaze on an object, an information card appears with option to add as entry to the logbook. 


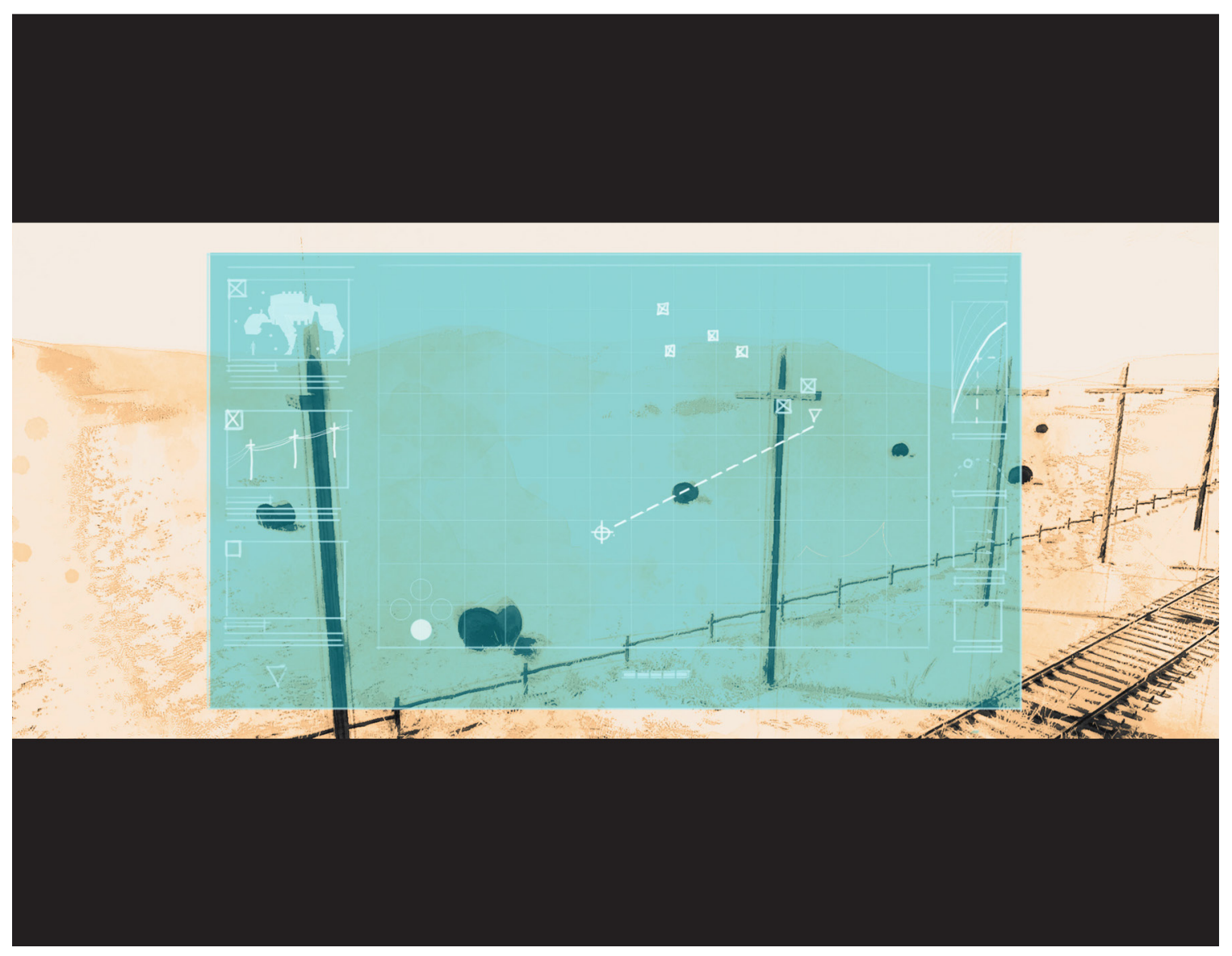

Figure $76>>$ Storyboard Frame

The player accesses the logbook menu. Weather displays now show an increase in humidity, signifying incoming precipitations. An option to plan a "wallow event" appears. As the player drops a pin on the map, a trajectory appears on the map and in the HUD. 


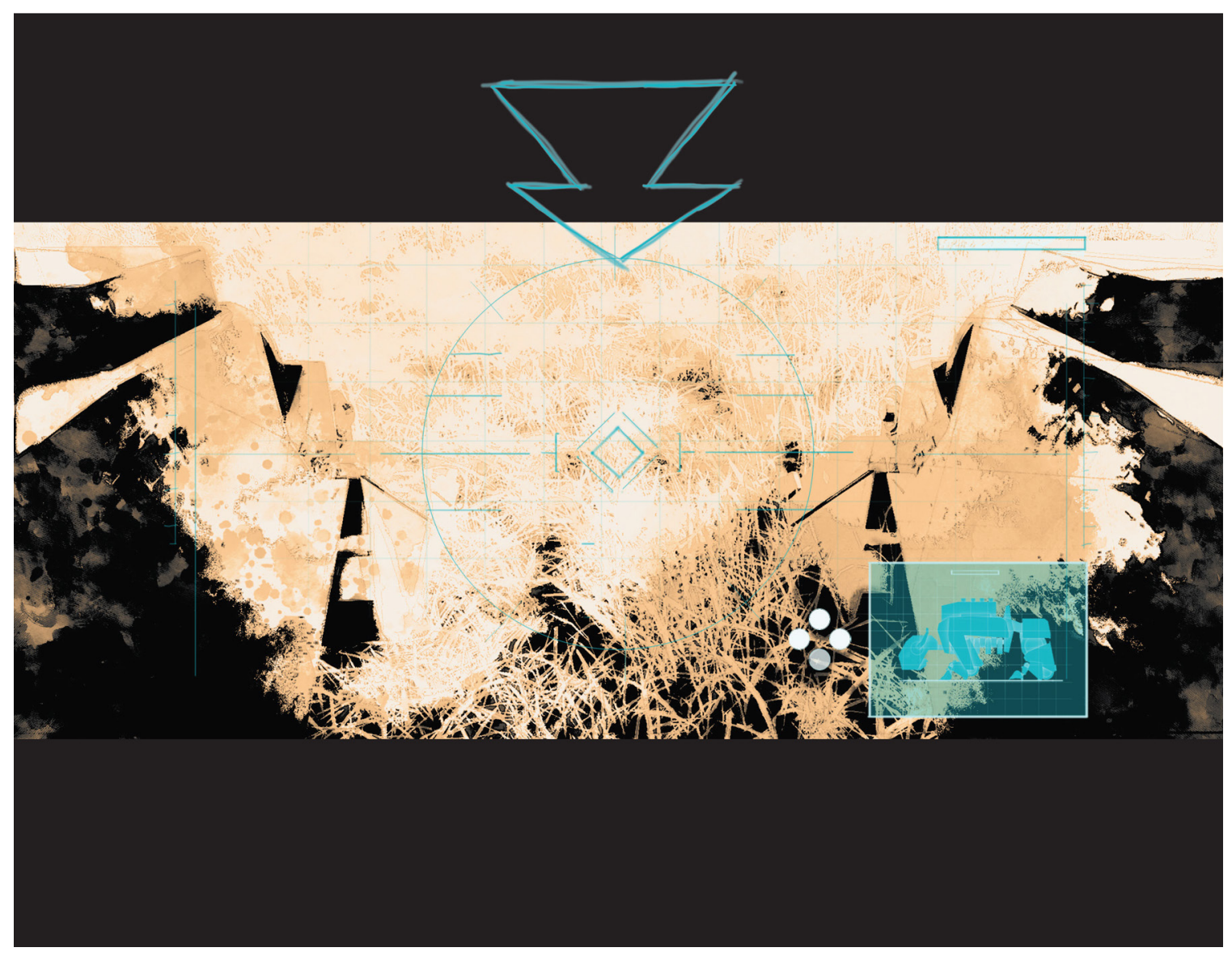

Figure 77 >> Storyboard Frame

The player navigates to the pinned location. Upon arriving, the player activates the wallow mode, then presses the four action buttons in a random order to control the wallow and dig a hole, which will collect precipitations. 


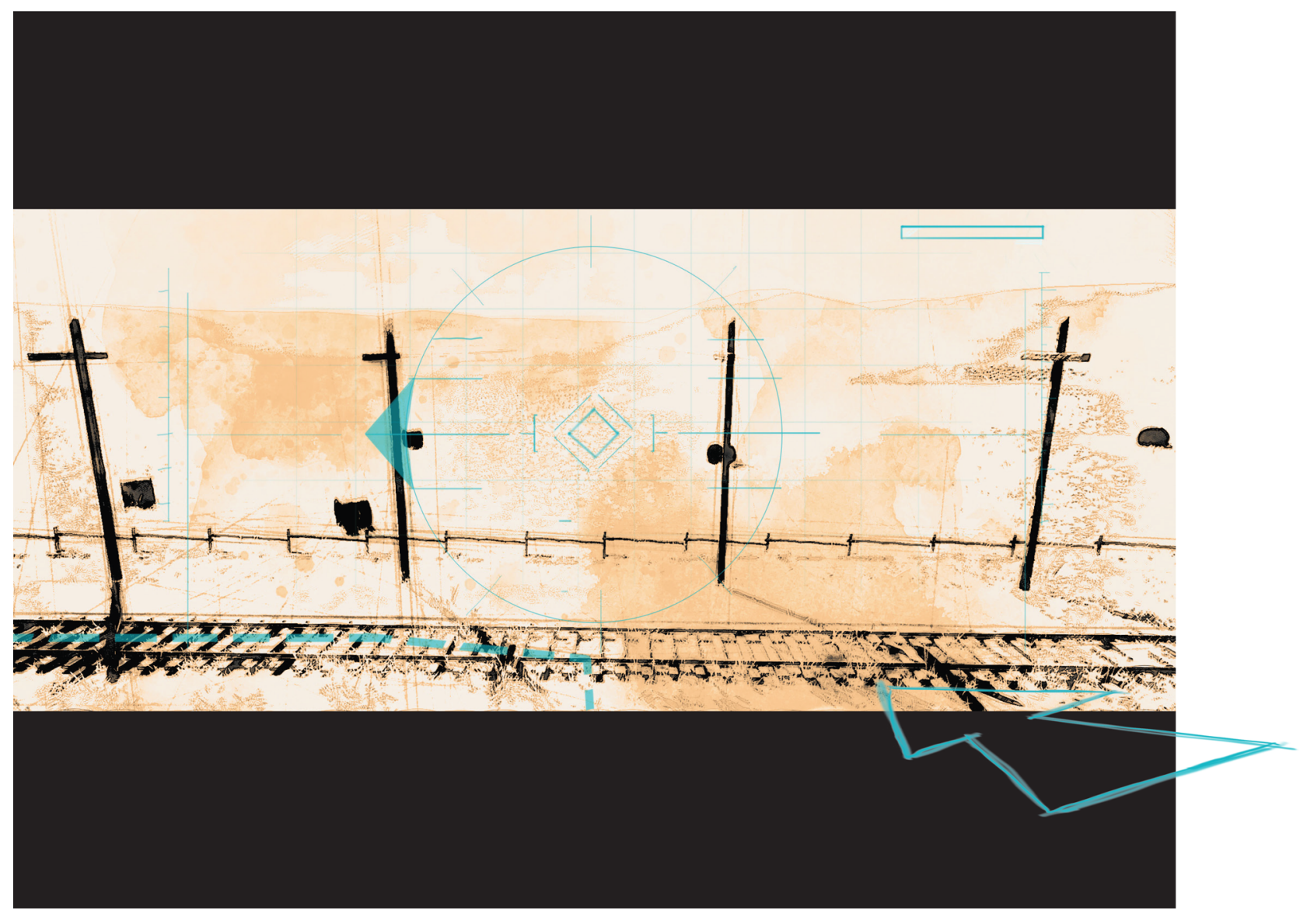

Figure 78 >> Storyboard Frame

Upon finishing the wallow sequence, the user interface indicates low energy levels. A trajectory to the nearest Carbon Elevator appears in the HUD. 


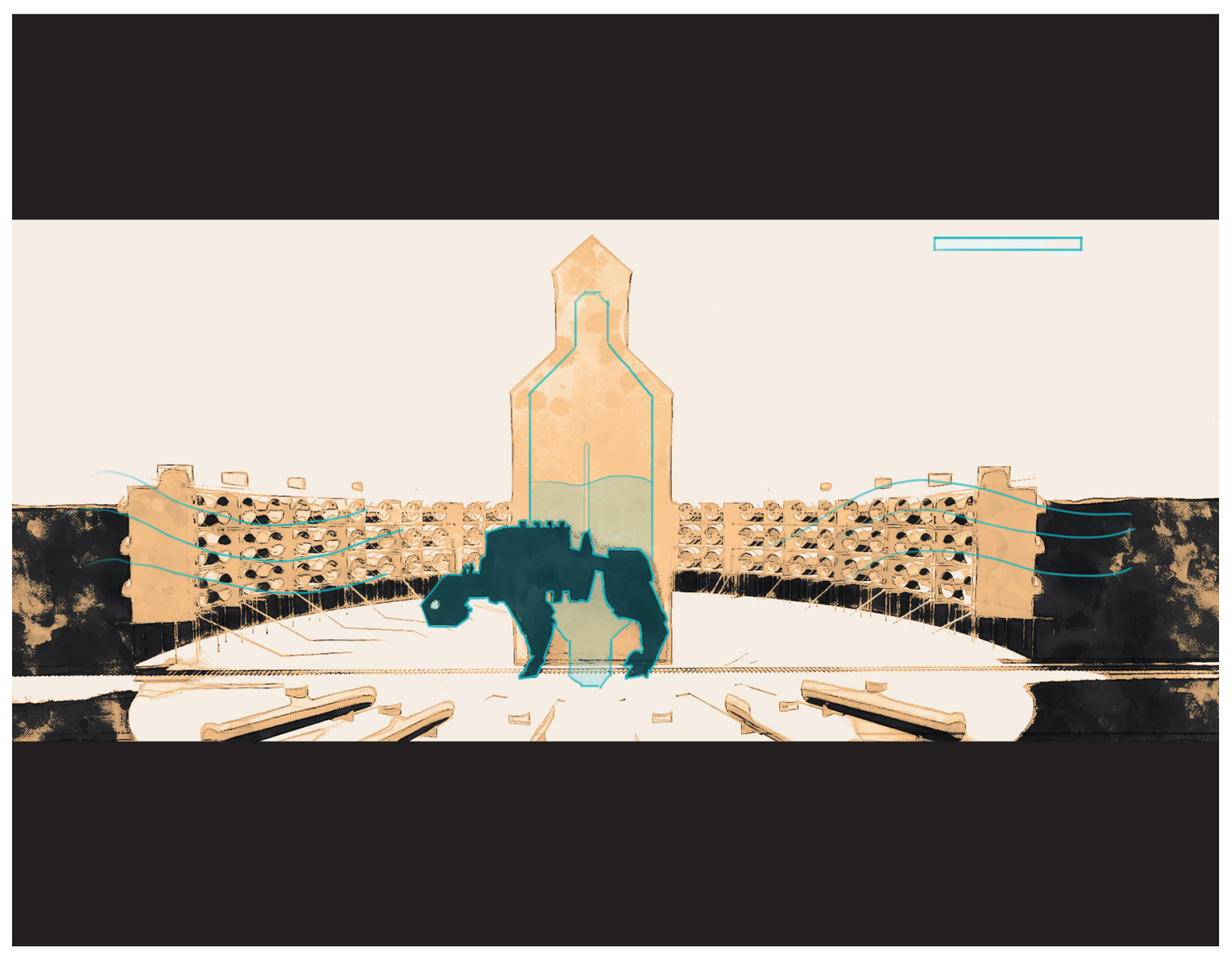

Figure 79 >> Storyboard Frame

The player connects to the Carbon Elevator. The camera switches to the third person view. An overlay showing the hidden systems of the charging station appears. The energy bar fills up, and the player proceeds with his exploration. 


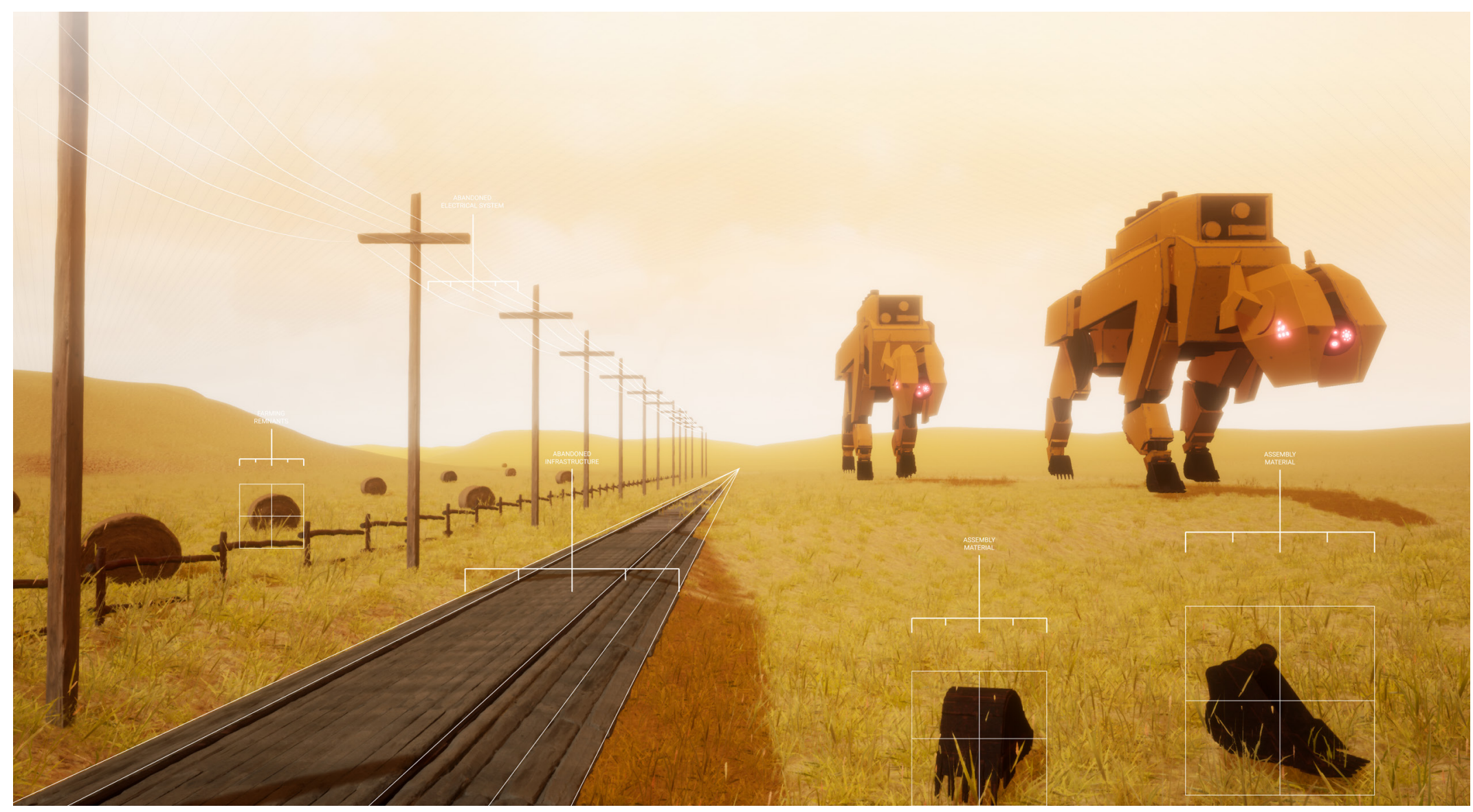

Figure 80 > Field Work 01

This drawing shows the player conducting fieldwork. The scene juxtaposes the Techno-Bovidae with cultural artefacts associated with prairies representation, creating a sense familiarity and alienation at the same time. 


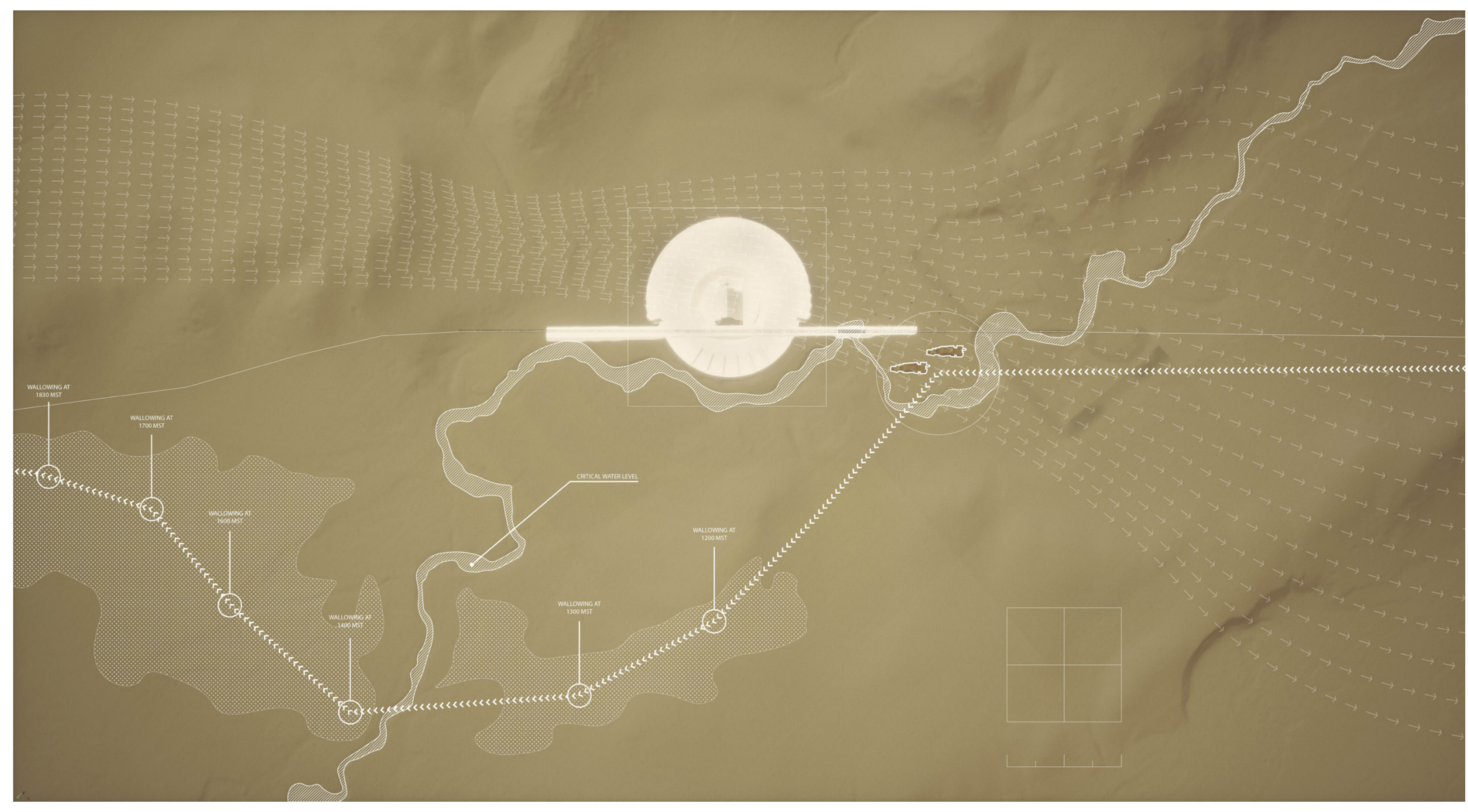

Figure 81 > Field Work 02

This image shows the map interface with logbook entries and wallow event traiectories. 


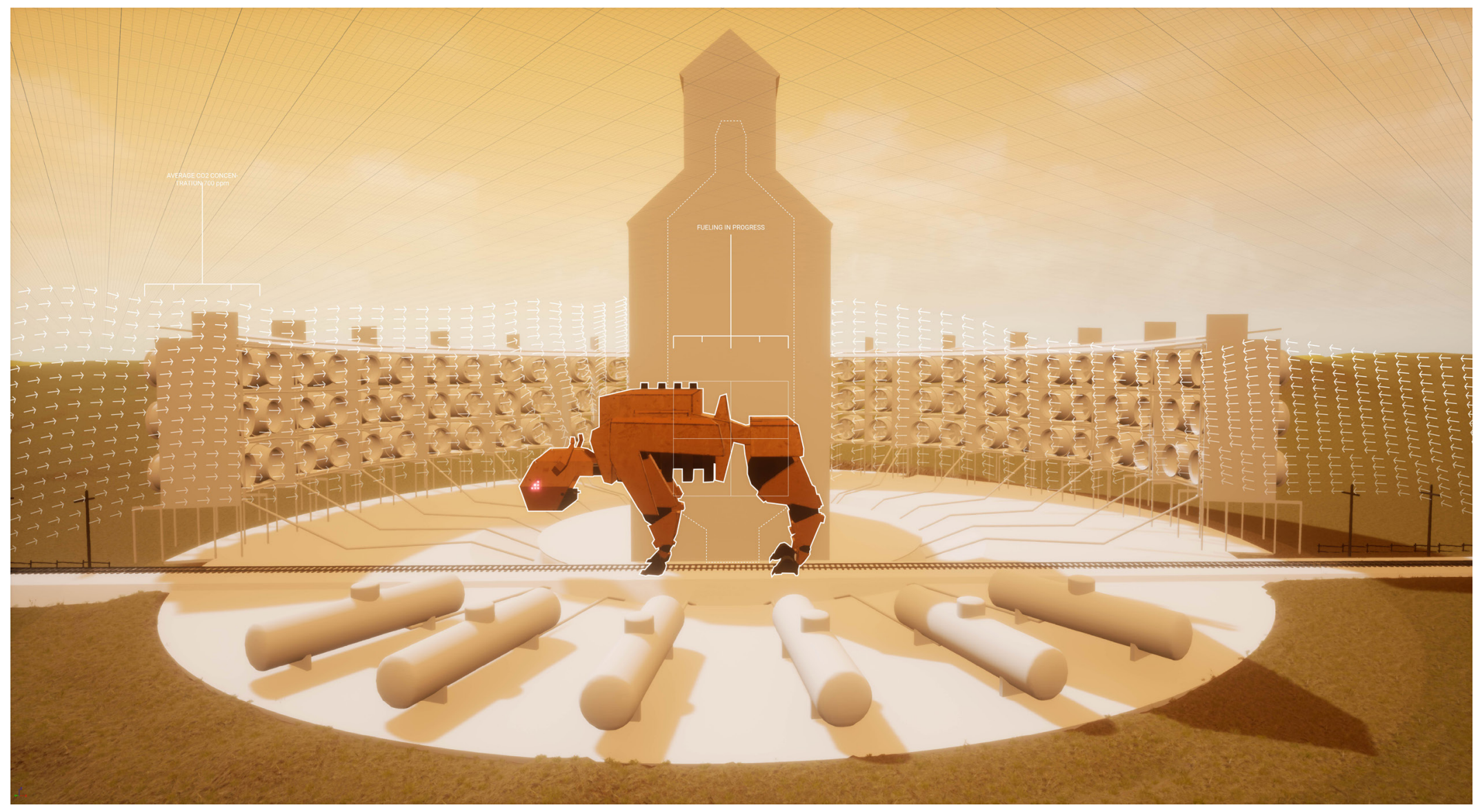

Figure 82 >> Field Work 03

The next image depicts the charging process at the Carbon Elevators. The interface shows the systems involved in the autonomous extraction and charging processes. 


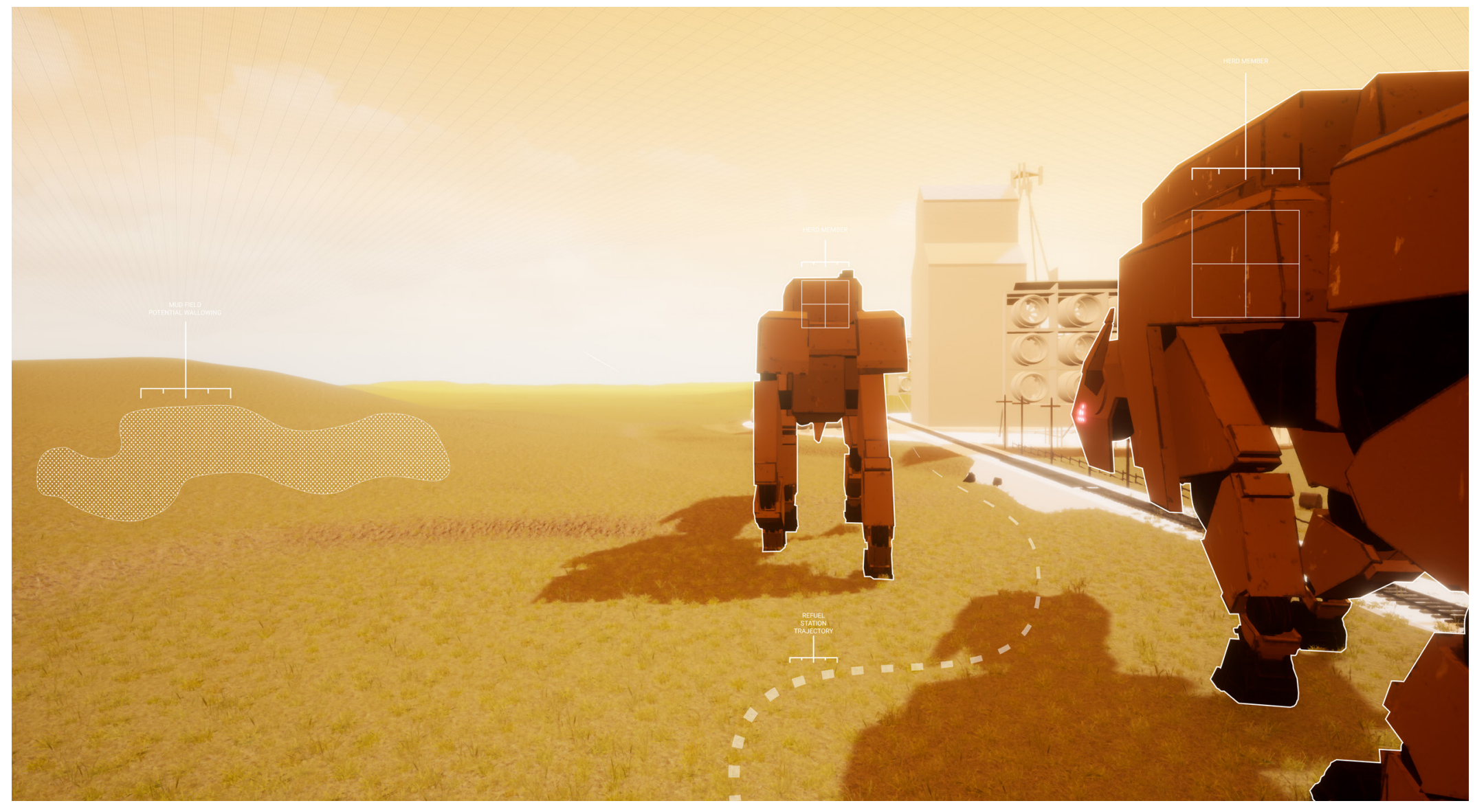

Figure 83 > Field Work 04

The final view is taken from the perspective of the Techno-Bovidae and shows information relevant to the Bovidae form, including suitable wallow areas and trajectory to charging station. The objects of interest are labelled from the Bovidae's perspective, alluding to a shift in perception of the landscape. 


\section{Epilogue}





\section{Postscript}

\section{On the Geographic and the Prosthetic Imagination}

This thesis set out with the intention of creating a videogame that could reorient geographic imagination, namely how individuals perceive and interact with the territories they occupy, both real and fictitious. While this objective remains ambitious, I believe that the game prototype developed is successful in achieving it to a degree.

It is important to note that the objective of the design work was never to propose solutions to climate changes, nor to provide a set of instructions for how to avoid civilizational collapse. Instead, the ambition of the project was to generate a discussion regarding the recording and representation of space, and the attitudes towards these landscapes that these images provoke. Through the Prosthetic Imagination, the game allows the player to project himself into these future worlds. From this perspective, the player can reflect critically on our reliance on technology, and in the process, to develop an empathetic vision towards the nonhuman.

While the proposed game allows for this projection into possible worlds, there remains a question of dissemination. While videogames remain associated to a particular culture, their popularity and outreach have drastically increased in recent times. The question, therefore, is not how to dis- 
seminate the proposed game, but rather, how to identify a suitable audience for this dissemination? Games, and in particular games based on navigation require a certain technical knowledge to operate. This is not surprising considering the military origins of the technology. From 3D navigation systems in virtual space, to advanced computing systems calculating coordinates, most technological infrastructure in videogames originated in the Military Eye. ${ }^{1}$ Knowing this, perhaps a suitable audience would be the trained professionals, those with a technical knowledge in the production and recording of space, be they artists, topographers, or architects.

\section{On the architect as a worldbuilder}

Architects create worlds. This position became increasingly obvious not only throughout the production of the game world, but also throughout the research on landscape representation. The design of a game world, of the topography, vegetation, and elements that populate it felt eerily similar to process of surveying and fieldwork. This is perhaps because the creation of spatial images, be it maps or landscape scenery, requires a technical expertise and knowledge of space making associated with architecture. It

$1 \quad$ C Mead, "War Play: Video Games and the Future of Armed Conflict," 2013, 16. 
is not surprising then, that military academies would teach architecture, alongside space-recording disciplines like surveying or topographical painting. ${ }^{2}$ This was notably the case for the Woolwich Academy in Britain, which trained the eyes through which many of the early representations of the Canadian landscape were produced.

While researching spatial images, it became clear to me that the production of these images catalysed a process of colonization and territorial control, a process to which architects contribute. Through the production of images, and the fictions they convey, architects build worlds, be they real or imagined. Realizing this, the thesis positions the architect as a storyteller, environments designer and animator, a worldbuilder using a videogame as a medium to cultivate better futures.

2 Rachel Hewitt, Map of a Nation (London: Granta Books, 2010), 260. 
Glossary 


\title{
Aggregate //
}

Constituted by the collection of many particles or units into one body, mass, or amount; collective, whole, total.

\author{
Albertian // \\ Referring to the Italian Renaissance man, Leon Battista \\ Alberti, known for using methods of projecting lines on a flat \\ surface to create perspective.
}

\section{Androgyne //}

A person who or animal which is physically both male and female. In mythological contexts it is seen as the original human form before humanity was divided into sexes, and encompassed the characteristics and nature of both sexes.

\section{Apocalypse //}

A disaster resulting in drastic, irreversible damage to human society and/or the environment on a global scale. The term is biblical in origin, referring to the Second Coming of Christ and the destruction of the world.

\section{Cosmography //}

The science that describes and maps the general features

of the universe (both the heavens and earth), without encroaching upon astronomy or geography. 


\section{Cultural //}

Of, belonging to, or relating to the culture of a particular

society, people, or period.

\section{Dystopian //}

Of an imaginary place or condition in which everything is as bad as possible; opposed to utopian.

\section{Gamedom //}

Portmanteau of "game" and "kingdom". Pertaining to the world of video games.

\section{Geoengineering //}

The modification of the global environment or the climate in

order to counter or ameliorate climate change.

\section{Head-up Display //}

A display of flight, navigation, attack, or other information superimposed upon the pilot's forward field of view.

\section{Hubris //}

Presumption, originally towards the gods; pride, excessive self-confidence. 


\section{Hybridity //}

Hybrid condition, where two animals or plants of different species, or elements from heterogeneous sources, form one entity.

Iconic //

Designating a person or thing regarded as representative of a culture or movement; important or influential in a particular (cultural) context.

\section{Imaginary //}

An imagination; a fancy; so mething imagined.

\section{Keystone Species //}

A species exerting a major influence on an ecosystem, esp.

one on whose activities the survival of other species de-

pends.

\section{Modernity //}

An intellectual tendency or social perspective characterized by departure from or repudiation of traditional ideas, doctrines, and cultural values in favour of contemporary or radical values and beliefs (chiefly those of scientific rationalism and liberalism). 


\section{Mythological //}

Of a body or collection of myths, esp. those relating to a par-

ticular person or thing, or belonging to a particular religious

or cultural tradition.

\section{Natural //}

A natural thing or object; something having its basis in the natural world or in the usual course of nature.

\section{Naturalism //}

The idea that only natural laws and forces operate within

the world.

\section{New World //}

Refers to the North American continent post "discovery" and colonization, establishing its view as the next frontier.

\section{Nonhuman //}

That is not of the human race; not belonging to or possess-

ing the characteristics of a human being.

\section{Old World //}

The world known to Europeans prior to the discovery of the Americas, this included the continents of Europe, Asia, and Africa. 


\section{Personhood //}

The quality or condition of being a person. The development of one's self or personal identity.

\section{Picturesque //}

An aesthetic category alongside beauty and sublimity, associated with the roughness and irregularity of nature harmonised by composition.

\section{Romantic //}

An artistic movement that made use of legendary, exotic, or imaginary settings, typically to explore the conflict between man and nature or the supernatural.

\section{Spatial Images //}

Representations of what is governed by or subject to the conditions of space, that speculate how we perceive relations involving space. 


\section{Suspension of Disbelief //}

Coleridge's phrase for the voluntary withholding of scep-

ticism on the part of the reader with regard to incredible

characters and events.

\section{Tableaux Vivants //}

A person or group of people forming striking or picturesque

scenes.

\section{Theodolites //}

A portable surveying instrument, originally for measuring

horizontal angles, and consisting essentially of a planisphere

or horizontal graduated circular plate, with an alidad or

index bearing sights.

\section{Topographic //}

The accurate and detailed delineation and description of any locality.

\section{Transcendentalists //}

Transcending or extending beyond the bounds of any single category, often made synonymous with the metaphysical. 


\section{Triangulation //}

The tracing and measurement of a series or network of tri-

angles used to survey and map out a territory or region.

\section{Trope //}

A significant or recurrent theme, esp. in a literary or cultural context; a motif.

\section{Turtle Island //}

In some interpretations of North American Indigenous

folklore, Turtle Island refers to the land from which their ancestors originated, and often refers to the land of North America.

\section{Worlding //}

To provide with a world of people; to people, inhabit. Also with it.

\section{Worldviews //}

A set of fundamental beliefs and values that determine a comprehensive outlook on the world. 


\section{Bibliography}


"The Creation of the World and the Expulsion from Paradise," n.d. https://www.metmuseum.org/art/collection/ search/458971.

Bakx, Kyle. "New Centre Aims to Capture CO2 and Monetize the Emissions." CBC News, 2018. https://www.cbc.ca/ news/business/acctc-shepard-xprize-co2-1.4676527.

Bélanger. Extraction Empire: Undermining the Systems, States and Scales of Canada's Global Resource Empire, 2017-1217. Cambridge, 2017.

Bogost, lan. "Anything but Games." In How to Talk about Videogames, 181-88. University of Minnesota Press, 2015.

Borges, Jorge Luis, and Margarita Guerrero. The Book Of Imaginary Beings. Penguin Books, 1974.

Boswell, Jacob. "Notes from the Wasteland: Competing Climatic Imaginaries in the Post-Apocalyptic Landscape." In Climates : Architecture and the Planetary Imaginary, edited by James Graham, Caitlin Blanchfield, Alissa Anderson, Jordan H. Carver, and Jacob Moore, The Avery. Lars Müller Publishers, 2016.

Bush, E. and Lemmen, D.S., ed. Canada's Changing Climate Report. Ottawa, ON.: Government of Canada, 2019. 
Charland, Maurice. "Technological Nationalism." Canadian Journal of Political and Social Theory X (1986): 196220.

Clark, Nicole. 'A Brief History of the 'Walking Simulator,' Gaming's Most Detested Genre." Salon, 2017. https://www. salon.com/2017/11/11/a-brief-history-of-the-walking-simulator-gamings-most-detested-genre/.

Collins, Michael. "The Ground Glass: Landscape Art, the Camera Obscura and Photography." Accessed August 15, 2021. https://www.bl.uk/picturing-places/articles/ the-ground-glass-landscape-art-the-camera-obscura-and-photography-coll-items-missing.

Cosgrove, Denis. Geography and Vision: Seeing, Imagining and Representing the World. Geography and Vision: Seeing, Imagining and Representing the World, 2008. https://doi.org/10.5040/9780755620791.

Cronon, William. "The Trouble with Wilderness: Or, Getting Back to the Wrong Nature." Environmental History 1, no. 1 (1996): 7. https://doi.org/10.2307/3985059.

Cunha, Dilip Da. The Invention of Rivers: Alexander's Eye and Ganga's Descent. Philadelphia: University of Pennsylvania Press, 2019. 
Daniels, Stephen. "Geographical Imagination." Transactions of the Institute of British Geographers 36, no. 2 (2011): 182-87. https://doi.org/10.1111/j.14755661.2011.00440.x.

Davis, Heather, and Zoe Todd. "On the Importance of a Date, or Decolonizing the Anthropocene." Acme 16, no. 4 (2017): 761-80.

Dawson, G. M. "Preliminary Report on the Physical and Geological Features of That Portion of the Rocky Mountains, between Latitudes $49^{\circ}$ and $51^{\circ} 30 . "$ Geological Survey of Canada, Annual Report vol 1 (1886).

Doove, Edith. "Textures of the Anthropocene: Grain Vapor Ray Textures of the Anthropocene: Grain Vapor Ray by Katrin Klingan, Ashkan Sepahvand, Christoph Rosol and Bernd M. Scherer. MIT Press, Cambridge, MA, 2015. 1008 Pp., Illus. Paper. ISBN: 978-0262527415." Leonardo 51 (August 6, 2018): 535-36. https://doi. org/10.1162/leon_r_01674.

Doyon, Pierre-Simon. "Topographic Painters." In The Canadian Encyclopedia, 1-4, 2009.

Eagan, William E. "BARLOW, ROBERT." Dictionary of Canadian Biography. University of Toronto/Université Laval. Ac- 
cessed August 14, 2021. http://www.biographi.ca/en/ bio/barlow_robert_11E.html.

Ghosh, Amitav. The Great Derangement. The Great Derangement. The University of Chicago Press, 2018. https:// doi.org/10.7208/chicago/9780226323176.001.0001.

Ghosn, Rania, and El Hadi Jazairy. Geostories. Actar Publishers, 2018.

Halbwachs, Maurice. "Space and the Collective Memory." The Collective Memory, 1941, 1-15.

Haraway, Donna J. Simians, Cyborgs, and Women: The Reinvention of Nature. Routledge, 1991.

Haraway, Donna J. Staying with the Trouble. Staying with the Trouble. Duke University Press, 2016.

Harvey, David. Social Justice and the City. Basil Blackwell, 1973.

Helmore, Edward. "Yep, It's Bleak, Says Expert Who Tested 1970s End-of-the-World Prediction." The Guardian, 2021. https://www.theguardian.com/ environment/2021/jul/25/gaya-herrington-mitstudy-the-limits-to-growth.

Hewitt, Rachel. Map of a Nation. London: Granta Books, 2010. 
Hill, Richard. "Too Silent to Be Real." In Expanding Horizons:

Painting and Photography of American and Canadian Landscape, 1860-1918, edited by Hilliard T Goldfarb. Montreal: Montreal Museum of Fine Arts, 2009.

Jameson, Fredric. Archaeologies of the Future: The Desire Called Utopia and Other Science Fictions, 2005. https://doi.org/10.1057/palgrave.cpt.9300288.

Jazairy, El Hadi. "Toward a Plastic Conception of Scale." New Geographies 4, no. Scales of the Earth (2011).

Jenkins, Henry. "Game Design as Narrative Architecture." In First Person : New Media as Story, Performance, and Game, 118-30. Cambridge: MIT Press, 2004.

Lam, Elsa. "Wilderness Nation: Building Canada's Railway Landscapes, 1885-1929." Columbia University, 2011.

Lambie, Ryan. "Greebles: How Tiny Details Make a Huge Star Wars Universe." Den of Geek, n.d. https://www.denofgeek.com/movies/greebles-how-tiny-details-makea-huge-star-wars-universe/.

McLuhan, Marshall. Understanding Media. Berkley California: Ginnko Press Inc, 2013.

Mead, C. "War Play: Video Games and the Future of Armed Conflict," 2013. 
Meinig, D W (Donald William), and John Brinckerhoff Jackson. The Interpretation of Ordinary Landscapes: Geographical Essays. New York: Oxford University Press, 1979.

Michael Taylor. "The Prosthetic Imagination: Meditations on Virtual Space and Experience in Single Player Computer Role Playing Games." University of Waterloo, 2011.

Morton, Timothy. "What Are Hyperobjects ?," 2019.

Parks Canada. "Plains Bison." Accessed August 18, 2021. https://www.pc.gc.ca/en/pn-np/sk/grasslands/ nature/faune-wildlife/bison?fbclid=IwAR2fau7BvfDTYbP44P-xB9mckOkx7VGtGKfbsYVDx9PG3u75QStZjOBSW3g.

Robertson, Carmen. Norval Morrisseau : Life \& Work. Toronto: Art Canada Institute, 2016.

Said, Edward W. Orientalism. First Vint. New York: Random House, Inc ., 1978.

Simon, Matt. "The Bay Area Just Turned Orange. All Eyes Are on Purple Air." Wired, 2020. https://www.wired.com/ story/bay-area-just-turned-orange-all-eyes-on-purpleair/?fbclid=IwAROFhkYRcy49X7UwXkYDXD- 
NG90mNQxzTS7xM_JawMvgsnjm8zzu3oFV9dHQ.

Spring, Jake. "Geoengineering Marks Scientific Gains in U.N. Report on Dire Climate Future." Reuters, 2021. https:// www.reuters.com/business/environment/geoengineering-marks-scientific-gains-un-report-dire-climate-future-2021-08-10/.

Tavares, Paulo. "Stratoshield." In Textures of the Anthropocene: Grain Vapor Ray, edited by Katrin Klingan, Ashkan Sepahvand, Christoph Rosol, and Bernd M. Scherer, 61-71. Cambridge, Massachusetts \& London, England: MIT Press, 2015.

The Economist." "It That Cannot Be Named: Geoengineering Is Conspicuously Absent from the IPCC's Report," 2021. https://www.economist.com/science-and-technology/2021/08/14/geoengineering-is-conspicuously-absent-from-the-ipccs-report.

Tyrrell, J Burr. "The Topographical Work of the Geological Survey of Canada." The Geographical Journal 10, no. 6 (August 14, 1897): 623-30. https://doi. org/10.2307/1774911.

Varley, Christopher, and Russell Bingham. "Group of Seven." In The Canadian Encyclopedia, 2013. https://doi. 
org/10.1093/gao/9781884446054.article.t035135.

Vodden;, C., L. A. Frieday, and Niko Block. "Geological Survey of Canada." In The Canadian Encyclopedia, 2007.

Weber, Bob. "B.C. Company Says It Is Sucking Carbon from Air, Making Fuel." The Canadian Press, 2018. https:// www.cbc.ca/news/canada/british-columbia/b-ccompany-says-it-is-sucking-carbon-from-air-makingfuel-1.4696817.

Young, Liam, and Geoff Manaugh. "Architectural Monsterology : An Interview with Liam Young." In Landscape Futures: Instruments, Devices and Architectural Inventions, edited by Geoff Manaugh, 2007:232. Actar Publishers, 2013.

Zaidi, Leah. "Brave New Worlds: Science Fiction and Transition Design." SSRN Electronic Journal. OCAD University, 2018. https://doi.org/10.2139/ssrn.3217423.

Zhang, Xuebin, Greg Flato, Megan Kirchmeier-Young, Lucie Vincent, Hui Wan, Xiaolan Wang, Guilong Li, Robin Rong, John Fyfe, and Viatchelsav V. Kharin. "Temperature and Precipitation Across Canada." In Canada's Changing Climate Report: Temperature and Precipitation Across Canada, edited by Editors Bush, E. and Lemmen, D.S, 112-93, 2019. 
Figures 


\section{Figure 01 >> Blade Runner 2049}

Ryan Gosling as K in BLADE RUNNER2049, which is nominated for an Oscar for Best Production Design, Architectural Digest, accessed August 16, 2021. https://www.architecturaldigest.com/story/5-reasons-were-not-surprised-blade-runner-2049-is-nominated-for-an-oscar?fbclid=IwAR26gbucJALojmnwfWS8a9nm-SBuGfgWkyGeP7H2DgMQcAwWkzoANzT_6Oc

Figure 02 >> California Wildfires 2020, San Francisco

Jessica Christian, Untitled, 2020, Digital Image, accessed August 16, 2021, https://www.wired.com/story/ bay-area-just-turned-orange-all-eyes-on-purpleair/?fbclid=IwAR1|DqHPKuDDmquDVq5v_ Z270HrGrtH-byKzFO00PYUteKVQZnLmhK8vX40

Figure 03 >> Discovery of the Mississippi by De Soto, William H. Powell

William H. Powell, Discovery of the Mississippi by De Soto, 1855, Oil on canvas, Architect of the Capitol, accessed on august 16, 2021, https://www.aoc.gov/explore-capitol-campus/art/discovery-mississippi-de-soto

Figure 04 >> Sable Video Game Still

Untitled, 2021, Digital Image, accessed august 16, 
2021, https://cdn.cloudflare.steamstatic.com/ steam/apps/757310/ss_dbe1b07f58393b56c20e9ac031442e1e161fa989.600×338. jpg?t=1632233395

Figure 05 > Sable Video Game Still

Untitled, 2021, Digital Image, accessed August 16, 2021, https://cdn.cloudflare.steamstatic.com/steam/ apps/757310/ss_f7cf5d40340dfcfc534daff63be314fdbb9e6817.116x65.jpg?t=1632233395

Figure 06 > The Creation of the World and the Expulsion from Paradise, Giovanni di Paolo

Giovanni di Paolo, The Creation of the World and the Expulsion from Paradise, 1445, Tempera and gold on wood, Metropolitan Museum, accessed on august 12, 2021, https://www.metmuseum.org/art/collection/ search/458971

Figure 07 > First Day of Creation, Francisco de Holanda

Francisco de Holanda, DE AETATIBUS MUNDI IMAGINES, 1545, ink on paper, National Library of Spain, accessed on august 12, 2021, http://bdh.bne.es/bnesearch/detalle/bdh0000137315 
Figure 08 >> Androgyny, Norval Morisseau

Norval Morrisseau, Androgyny, 1983, Acrylic on canvas, Aboriginal Affairs and Northern Development CanadaAboriginal Art Collection, accessed on august 12, 2021, https://www.aci-iac.ca/wp-content/ uploads/2020/09/art-books_11_norval-morrisseau-androgyny-kw.jpg

Figure 09 >> Ordnanace Survey Triangulation Diagram, Alexander Ross Clarke, 1868

Henry James, Diagram showing the principal triangulation for the Ordnance trigonometrical survey of Great Britain and Ireland., 1858, Survey Map, David Rumsey Map Collection, accessed on august 15, 2021, https://www.davidrumsey.com/luna/ servlet/detail/RUMSEY 8 1 257424 5520921:Diagram-showing-the-principal-trian\#

Figure 10 >> General View of the Instrument Mudge and Dalby, Great Ramsden Theodolite., 1799, engraving, Science Photo Library, accessed on august 15, 2021, https://media.sciencephoto.com/image/ c0095240/800wm/C0095240-Great_Ramsden_Theodolite,_18th_century.jpg 
Figure 11 >> Geological Survey of Canada, Montreal

New Headquarters, 1881, photograph, Government of Canada, accessed on august 15, 2021, https://science. gc.ca/eic/site/063.nsf/vwimages/175_34a_400.jpg/\$file/175_34a_400.jpg

Figure 12 >> Alfred Selwyn

William James Topley, Alfred Richard Cecil Selwyn, 1889, photograph, Library and Archives Canada, accessed on august 15, 2021, http://www.biographi.ca/bioimages/w200.6420.jpg

Figure 13 >> George Dawson

William Notman, Dr. George Mercer Dawson, 1891, photograph, McCord Museum, accessed on august 15, 2021, http://collections.musee-mccord.qc.ca/ObjView/ ii95313.jpg

Figure $14>>$ Theodolite

Theodolite, 1966, digital image, Ingenium, accessed on June 15, 2021, http://source.techno-science.ca/artifacts-artefacts/images/1966.0525.001.aa.cs.png

Figure 15 >> Telescope

Telescope, 1978, digital image, Ingenium, accessed on 
June 15, 2021, http://source.techno-science.ca/artifacts-artefacts/images/1978.0715.001.aa.cs.png

Figure 16 >> Measuring Tape

Tape, digital image, 2002, Ingenium, accessed on June 15, 2021, http://source.techno-science.ca/artifacts-artefacts/images/2002.0387.001.aa.cs.png

Figure 17 > Reconnaissance Map of the Rocky Mountains, Alfred Barlow

Richard, L N; Barlow, A E; White, J, Reconnaissance map of a portion of the Rocky Mountains between latitudes 49 and 51-30 degrees, 1886, digital image, Geological and Natural History Survey of Canada, accessed on august 15, 2021, https://geoscan.nrcan.gc.ca/images/ geoscan/gscmcm_223_e_1886_mn01.jpg

Figure 18 >> Geological and Topographical Map of the Northern Part of the Lake of the Woods and Adjacent County, Alfred Barlow

Lawson, A C, Geological and Topographical map of the northern Part of the Lake of the Woods and Adjacent Country, Ontario, 1887, Geological and Natural History Survey of Canada, accessed on august 15, 2021, https://geoscan.nrcan.gc.ca/images/geoscan/gscm- 
cm_227_e_1887_mn01.jpg

Figure 19 >> Steam Engine Locomotive

Darius Kinsey, Four Logs from One Fir Tree Scaled 27,000 Feet. Cherry Valley Timber Co., 1918, photograph, Expanding Horizons (Montreal Museum of Fine Arts, 2009), 162

Figure 20 >> The New Highway to the Orient: Across the Mountains, Prairies and Rivers of Canada

The Canadian Pacific - The New Highway to the Orient, 1893, digital image, Canada Science and Technology Museum, accessed on august 15, 2021, http://images. techno-science.ca/images_site/jasper/letters/ L36157_l.jpg

Figure 21 >> Map of Western Canada

The Canadian Pacific Railway land grant in Manitoba and the North-West Territories, 1882, digital image, Library and Archives Canada, accessed on august 15, 2021, https://data2.collectionscanada.gc.ca/e/e001/ e000007927.jpg

Figure 22 >> CPR Poster

Canada West, digital image, South Asian Canadian Heritage, 
accessed on august 15,2021, https://www.southasiancanadianheritage.ca/wp-content/uploads/2018/11/ canada-west.jpg

Figure 23 >> Irrigation Farming in Sunny Alberta

Irrigation Farming in Sunny Alberta, digital image, Canadian Pacific Railway Company, accessed on august 15, 2021, https://www.canadiana.ca/view/oocihm.79663

Figure 24 >> Priarie Grain Elevator

Prairies Grain Elevator, 2012, digital image, Alberta Historic Places, accessed on august 16, 2021, https://albertashistoricplaces.files.wordpress.com/2012/07/ p6220503.jpg? $w=600 \& h=450$

Figure 25 >> Pinhole Camera, Louis-Jacques Goussier

Louis-Jacques Goussier, The components of a camera obscura., digital image, Welcome Collection, accessed on august 15, 2021, https://iiif.wellcomecollection.org/ image/N0049632ER/full/300,/0/default.jpg

Figure 26 >> Fall of Montmorenci, George Fisher

Lucius R. O'Brien, Sunrise on the Saguenay, Cape Trinity, 1880, oil on canvas, UQÀM, accessed on august 15, 2021, https://150ans150oeuvres.uqam.ca/wp-content/ 
uploads/2017/07/1880-OBrien-A.jpg

Figure 27 >> Victorian Panorama

Robert Mitchell, Cross-Section of the Panorama Building in Leicester Square., 1801, etching, British Library, accessed on august 15, 2021, https://www.bl.uk/ britishlibrary/ /media/bl/global/picturing\%20 places/56_i_12.jpg

Figure 28 >> Sunrise on the Saguenay, Lucas O'Brien

Lucius R. O'Brien, Sunrise on the Saguenay, Cape Trinity, 1880, oil on canvas, UQÀM, accessed on august 15, 2021, https://150ans150oeuvres.uqam.ca/wp-content/ uploads/2017/07/1880-OBrien-A.jpg

Figure 30 >> The Drowned World

Richard Powers, Coverforthe Drowned World, 1962, VintagePaper Backs, accessed on august 15, 2021, https://www. flickr.com/photos/jlevar/227643208/?fbclid=IWAR0JI64-HVu-h6sv9QC6nnw1sQObphM-k2MNk04nBg1A NXONkzqQHWIrGzS

Figure 31 > The Burning World, or The Drought

Richard Powers, Cover for the Burning World, Vintage Paper Backs, accessed on august 15, 2021, https://www. 
flickr.com/photos/jlevar/227643208/?fbclid=IwAR0JI64-HVu-h6sv9QC6nnw1sQObphM-k2MNk04nBg1A NXONkzqQHWLrGzS

Figure 32 >> The Road

Chip Kidd, Cover for the Road, 2006, digital image, L. W. Currey Inc, accessed on august 15, 2021, https://www.lwcurrey.com/pictures/157004.jpg

Figure 33 >> Man versus Nature

Shooting The Road: How to Find Hell on Earth, Time Magazine, accessed on august 15, 2021, http://img.timeinc. net/time/photoessays/2009/road_landscapes/ road_landscapes_03.jpg

Figure 34 > Geostories: Another Architecture for the Environment

Rania Ghosn and El Hadi Jazairy, Cover for Geostories: Another Architecture for the Environment., digital image, Design Earth, accessed on august 15, 2021, https:// design-earth.org/files/gimgs/215_Geostories_coVER_small.jpg

Figure 35 >> Pacific Aquarium

Rania Ghosn and El Hadi Jazairy Pacific Aquarium, digital image, Design Earth, accessed on august 15, 2021 , 
